Aus der Abteilung Ethik und Geschichte der Medizin

(Prof. Dr. med. C. Wiesemann)

im Zentrum Psychosoziale Medizin

der Medizinischen Fakultät der Universität Göttingen

\title{
Arzneiöle in der Medizin des Mittelalters \\ Untersuchungen zu spätmittelalterlichen Kodizes \\ aus Farfa, Harburg und Memmingen
}

\author{
Inaugural-Dissertation \\ zur Erlangung des Doktorgrades \\ der Medizinischen Fakultät der \\ Georg-August-Universität zu Göttingen
}

vorgelegt von

Thomas Aßfelder

aus

Essen

Göttingen 2011 
Dekan: Prof. Dr. med. C. Frömmel

I. Berichterstatter: Prof. Dr. phil. Dr. med. habil. V. Zimmermann

II. Berichterstatter/in: Priv.-Doz. Dr. rer. nat. Müller

III. Berichterstatter/in: Prof. Dr. med. Oppermann

Tag der mündlichen Prüfung: 01.11.2011 


\section{Inhaltsverzeichnis}

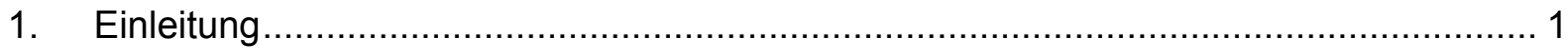

2. Textausgabe

$2.1 \quad$ Vorbemerkung zur Edition...................................................................... 4

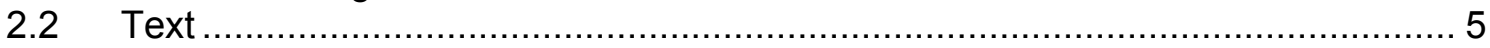

3. Einführung in die Herstellungsverfahren von Arzneiölen.......................................... 28

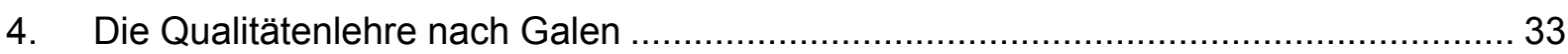

5. Kommentar zur Farfensischen Handschrift ,Cod. 200 …………………………........ 35

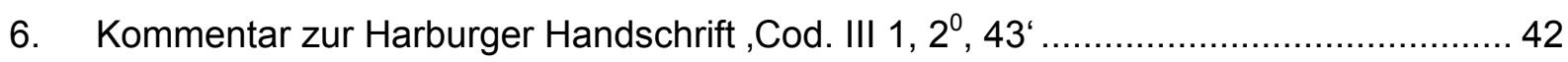

7. Kommentar zur Memminger Handschrift ,Cod. 2, 39'............................................. 47

8. Vorbemerkungen zur Analyse der edierten Arzneien .............................................. 52

9. Vorbemerkungen zur Literatur im Analyseteil.......................................................... 55

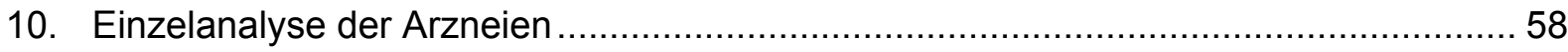

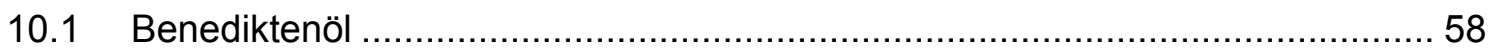

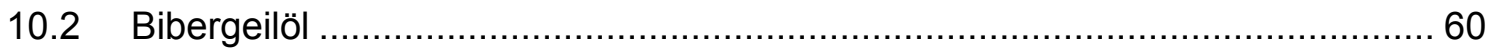

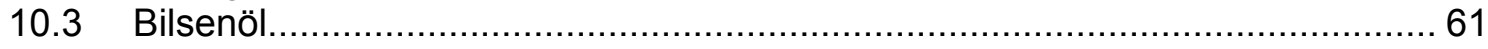

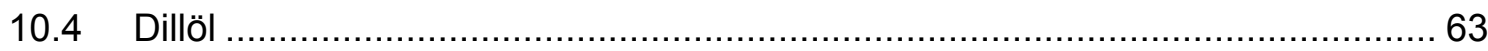

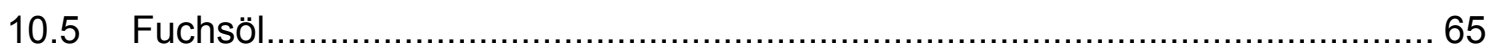

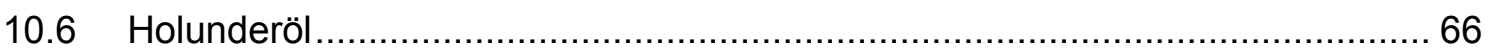

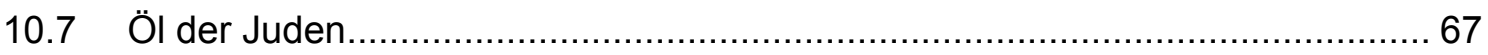

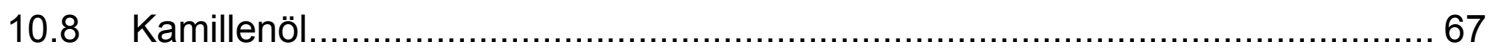

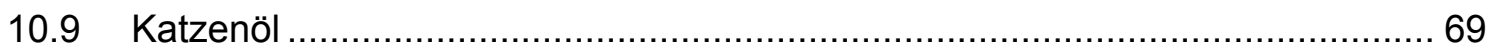

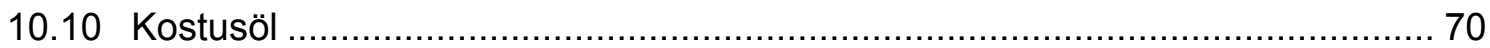

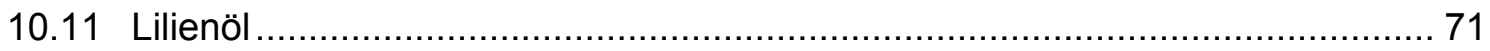

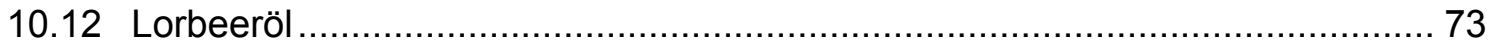

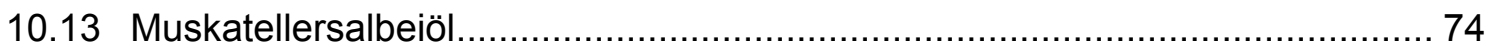

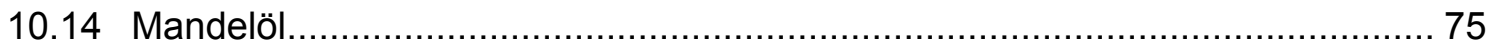

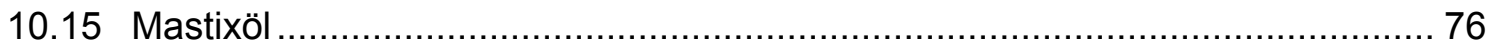

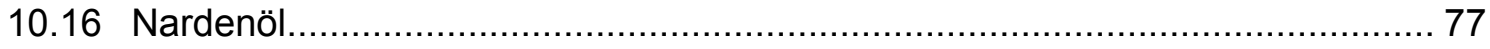

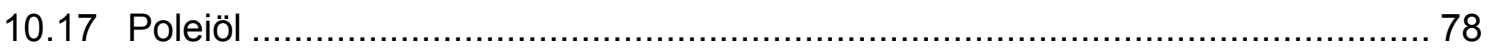

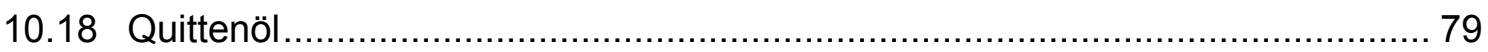

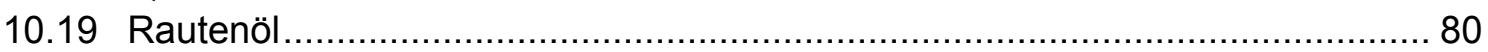

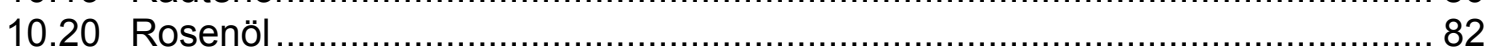

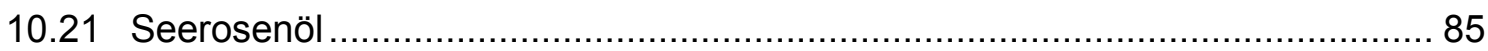

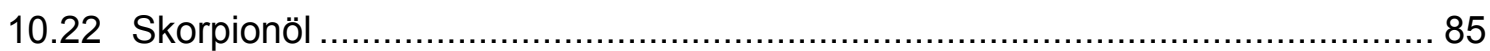

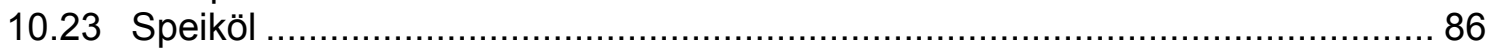

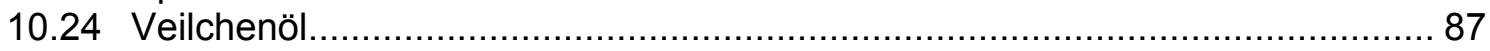

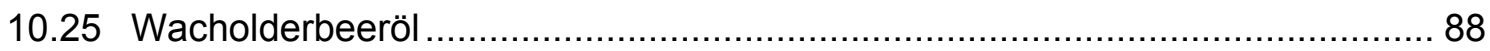

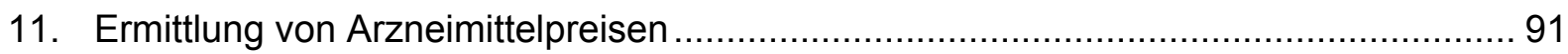

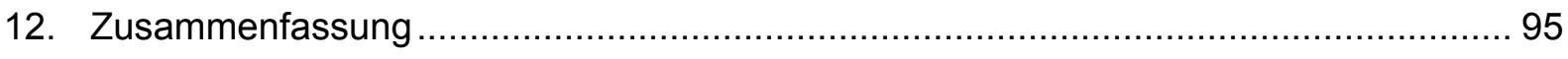

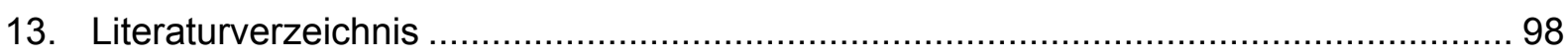




\section{Einleitung}

Die Verwendung von Pflanzen und die Erforschung ihrer Wirkung mittels empirischer Maßnahmen führen vermutlich bis auf die Anfänge der Menschheitsgeschichte zurück. Dabei stellten die pflanzlichen Arzneien stets den herausragenden Anteil des aus der Umwelt genutzten Reservoirs. ${ }^{1}$

Die ersten schriftlichen Belege für die Nutzung von Heilpflanzen in einem pharmazeutisch-medizinischen Sinn, stammen aus den Hochkulturen der Völker Israels, Mesopotamiens und Ägyptens. Ihre Entstehung wird von Forschern auf den Beginn des 2. Jahrtausends v. Chr. geschätzt. ${ }^{2}$ Der Einfluss der Religion auf die Vorstellung von Herkunft und Behandlung von Krankheiten spielte jedoch weit über diese Zeit hinaus eine der Medizin übergeordnete Rolle.

Den wissenschaftlichen Grundstein für die Entwicklung der Medizin und Pharmazie in Europa legten wiederum die Griechen und Römer. „Die Natur ist Heilerin der Krankheit““3, lautet ein hippokratischer Ausspruch, der ausdrückt, worin der griechische Arzt die Zukunft bei der Behandlung von menschlichen Gebrechen sieht. Dieser These nacheifernd, sind es Gelehrte wie Dioskurides, Galen oder Plinius d. Ä., die mit ihren ausführlichen Niederschriften dafür sorgen, dass sowohl das Wissen früherer Generationen als auch die zu dieser Zeit erlangten Erkenntnisse für viele Jahrhunderte im geistigen Besitz ihrer Nachfolger bleiben.

Eben aus diesem Grund bilden jene Gelehrten, insbesondere in Form des wichtigsten Werkes des Dioskurides, seiner ,Arzneimittellehre', das Fundament der vorliegenden Arbeit.

Zu Beginn der vorliegenden Arbeit steht selbstverständlich die Edition der ausgewählten drei ,Ölbücher‘. Den Beginn macht der Kodex aus dem Benediktinerkloster Farfa bei Rom. Es folgen die Kodizes aus den süddeutschen Städten Harburg und Memmingen. Ziel ist es, die Ölbücher der Analyse auf diese Weise besser zugäng-

\footnotetext{
${ }^{1} \mathrm{vgl}$. Schmitz (1998), S. 403

${ }^{2}$ vgl. Schmitz (1998), S. 9-14

${ }^{3}$ Haas (1956), S. 105
} 
lich zu machen. Es erfolgt eine wortgetreue Wiedergabe der Originalhandschriften sowie die Aufschlüsselung schwer verständlicher Textpassagen. Der Edition schlieBen sich ein text- und quellenkritischer Kommentar sowie ein inhaltlicher Vergleich der Quellen untereinander an. Im Fußnotenteil der Edition richtet sich das Hauptaugenmerk mehr auf die Zuordnung der botanischen Nomenklatur der genannten Pflanzen als auf ihre Anwendung. Dazu folgt im weiteren Verlauf ein separater Analyseteil. Dort werden Werke der Arzneimittellehre aus der Zeit des Dioskurides (1.Jh.) bis hin zu aktuellen Büchern der Phytotherapie exzerpiert. Der Vergleich bezüglich Anwendungen der Arzneien im Laufe verschiedener Epochen soll darstellen, ob es Parallelen und Konstanten über diesen knapp 2000-jährigen Zeitraum gibt.

Als eine der zentralen Fragestellungen in der wissenschaftlichen Betrachtung einer solchen Quelle, darf die Hervorhebung dessen, was selten oder gar neu in dieser ist, natürlich auch hier nicht fehlen. Bei der Untersuchung der einzelnen Öle soll im Analyseteil gezeigt werden, welche wissenschaftlichen Vorgänger (Dioskurides, Hildegard, Albertus Magnus, etc.) das Öl oder deren zugrunde liegende Arznei bereits kennen und welche Anwendung sie dafür finden. Diese Untersuchung kann aus Gründen der Übersicht verständlicherweise nur eine Auswahl an Monografien zu diesem Thema mit einbeziehen. Nähere Informationen zur Auswahl der Werke folgen im Kapitel ,Vorbemerkungen zur Literatur'.

Die Kenntnis von der Humoralpathologie als Basis der antiken Medizin ist für das Verständnis der Analyse unerlässlich. Aus diesem Grund geht dem Abschnitt eine Einführung in die ,Qualitätenlehre nach Galen' voraus.

Die Tatsache, dass es sich bei den untersuchten Arzneivorschriften ausschließlich um Öle handelt, rechtfertigt eine weiterreichende Auseinandersetzung mit der ,Herstellung von Arzneiölen' in einem eigenen Kapitel. Dieser Teil bildet zusammen mit der ,Ermittlung von Arzneiölpreisen im späten Mittelalter' einen Sonderabschnitt, begründet durch die genannte thematische Eigenständigkeit der edierten Kodizes.

Abschließend findet sich die obligatorische Zusammenfassung der untersuchten Inhalte. Hier soll möglichst im Überblick zu erkennen sein, ob die editierten Ölbücher neue Informationen liefern, und wenn ja, welche. 
Untersuchungen im Bereich der spätmittelalterlichen Ölbücher sind bisher nur in geringem Maße durchgeführt worden. Crones Dissertation über die ,Würzburger Wundarznei‘ (2002) bietet einen Einblick in das Farfensische Ölbuch. Ziel der Arbeit Crones ist es, die teilweise edierten Rezepte in den chirurgischen Forschungskontext der mittelalterlichen Medizin einzuordnen.

Die komplette Edition und eine detailliertere Analyse der Arzneien mit Schwerpunkt auf den Ölen als Applikationsform finden sich in der hier folgenden Untersuchung. 


\section{Textausgabe}

\section{$2.1 \quad$ Vorbemerkung zur Edition}

Die aus den in Kopie vorliegenden Handschriften entnommenen Rezepte werden buchstabengetreu wiedergegeben. Zeilengetreue Wiedergabe ist aus Gründen der Formatierung ausschließlich für die Memminger Handschrift vorgenommen worden. Die Textwiedergabe folgt den Richtlinien zur Herausgabe deutscher Texte im Mittelalter. ${ }^{4}$ Eine eigene Interpunktion wird nicht durchgeführt. Die Groß- und Kleinschreibung erfolgt originalgetreu nach der Textausgabe. Zum besseren Verständnis einiger Passagen werden gliedernde Absätze gemacht.

Rund- „s“ und Lang-,„s" werden einheitlich als Rund-,,"“ wiedergegeben. Die Kombination aus Lang-,," und „Z“ wird als „ß“ transkribiert. Ansonsten wird die buchstabengetreue Wiedergabe beibehalten. So wird der Gebrauch von "" und „u“ (oder „w“) genauso wenig normalisiert wie die Verwendung von „““ und „““. Bei der Edition der superskribierten Zeichen dient die Vorgehensweise Polhills als Vorbild. ${ }^{5}$ Ist kein eindeutig superskribiertes "e“, „u“ oder " " zu erkennen, wird der Buchstabe als Umlaut mit (z.B. „ä“) wiedergegeben. Ausnahme bilden zwei Punkte, die nach rechts hin aufsteigend sind. Diese werden dann zum Beispiel als „ü“ transkribiert.

Worte werden in runde Klammern gesetzt, wenn sie nicht eindeutig entzifferbar sind. Das in Klammern gesetzte Wort ist ein Lesevorschlag.

Die Abbreviationen im Text werden aufgelöst.

Die Blattzählung steht fettgedruckt eingefügt in die Gesamtformatierung des übrigen Textes. Eine Zeilenzählung erfolgt nicht. Die Durchnummerierung der Rezepte erfolgt in runden Klammern am Ende des jeweiligen Rezepts.

\footnotetext{
${ }^{4}$ Hübner (1934), S. 5-9

${ }^{5}$ vgl. Polhill (2006), S. 33-34
} 


\subsection{Text}

\section{Das „Ölbuch" aus der farfensischen Handschrift} ,Codex Farfensis 200'

\section{BI. $143^{r}$}

Hie hebet sich an daz buch vnd saget vns von den edeln guten Oley ${ }^{6}$ di vns vnßm leibe gut sint das sint 21

\section{Oley von den mandelkern sawer ader susse ${ }^{7}$}

Nym mandelkern wie vil du wilst vnd stos sie wol vnd tu sie denn in einer phannen uber daz fewer vnd rhere sie stetes vmb in der phannen das sie also heis werden daz du die hant magest dorine behalden vnd nym ein besemlein ${ }^{8}$ vnd $^{9}$ besprenge den boden der panne vnd wende ez alle wege vmb yn der phanne also tu czu drei mol vnd nym denn eine herrin ${ }^{10}$ leimet die starck ist vnd necze sie winde sie ader drucke si gar wol aus vnd tu denn di mandelkern darin

\footnotetext{
${ }^{6}$ Es wird in keinem Kodex ein Grund für die Verwendung des Öls als Lösungsmittel genannt. Galen spricht dem Öl eine symmetrische beziehungsweise indifferente Eigenschaft zu. Es befinde sich im Mittel zwischen allen Qualitäten. Als möglicher Grund für die Nutzung des Öls könnte also dessen Neutralität gewesen sein. Es könnte die Vorstellung von einer Unverfälschtheit der Qualitäten zugegebener Ingredienzien existiert haben. Vgl. Berendes (1965), Bd 2, S. 62

7 Zu den Begriffen der bitteren und der süßen Mandel liefert Berendes in seinem DioskuridesKommentar eine hinreichende Erklärung. Er hielte es für wahrscheinlich, dass die bittere Mandel die Urform sei, aus der sich die süße Mandel entwickelt habe. Durch Kontakt mit der Fauna der Umwelt könne jedoch eine Umwandlung zurück zur bitteren Mandel geschehen. Vgl. Dioskurides (1902), S. 143-144

${ }^{8}$,besemlein': „ein kleiner Wasserwedel". Crone (2002), S. 28

${ }^{9}$ Die Abbreviation , $\overline{\mathrm{v}} \mathrm{n}$ ' wird in der gesamten Edition mit , vnd' wiedergegeben.

10 ,herrin': „ein aus Haaren gefertigtes Tuch“. Crone (2002), S. 28
} 
vnd tu das seckel yn die turckel ${ }^{11}$ vnd drucke daz oley daraus vnde nucze es wenn ez dir not ist Dicz oley ist gut vor daz we yn dem rucken vnd we der seiten vnd dem dye Nerwer ${ }^{12}$ we tun

\section{Oley von den sawern mandelkern}

Oley von den sawern mandelkern auf einen andern sin Nym sawer mandelkern i libra die gestosen sint vnd tu sie in iij libra gemeyn oley ${ }^{13}$ vnd seut ez wenn es wol gesoten ist so tu daz oley mit den mandelkern yn einen peczen ${ }^{14}$ vnd tu ez in die turckel vnd fach denn daz oley vnd henge es an die sunne vnd las es viiij tage an der sunnen hengen Dicz oley ist der we ${ }^{15}$ vnd in der seiten vnd vor rucke we der nerfen ${ }^{16}$ (1)

\section{Oley von costoria}

Oley von costoria ${ }^{17}$ Nym unciam i, pilatro ${ }^{18}$ unciam iij, wermut euforbyo ${ }^{19}$ eleboro swarczen ${ }^{20}$ einez icli-

\footnotetext{
11 ,turckel': „Saftpresse“. Crone (2002), S. 28

12 „Nerwer' lies ,nerven“ - vermutlich sind damit die Strukturen „Muskeln, Sehnen, Bänder, Geäder“ gemeint. Höfler (1970), S. 441

13 ,gemeyn oley“: „oleum commune“ - Olivenöl durch Auspressen reifer Oliven. Fischer (1967), S. 82

14 ,peczen': „Tuchstück“. Crone (2002), S. 29

${ }^{15}$ An dieser Stelle ist der Originaltext verderbt. Die Lücke macht etwa ein Fünftel der gesamten Zeile aus.

${ }^{16}$ Dieser gesamte Abschnitt und Teile aus dem restlichen Ölbuch des ,Cod. Farf. 200، wurden ebenfalls von Crone bearbeitet. Vgl. Crone (2002), S. 26-39

17 ,costoria“ lies ,castoreum‘: „Bibergeil“. Lonitzer (1962), S. 600

18 ,pilatro': „Schmerzwurz“. Crone (2002), S. 33

19 ,euforbyo' lies ,euphorbium‘ oder ,euforbium‘: Die verschiedensten Arten der Gattung Euphorbia sind heute bekannt. Fischer nennt allerdings nur „Euphorbia lathyris“ (L.), für die das Synonym „euphorbia“ benutzt wird (Dioskurides). Fischer (1967), S. 268-269

20 ,eleboro swarczen“ lies ,elleborus niger': „Helleborus niger“ (L.). Fischer (1967), S. 270
} 
chen $^{21}$ i hantvol, gemein ole libra ij, wein unciam iiij vnd seut es daz der weyn ist gesoten vnd turckel daz oley vnd henge ader secze es an die sunnen acht tage Dicz oley ist gut vor daz we dez magen vnd ist gut vor daz we der muter ader matrice ${ }^{22}$ vnd erwemet den erfron wetagen (2)

\section{Oley von costo ${ }^{23}$}

Oley von costo unciam semis ${ }^{24}$, pheffer pilatro euforbio iclichs unciam semis vnd mische alle ding mit ${ }^{25}$ libra ij gemeyn oley In dem selben sol sein libram semis rauten oley vnd tu ez an di sunne acht tage Dicz oley ist gut fur alle chalde wetagen vnd sich do mite salbet do der wetagen ist (3)

\section{Oley scorpion}

Oley von scorpion Nym gemeyn oley ij libra, oley von den

\footnotetext{
${ }^{21}$,einez iclichen': eines jeden

22 ,matrice“ von ,matrix (lat.) = „Mutter, Gebärmutter, Schwangere“. Georges (1998), Bd 2, Sp. 830

23 ,costo: Es finden sich zahlreiche Pflanzen, die mit dem Erstnamen (Gattungsnamen) ,costus' beginnen. So zum Beispiel "Costus arabicus", "Costus dulcis" oder "Costus amarus". Eine eindeutige Klärung um welche Art der "C. spec." es sich in diesem Fall handelt, ist nicht zu leisten. Schneider (1968), Bd 5/1, S. 380
}

Weitere Aspekte dieser Fragestellung sind Bestandteil des Kapitels ,Einzelanalyse der Arzneien:

24 ,unciam semis': Eine halbe Unze entspricht einem Loth (= „semiuncia“), dessen Gebrauch demnach hier ebenso zulässig wäre. Schneider (1962), S. 52. Das Gewicht einer halben Unze entsprach nach dem 1555 verabschiedeten Nürnberger Apothekergesetz einer Menge von 14,9 Gramm. Schneider (1962), S. 91

${ }^{25}$ An dieser Stelle hat der Verfasser im Text das Symbol für Unze durchgestrichen. 


\section{BI. $144^{\mathrm{V}}$}

Sawern mandelker unciam vj, aristologia ${ }^{26}$ der keulichten $^{27}$ pheffer salte de cape $^{28}$ redixe de capari ${ }^{29}$ iclichs unciam semis nym dise ding allessamet vnd secze es an di sunne xv tage vnd tue genug scorpion dorin vnd nucze es alz ez dir not ist Dicz oley ist gut fur alle giftige bise sam spinnen vnd scorpione (4)

\section{Oley von fochsen}

Oley von fochsen Nym ein ganczen fochs vnd sewt inn in gemein oley daz des oles also vil sey daz ez den fochs bedecket vnd seut in alz lange bis daz daz fleisch von dem gebeine fellet vnd tu ihn denn in di turckel vnd fach daz oley vnd henge ez viij tage an di sunne Dicz oley ist gut fur alle gruntlose we di mit chelde lauffen vnd vor we der vergicht ${ }^{30}(5)$

\footnotetext{
26 ,aristologia“: In Frage kommen „Aristolochia baetica”, „A. clematitis”, „A. longa”, „A. parviflora”(alle Artennamen nach L.). Fischer (1967), S. 260. Die Häufigkeit mit der in Arznei- und Kräuterbüchern von der Osterluzei (,A. longa“) die Rede ist, bietet einen Hinweis, der ihre Verwendung auch in diesem Rezept nahelegt.

${ }^{27}$,keulichten“ lies ,kaulich' o. ,käulich': „kugelicht, kugelrund“ - im Zusammenhang mit Pfeffer könnten somit die Pfefferkörner gemeint sein. Grimm (1984), Bd 11, Sp. 351

${ }^{28}$,salte de cape‘: Die Auflösung dieser Formulierung ist letztendlich nicht vollständig zu leisten. Für ,salte' ist die Entlehnung aus dem germanischen Wort ,salt' für "Salz" denkbar. Das Wort ,de' ist mit der Übersetzung „von, aus“ (lateinisch, italienisch) bedeutungstechnisch noch am eindeutigsten zuzuordnen. ,Cape' ist im Italienischen nicht belegt. Eine abgewandelte Form des Wortes "capo, testa" = „Haupt" muss in Betracht gezogen werden. Die Herleitung wird durch die Tatsache mit Sinn gefüllt, dass das Rezept die Herstellung eines Öls aus dem Skorpion vorschreibt.
}

Für seine sachdienlichen Hinweise möchte ich Prof. Bracchi aus Rom herzlich danken.

29 ,redixe de capari': Denkbar sind die Ableitungen ,radice“ = „Wurzel” und ,capari“ von „capparis spinosa“ (L.) = „Kapernstrauch“. Dem Rezept entsprechend wären demnach die Wurzeln des Kapernstrauchs zu verwenden. MlatWb (1999), S. 238 und Pons (1998), S. 583

${ }^{30}$,vergicht': „Arthritis vaga, die ihren Sitz ändert“, „Rheumatismus“. Höfler (1970), S. 192 


\section{Oley von mastic mi $^{31}$}

Oley von mastic unciam semis, gemein oley unciam i vnd tu ez in einen rosen huet czu stilliern vnd fach daz oley

Dicz oley ist gut fur alle siechtum dez magen vnd der ez in di orn tut den machet ez gehorn (6)

\section{Oley von quitten}

Oley von quitten i libra, gemein oley libra iiij vnd tue dise ding czu samen vnd tu ez $\mathrm{x}$ tage an die sunne vnde brenn ez denn aus in i Rosen hutte ${ }^{32}$ der von glase ist vnd fach denn daz oley Dicz oley ist gut die flusse dez bauches czu verstellen di si den bauch mit salbet (7)

\section{Oley von spigo ${ }^{33}$}

Nym unciam ij gemeyn ole, oley von spigo libra ij vnd sewt es i halbe stunde bei dem fewer vnd tu es denn an die sunne $x$ tage Dicz oley ist gut fur siechtum das chalt ist (8)

\section{Oley von lorbern}

Oley von lorbern Nym lorber von dem lorberbawme wie vil du wilt vnd stoz die wol vnd sewt sy denn in waß i stunde vnd loz denn daz waß chalt werden vnd

\footnotetext{
31 ,mastic' lies ,mastix“: „Pistacia Lentiscus“ (L.). Fischer (1967), S. 278

32 ,Rosen hutte“ lies ,rosenhut”: „Destillierhelm, Alembicus“. Grimm (1984), Bd 14, Sp. 1203

33 ,spigo': „fior di spigo“ ist bei Fischer belegt als „Lavendula spica“ (L.). Fischer (1967), S. 273
} 
nym denn daz feiste oben von dem waß vnd behalt ez denn yn einem reinen gefese Dicz oley ist gut fur alle we die von chalden sachen chomen sinz Salbet man daz we do mit vnd lege henffin werg $^{34}$ darauf ader vngewaschen wolle (9)

\section{Oley von cramptbern ${ }^{35}$}

Oley von krampbern Nym gemein [oley] iiij libra, cramptber libra i vnd seut ez denn mit den cramptbern alz lange daz sein genug ist vnd seye

\section{BI. $144^{r}$}

es vnd behalt ez denn Dicz oley ist gut fur daz we in der seiten vnd fur daz vergicht der sich mit salbt (10)

\section{Oley von chaczen}

Oley von kaczen Nym eine chacze ane heupt vnd seut sie yn waß also lange daz sie czu fellet vnd tu sie denne in einen sack vnd turckel si vnd fach daz feiste vnd tu ez an di sunne yn dem augoste Vnd daz oley ist gut fur alle we dez rucken vnd rene ${ }^{36}(11)$

${ }^{34}$,henffin werg' lies ,henfîn wërc': bezeichnet einen aus Hanf gearbeiteten Stoff. Lexer (1992), S. 86, 314

35 ,cramptbern“ lies ,kraumetper': gemeint sind die Beeren des Wacholders („Juniperus communis“ (L.)). Fischer (1967), S. 272

${ }^{36}$,rene': mögliche Herkunft von „ren, renis = die Niere“. Georges (1998), Bd 2, Sp. 2312 


\section{Oley von chamamille ch $^{37}$}

ader Oley von chamamille Nym gemein olei hermenczel $^{38}$ ist $\mathrm{i}$ vnd wasche es czu drei mol mit waß vnd tu es denn in i uberglastes gefese vnd tu i libra camamillen blumen darin vnd tu ez an di sunnen vnd loz ez daran sten 25 tage xxv vnd nym ez denn so ez gepurgirt ist vnd gemachet Dicz oley ist gut fur alle tieffe we der beine vnd der nerfen vnd fur geswolst die von chelde sint vnd fur alle chalde we vnd vertreibet daz we in den gelencken vnd nimpt den wetagen $\operatorname{der}^{39}(12)$

\section{Oley von Raute}

Oley von Raute nym raute bis daz es gemachet wirt vnd gemein oley vnd seut es vnd secze es an di sunne $\mathrm{xl}$ tage Dicz oley ist gut der erhiczet ist an dem gesichte vnd an den steten ${ }^{40}$ dez leibes (13)

\section{Von dem oley Reifar daz ist aneto ${ }^{41}$}

Oley von Reifar aneto Nym reifar vnd tu $\operatorname{sem}^{42}$ in $\mathrm{i}$ uberglastes gefese vnd fulle ez fol vnd geus ez denn vol mit gemein olei vnd secze virczig tage an di su-

\footnotetext{
${ }^{37}$ Haas spricht in seinem ,Spiegel der Arznei' den Germanen einen Einfluss auf die Einführung der Kamille als abendländisches Heilmittel zu. Vgl. Haas (1956), S. 171

${ }^{38}$ Crone (2002), S. 30

${ }^{39}$ Hier ist eine weitere Stelle im Text verderbt. Diese macht eine halbe Zeilenbreite aus. Es ist möglich, dass der Verfasser keine Heilanzeigen kannte. Eventuell ließ er die Zeile für Nachträge frei.

40 ,steten': „stete“ = „Platz“. Lexer (1992), S. 211

41 ,aneto“ lies ,anetum': „Anethum graveolens“ (L.). Fischer (1967), S. 259

42 ,sem': vermutlich im Sinne von ,semen“ = „der Samen“. Die Samen des Dills fanden in der Heilkunde häufig Verwendung.
} 
nen vnd geus alle wege me doran bis daz ez gemachet sey Dicz oley ist gut fur di swacheit dez gehirnes vnd des magens (14)

\section{Oley von liligen ${ }^{43}$ wurczel}

oley von Lilligen vnd tu sie yn bawm oley ${ }^{44}$ iij libra vnd seut ez denn bey dem fewer vnd secze ez an die sunne $x v$ tage Dicz oley ist gut fur heise wetagen ${ }^{45}$ (15)

\section{Von dem edeln feiol ${ }^{46}$ oley}

Oley von feiol Nym veiol iij oz, bawm oley iiij libra vnd tu ez denn in i uberglastes gefese und secze ez denne an di sunne fur $x x$ tage Dicz olei ist gut czu salben die tobelichen fieber ${ }^{47}$ vnd fur alle vergicht di heis ist (16)

\footnotetext{
${ }^{43}$,lilig": „Lilium candidum“ (L.) Pritzel und Jessen (1967), S. 273

44 ,bawm oley': „Baumöl“ - gemeint ist „oleum commune“ (=Olivenöl). Schneider (1962), S. 103

${ }^{45}$ Es wird von einem Mittel gesprochen, das gegen "heise wetagen" hilft. Die Schwertlilie ist warm und trocken (H. v. Bingen). Die Lilie (Lilium candidum L.) ist mehr kalt als warm (H. v. Bing.). Demnach kommt die Schwertlilie nicht in Betracht. Im Kommentar der ,Arzneimittellehre' des Dioskurides berichtet Berendes zudem, dass Lilium candidum L. die einzige Lilienart sei, die im Arzneischatz zu finden ist.

${ }^{46}$,feiol' lies ,veyal': „Viola odorata“ (L.). Fischer (1967), S. 288

47 ,tobelichen fieber': 'tobelich“ nach Lexer „wahnsinnig, toll“. Höfler gibt „Tobfieber” - aus Tobsucht entstandenes Fieber - und "tolles Fieber" an. Letzteres kommt aus dem westfälischen Sprachgebrauch und ist durch die süddeutsche Herkunft des Schreibers eher unwahrscheinlich. Höfler (1970), S. 143
} 


\section{Oley von Rosen}

Nym oley von Rosen wilde rosen ${ }^{48}$ wie vil du wilst tu sie in ein uberglastez

\section{BI. $145^{\mathrm{V}}$}

gefese vnd fulle es czu mit gemeyn ole

Wiltu es noch besser machen So wasche daz oley drei fach vnd tu denne die rosen in daz olei vnd secze es an die sunne $x x v$ tage

Dicz oley ist gut fur erhiczunge vnd geswolne vnd heise siechtum (17)

\section{Oley von moton daz sint cziegel}

Oley von moton cziegel etlichen heisen es oley von le lateribus ${ }^{49}$ Etliche heisen ez [oleum] philosophorum $^{50}$ Etliche heisen es oley benedicto ${ }^{51}$ ader gesegent Nym alde steine di lange czeit gelegen sint vnder der erden vnd lege si in daz fewer daz sie heis und glunde rot werden vnd lesche sie denne $a b$ yn oley vnd tu also czu v ader czu vj mol vnd stos denn die steine vnd tu dorin ij libra centaurea ${ }^{52}$ vnd i libra putter die alt ist vnd tu es denn yn ein rosen hut vnd fach denn daz oley Dicz oley ist gut fur alle we

\footnotetext{
48 ,wilde Rosen': Mildenberger belegt ,wilde Rose“ als „Rosa canina“ (L.). Mildenberger (1997), Bd 5/3, S. 1604. Denkbar ist des Weiteren, dass der Kompilator damit wildwachsende, nicht kultivierte Rosen meint.

${ }^{49}$,oley von le lateribus': vgl. hierzu: Braekman und Keil (1971), S. 303-305

50 , [oleum] philosophorum‘: „Dieses wird bereitet, wenn man das Baumöl mit glühenden Ziegelsteinen vermischt und aus einer Retorte destilliert. Es...taugt zu den harten, kalten Geschwulsten." Schneider (1968), Bd 5/2, S. 375

51 ,oley benedicto': vgl. hierzu Keil (2004), Sp. 236f.

52 ,centaurea': „Erythraea centaurium“ (L.). Fischer (1967), S. 268
} 
Das ist der dritte balsam vnd ist gut fur daz [we] der

gelencke vnd der nerfen vnd fur di chalde vergicht

(18)

\title{
Oley balsamyno
}

\author{
Oley Balsamino ader gebalsamet oley der Juden ${ }^{53}$ \\ Nym mirre aloe pheffer spigo nardo ${ }^{54}$ olibano $^{55}$ mus- \\ caten (ibunna) ${ }^{56}$ saffran mastic opopponago ${ }^{57}$ tra- \\ chen blut ${ }^{58}$ delio $^{59}$ carpo balsamo $^{60}$ armoniago $^{61}$
}

${ }^{53}$ Gerhard Eis belegt die Existenz eines Juden mit Namen ,Chilo‘ (nicht sichere Lesung). Zimmermann
macht einen Vorschlag für die Herleitung des Namens. Er belegt einen gleichnamigen Ephoren aus
Sparta, der zu den sieben Weisen im 6 . Jahrhundert v. Chr. zählte. Er kommt ebenso als Namensvor-
bild in Frage wie der hebräische Name Shilo, ohne diesmal mit einer konkreten Person verknüpft zu
sein. Diesem wird eine Latwerge auf Bl. $147^{V}$ ' zugeschrieben: „Lectuarie der ist meisterlich gut vnd ist
gecronet von meister Chilo (?) dem Juden.“ Das ,Ölbuch' endet mit Blatt $145^{r}$ und geht damit der Lat-
werge unmittelbar voraus. Es lässt sich zwar keine direkte Beziehung der Arzneien miteinander ablei-
ten oder gar in Wortform feststellen. Die Erwähnung einer weiteren Arznei, die der Kompilator dem
jüdischen Heilmittelschatz zuspricht, mag jedoch als Erklärungsansatz auf die Einbeziehung der jüdi-
schen Medizin in diesem Zusammenhang dienen. Vgl. Eis (1982), S. 12 und vgl. Zimmermann (1985), S. 250

54 ,spigo nardo“ lies ,nardus': In die nähere Auswahl kommen „Valeriana celtica“ (L.) und „Lavandula latifolia" (Vill.). Fischer (1967), S. 273, 287

55 ,olibano“ lies ,olibanum': „Boswellia thurifera“ (Rosch.). Fischer (1967), S. 262

${ }^{56}$ Das Wort ist im Originaltext zu stark verderbt und damit nicht lesbar.

57 ,opopponago' lies ,opoponax': „Opoponax Pastinaca“ (L.). Fischer (1967), S. 276

58 ,trachen blut' lies ,trachenblůt': „Dracaena Draco“ (L.). Fischer (1967), S. 267

59 ,delio': Eine Ableitung von 'dellium' = 'bdellium' ist wahrscheinlich. Laut Fischer gibt es drei Pflanzenarten, denen dieser Name zugeordnet werden kann. „Acacia gummifera“ (Willd.) - Fischer (1967), S. 257 oder "Chamaerops humile" (Avicenna, Albertus Magnus) - Fischer (1967), S. 262 oder "Commiphora africana" (Engl.), das Einzug in die mittelalterliche Medizin durch den Einfluss der Araber hielt. Fischer (1967), S. 265

60 ,carpo balsamo“ lies ,carpobalsamum': „Balsamfrucht” einer „Commiphora“ Art. Georges (1998), Bd 1, Sp. 1009. Daems Balsamartikel gibt darüberhinaus Aufschluss über die Qualität der Frucht im Vergleich zum Balsamholz (,xylobalsamum') und dem Balsamsaft ,Opobalsamum'. Sie steht in deren Mitte. Vgl. LexMA (1980), Bd 1, Sp. 1389.

61 ,armoniago' lies ,armoniacum': Diesen Namen trägt ein Gummi in Lonitzers Kräuterbuch. Lonitzer (1962), S. 733. Inm zufolge benutzt Dioskurides den Namen „Thimiana“. Fischer führt ,thimiana' als Synonym für "Thymus vulgaris“ (L.). Fischer (1967), S. 286 
sarcocolo $^{62}$ gamarabica $^{63}$ dragantz $^{64}$ iclich unciam semis, storace liquido londano feistes von chastoria iclichs ein dramer (Dhesem) $)^{65}$ muschado scropolo ${ }^{66} \mathrm{i}$ trementina $^{67}$ vnd tu alle ding [in einen] alambico von glase vnd fach daz selbe daz aus dem rosen hute treuft So halt es schone sam einen schacz

Dicz oley ist gut fur alle siechtum Wenne die Juden halden es gar vor ein chastlich ding vnde ist gut fur alle chalde siechtum (19)

\section{Der moren balsame}

Balsamo der morn balsam Nym trementina libram semis, weiroch unciam semis, muscaten cubebe ichlichs gleich unciam semis, vor eines gomo ${ }^{68}$ von trucken feigen libram semis vnd tu daz ding czu stilliern in einen rosen hute von glase vnd fach daz selbe Dicz ist eyn perfecta lectuarie ${ }^{69}$ ader licore vnd ist gut fur die we vnd die enge der brust vnd fur alle wee der vergicht (20)

\footnotetext{
62 ,sarcocolo“ lies ,sarcocolla': „Agrimonia Eupatoria“ (L.). Fischer (1967), S. 257

63 ,gamarabica' lies ,gummi arabicum': Wird bei Fischer als weiteres Synonym für „Acacia gummifera“ (Willd.) geführt, vgl. 'bdellium'. Fischer (1967), S. 257

64 ,dragantz' lies ,dragant': „Artemisia Dracunculus“ (L.). Fischer (1967), S. 260

${ }^{65}$ Die Anfangsbuchstaben des Wortes sind nicht klar entzifferbar.

66 ,scropolo“ lies ,scrupolo': „(als altes Gewicht) vierundzwanzigster Teil der Unze“. Bulle und Rigutini (1912), S. 760

67 ,trementina': ,trementina raxa“ belegt Daems mit „Pinea” = „tannzapf' einer nicht näher eingegrenzten Pinusart. Gemeint ist vermutlich das Harz des Zapfens. Daems (1993), S. 227

68 ,gomo' ist bei Battisti aufgeführt als abgewandelte Dialektform des Wortes "góme“ = „scròfole“, für das durchaus der Wortursprung ,scropolo' beziehungsweise ,scrupolo' denkbar ist. Die Übersetzung ist der Fußnote 62 zu entnehmen. Battisti und Alessio (1952), S. 1841
}

69 ,lectuarie‘ lies ,lectuârie‘ = ,latwârje‘: „durch Einkochen dicker Saft, latwerge.“ Lexer (1992), S. 421 


\section{Balsam der feyn [ist]}

Balsamo der fein vnd gut ist ist ${ }^{70}$ Nym oley von trementina libram semis i vnd halbes bawm olei libra ij, Ior olei libram semis, Stengel von negelein daz vindestu yn

\section{BI. $145^{r}$}

aptecken cinamomo ${ }^{71}$ iclichs unciam ij, euforbio lorbe gomo edera ${ }^{72} i$ unciam, vor eines tegole ${ }^{73}$ biscote $^{74}$ libram semis, laudano ${ }^{75}$ unciam semis, mastic vor eines, mirre galbano ${ }^{76}$ vor eines unciam semis, grunspan ${ }^{77}$ oder verderame ${ }^{78}$ unciam i, aloe ${ }^{79}$ unciam iij, oley von stein moton libram semis, borge ${ }^{80}$

\footnotetext{
70 ,ist' kommt im Originaltext doppelt vor und wird deswegen hier buchstabengetreu übernommen

71 ,cinamomo“ lies ,cinamomum': in Frage kommen „Cinnamomum ceylanicum" (Bryan) und „Cinnamomum Cassia“ (Avicenna). Fischer (1967), 264-265

72 ,edera': „Hedera helix“ (L.). Fischer (1967), S. 270

73 ,tegole': Eventuell von ,tegula“ = „Pfanne, Ziegel" abgeleitet, da im Kompendium mehrmals „cziegel" bzw. „moton“ Erwähnung finden. Georges (1998), Bd 2, Sp. 3038

${ }^{74}$,biscote' lies 'biskot': „Zwieback”. Bunsmann-Hopf (2003), S. 31

75 ,laudano“ lies ,landanum': „Cistus creticus“ (L.). Fischer (1967), S. 265

${ }^{76}$,galbano“ lies ,galbanum”: „Galbanum officinale” (Don.). Fischer (1967), S. 269

77 ,grunspan' lies ,grünspan': Schneider führt es in seinem ,Lexikon der alchemistischpharmazeutischen Symbole“ als "Aes viride“ auf. Schneider (1962), S. 113. Als „Kupferoxid“ in erster Bedeutung und nachrangig in den unterschiedlichsten Abwandlungen einiger Pflanzennamen "grünsper" für "cysticus scoparius" - belegen es die Gebrüder Grimm. Grimm (1984), S. 960-961. Vgl. auch Mildenberger (1997), Bd 56/2, S. 628-629

78 ,verderame': zusammengesetzt aus „verde“ = „grün“ und ,il rame“ = „das Kupfer". „Kupfergrün“ ist bei Grimm belegt als "grünspan“. Es ist folglich nichts anderes als die Übersetzung des direkt im Kodex vorher genannten Grünspans ins Italienische. Pons (1999), S. 586, 788 und Grimm (1984), S. 2763

79 ,aloe': „Aloe socotrina“ (L.) . Fischer (1967), S. 258

${ }^{80}$,borgel': „kleines Schwein“ lat. porcillus 'Ferkel' $\rightarrow$ ital. porcello 'Schwein(chen)';

„porcello" spricht sich [portschello] - spricht man „borgel" italienisch aus, klingt dies wie [bordschel].
} 
smer $^{81}$ feistes von gensen feistez von putter die alt ist libra ij, trementina honig iclichs libra iij vnd tu daz ding czu stilliern yn einen hute von glase

Daz ist eine austermosen gute arcztney fur tieffe vnd vngruntliche $^{82}$ we vnd fur di cicatrice ${ }^{83}(21)$

Oley daz wunder gut ist fur die di speise czu dem munde auswerffen vnd nicht behalden mugen vnd vndewent Darczu nym mynczen ${ }^{84}$ rosen wermut ichlichs ein unciam, costo unciam i, cennamon zinziber $^{85}$ quintin i, anesi unciam semis, fenchel somen unciam semis, saffran unciam semis, czocker unciam i, asia pulver rosa ${ }^{86}$ vnd seut daz vor geschriben ding mit vj libra gemein oley off den omern vnd salbe inm offte die sole des fusses mit dem oley also warm vnd salbe dem siechen auch den magen der daz fieber hat ader ane fieber. Es verstelle ym die vndewunge; etcetera (22)

81 ,smer' lies ,smër': „Fett“. Lexer (1992), S. 199

82 ,vngruntliche‘ lies ,ungründic': „unergründlich“. Lexer (1992), S. 253

${ }^{83}$,cicatrice“ von ,cicatrix‘ (lat.) = "Narbe“. Georges (1998), Bd 1, Sp. 1126

84 ,mynczen“ lies ,minze': Unter den zahlreichen Minzearten führt Fischer nur die "Mentha aquatica“ (L.) auf, die mit dem Synonym "minze“ vorkommt, ohne einen weiteren Beinamen wie "Garten-“, „Ross-“ oder andere zu tragen. Fischer (1967), S. 275

85 ,zinziber' lies ,zingiber': „Zingiber Amomum“ (L.). Fischer (1967), S. 289

An dieser Stelle möchte ich Gundolf Keil recht herzlich für die Auflösung einiger Abbreviationen und weitere hilfreiche Kommentare zum letzten Abschnitt des ,Ölbuchs' aus dem ,Cod. Farfensis' danken.

${ }^{86}$,asia pulver rosa': im Sinne von „ossia pulvere rossa“ bezogen auf den feinkörnigen Rosenzucker. 


\section{Das ,Ölbuch“ aus der Harburger Handschrift ,Codex III 1, $2^{0}, 43^{\prime}$}

\section{BI. $69^{r}$}

Hie nach volgen Etliche o̊l warczu die gut sein vnd wie man die bereuten vnd machen soll:,

\section{Rosenöl}

Item also mach Rosen ${ }^{87}$ o̊l Nym iij libra pawmole vnd i libra rosen pleter vnd thue das in ein glaß oder in einen hafen ${ }^{88}$ der glasen sey vnd mach das oben gantz oben zu vnd henck das an die sunnen dreyssig tage und darnach truck es durch ein tuch Das o̊l ist zumol gut fur alle hitz die dem menschen kumbt in der kranckheyt So man die wipron ${ }^{89}$ vnd die stirn do mit bestreicht magstu nit gehabn pawmol So nym gut meyen puttern ${ }^{90}$ vnd ein vntz wachs $z$ lap ${ }^{91}$ das allererst vnd thue es dann zusammen man sagt das es pesser sey dann das erste:, (1)

\footnotetext{
${ }^{87}$,Rosen': Da eine genauere Spezifizierung der Rosenart aus dem Text nicht ableitbar ist, wird an dieser Stelle die Zitat-Empfehlung Schneiders übernommen. „Rosa foetida“, „R. canina“, „R. rubiginosa“, „R. gallica“, „R. arvensis“, „R. alba”, „R. damascena”, „R. centifolia”. Schneider (1968), Bd 5/3, S. 182

${ }^{88}$,hafen": "geschirr, topf" - ein Begriff, der im oberdeutschen Sprachgebrauch zu finden ist und im mhd. „topf" genannt wird. Grimm (1984), Bd 10, Sp. 120

89 ,wipron': frühnhd. für „Wimpern“. Grimm (1984), Bd 30, Sp.228

90 ,meyen puttern' lies ,Maibutter' oder ,Maienbutter': vgl. Crone (2002), S. 4

91 ,lap': „,mittel zum gerinnen lassen, lab“. Lexer (1992), S. 122
} 


\title{
Veilchenöl $^{92}$
}

Veilcheno̊l das hat geleich die selben Krafft vnd ist auch gleich zu den dingen gut als das roseno̊l: (2)

\section{Seerosenöl}

\author{
Barrago $^{93}$ heißt gruntletichen ${ }^{94}$ das macht man als \\ das roseno̊l
}

das hilfft fur aller hand seuchen die von hitz kommen wann es ist vil kelter natur dann das veiol ol oder roseno̊l:

\section{Muskateller-Salbeiöl}

Item Barrago heyßt scharlay darvmb heyßt das o̊l Barragmatum oleum des scharlas plumen das macht man geleich als vor geschriben stet das ist ein teyl wermer dann das annder von natur vnd ist gut den die an der quartan ${ }^{95}$ arbeuten vnd alle des hertzen tragheit und das understandn zweyfel an den sinnen

\footnotetext{
${ }^{92}$,Veilchenöl': Im dritten Kapitel des Traktats spielt der Kompilator vermutlich auf die vorhergehenden Öle an, woraus zu ersehen ist, dass im zweiten Kapitel das Veilchenöl beschrieben wird. Diese Schlussfolgerung ist dadurch zu stützen, dass es sich dabei um ein seit der Antike sehr gebräuchliches Arzneiöl handelt, dessen Eigenschaften passenderweise kalter Natur sind. Aus dem verderbten Wort zu beginn des zweiten Kapitels lässt sich nichts Genaueres edieren.

93 ,Barrago': „Borrago officinalis” (L.) und „Salvia sclarea“ (L.) sind beide bei Marzell belegt. Zu überlegen ist: Sowohl dem Borretsch als auch dem Muskatellersalbei werden in der Sekundärliteratur warme Qualität zugeschrieben. Im Kodex ordnet es der Schreiber eindeutig den kalten Ölen zu. Ein Grund, der gegen beide Pflanzen spricht. Andererseits gibt der Kompilator am Ende des zwölften Kapitels einen Rückschluss auf die Herstellung von „Muscatillium“ an. Diese Textstelle dient als Referenz für die Entscheidung, dass im Kodex der Muskatellersalbei gemeint ist. Aus diesem Grund wird fortan bei der Analyse nur noch auf den Salbei eingegangen. Vgl. Marzell (1943) Bd 1, Sp. 625-629.

94 ,gruntletichen': wird bei Daems mit „Nenufar = Nymphea alba“ (L.) belegt. Daems (1993), S. 217

95 ,quartan': „Quartanfieber" oder „Quartanie“ bezeichnet ein „sich alle vier Tage einstellendes Wechselfieber". Höfler (1970), S. 486. Galen ordnet seine Herkunft der schwarzen Galle und damit dem sie produzierenden Organ der Milz zu. Schöner (1964), S. 89
} 
und doch nit gar unsinnig sein:, (4)

\section{Bilsenöl}

Oleum Jusquiam ${ }^{96}$ Macht man also lusquiam heyßt pilsen fulle einen hafen mit dem samen der locher hab der new ist vnd die ko̊pfchen vnd pleter zu schnitten Nym einen andern hafen und grab den vnder die erden und setz den ersten locherettn auff den in die erden vnd stopff es wol zu das nihtz dar ein felt und deck dann die erden vber die lochern

BI. $70^{v}$

hafen vnd laß die ein Jar sten. Wenn das jar vmb kumbt so nÿms her auß so vindestu schon vnd lauter o̊l in dem vndersten hafen

Das o̊l ist gar gut zu allerley seuchen die von hitz kommen wan es kelt ser (5)

Ich hab ÿetzund gesagt von den o̊len die kalter natur sein Nun will ich sagen von den die heysser natur sein:,

\section{Lorbeeröl}

Lorôll: Das mach also Nym lorber vnd auch die pleter ob du so gehabn magst stoß sie vnd seud sie mit wasser ser vnd das o̊berst nÿmbt man ab vnd behelt

96 ,Jusquiam“ lies ,jusquiamus': „Hyoscogamus niger“ (L.). Fischer (1967), S. 271 
es das ist gut fur die kalten gicht ${ }^{97}$ und fur alle seuchen die von kalten dyngen komen wann es ist heyß in dem dritte grad (6)

\section{Poleiöl}

Oleum puleginum ${ }^{98}$ Das macht man vonn poley das ist heyß in dem vierden grad Nÿm poley so er pluet vnd seud den mit o̊l als hie vor geschriben stett vnd tempir ${ }^{99}$ es pei dom fewer ÿe lenger es seudt ÿe pesser es wirt So soll mans dann auß zwingen vnd behalten (7)

\section{Holunderöl}

Oleum sambucum Sambucus ${ }^{100}$ heyßt holder der ist heyß an dem dritten grad das o̊l macht man von holder plut vnd seudt es auch als ir vernomen habt mit o̊l vnd ist gut als die andern die heyß sein Auch ist ein ander o̊l von holder das ist kalter natur das macht man von den pern die man über mer bringt der vindt man hie nicht:, (8)

\section{Nardenöl}

Oleum Nardinum Das fleuß in Indea auß einem stein

\footnotetext{
97 „kalten Gicht“: „Arthritis frigida“. Eine Gichtform, bei der „die Kranken mehr Frost leiden“. Höfler (1970), S. 190

98 ,puleginum“ : „Mentha pulegium“ (L.). Fischer (1967), S. 275

99 ,tempir‘ lies ,tëmperieren‘: „im gehörigen Verhältnisse mischen“. Lexer (1992), S. 225

100 ,Sambucus': „Sambucus nigra“ (L.), Fischer (1967), S. 283
} 
nit als man sagt Mann macht es also man nÿmbt spicanardt ${ }^{101}$ gantz vnd seudt in in wasser mit o̊l als ir vor vernomen habt zu einem sampfftenn wein vnd lest es darnach tzweintzig tag darynnen ligen wenn dann die Krafft gantz in das o̊l kumbt So rnig es auß vnd behalt es Es hilfft fur alle seuchen die von kalter natur komen vnd hilfft zu der dewng (9)

\section{Rautenöl}

Oleum Ruteleon Macht man von den Rauten ${ }^{102}$ als die schelhein ${ }^{103}$ mit den truvten pletern soll man zu sammen sieden mit einem senfften wein vnd o̊l vnd laß es tzweintzig tag also darinne sten so rnig es dann auß vnd behalt es, es ist gut vnd heÿß in dem vierdn $\operatorname{grad}^{104}:,(10)$

\section{Bibergeilöl}

Oleum Castreleon Castorium macht man also Die Bibergeyl soll man siedn in o̊l mit sanfftem wein man darff das nit rnigen wann die pibergeil zusert all gar Das o̊l ist gut Epilentiris Epilenpsia ${ }^{105}$ ist ein seuch in

\footnotetext{
101 ,spicanardt': Im Text spielt der Kompilator auf eine Legende an, die den Ursprung der Pflanze in "Indea“ angibt. Der Zitatempfehlung von Schneider folgend, handelt es sich am ehesten um Nardostachys jatamansi (S.). Schneider (1968), S. 352

${ }^{102}$,Rauten': Es ist an dieser Stelle keine genauere Eingrenzung der Rautenart möglich, weshalb auf die Zitatempfehlung Schneiders verwiesen wird. „Ruta graveolens“ (L.), „Ruta montana“ (L.). Schneider (1968), Bd 5/3, S. 201. Vgl. hierzu auch Becela-Deller (1998), S. 18-20

103 ,schelhein': geht vermutlich auf ,schelkrudt" = „Chelidonium majus“ (L.) zurück. Daems (1993), S. 138

${ }^{104}$ Alle wichtigen Informationen zur medizinischen Verwendung der Raute liefert der 65 . Band der Würzburger medizinhistorischen Forschungen. Vgl. Becela-Deller (1998), S. 56-64; 113, 230-234

105 ,Epilentiris Epilenpsia‘: „Epilepsie“ = „Fallsucht“. Höfler (1970), S.703-704
} 
dem hirn vnd verirret den menschen seiner sinne Auch ist es gut fur das gicht Es sterkt vnd gibt Krafft allen gelidern:, (11)

\section{Dillöl}

Oleum Anetileon Anetum heißt tille des samen zu stoß man ein teyl in o̊l zu einem sanfften wein vnd rnig das auß das ist gut als ich vor gesprochen als man hie vernomen hat (12)

Also soll man machen die o̊l

Es seÿ von kraut oder vonn tzolchem von plumen oder von wurtzeln

Item Wer do wil machen oleum muscatallium oder Nardinum oder Ruteleon oder

\section{BI. $70^{r}$}

welcher name es sey Der nem das kraut plumen oder holtz vnd stoß das nit vnd leg es in o̊l drei stund alsovil zusampt denn weine vnd laß es darÿnnen ligen dreÿssig tag vnd faulen ye leng es ligt ye pesser es wirt dann so rnig man es durch vnd behalt das o̊l:, (13)

Item Wenn man von samen will o̊l machen So soll man den samen stoßen vnd im sieden wie vor gesagt ist Er sule auch merken wo des ols nit aust So ist meyen puttern gut darzu wann sie ist gut vnd heylsam Darumb wer des o̊ls nit mag gehaben der nem meyen puttern:, (14) 


\section{Das Ölbuch aus der Memminger Handschrift}

,Codex 2, 39،

\section{BI. $85^{\mathrm{V}}$}

Item ain gůt o̊l bewertz ${ }^{106}$ vnd daz als gůt

ist als walsam niem ainen nüen ziegel

vnd wäsch jn vast vnd leg jn über nacht

jn ain wasser daz er sich deper baß

wasch vnd schlach jn den zů clainen

als clain als die wålschen nůß

sind oder clainer dar nach leg die stücklin

jn ain lo̊cheroren pfannen vnd setz

die pfanen vf ain glưend fưr hintz ${ }^{107}$

sÿ auch glueend [sind] mit sombt als ain

snidel jn ainem offen vnd hab den [in]

ain ůber glesten haffen der mer den

halb mit bom o̊l ${ }^{108}$ sÿ vnd schůt den

glůenden ziegel dar jn vnd håb die

pfanen ůber den haffen vnd nimm

\section{BI. $85^{r}$}

ain naß tůch vnd hebs ůber das hefflin vnd ůber die pfanen vnd hiet daz der rauch nit da von kom vnd lazz dar jn zwen tag ligen $v ß$ vnd $v ß$ vnd dar nach niem den selbigen ziegel vnd leg jn jn ain vaß

\footnotetext{
${ }^{106}$,bewertz' lies ,bewert‘ von ,bewæren': „(erfolgreich) ausprobieren“. Mildenberger (1997), Bd 56/1, S. 207

107 ,hintz‘ lies ,hinz': „bis“. Lexer (1992), S. 90

108 ,bom o̊l' lies ,baumöl' vgl. hierzu Fußnote 44
} 
da man rosen brent vnd daz vaß sol

erde sin oder kůpferin oder eÿs[en] nÿm vnd prenn

hie vor genempten sarck als man rossen

prent vnd traff ez dez ersten mit ainen

clainen fưr vnd dar nach mit ainem

grossen vnd behalt daz vßtgerraifft o̊l

daz ist gar kosber vnd ist ain hainlichait ${ }^{109}$

der phÿlozpharen ain lob gotes daz gar

hailsam [ist] vnd hat grossen tugent an den

siechtůbigen die da kalt send wer dez

oles jn die vngeho̊rend oren gůst daz

wider bringt daz geherd er tôt die würm

jn dem mund ${ }^{110}$ ez ist gůt vir daz gicht ${ }^{111}$ vnd

vir den grossen stanck des munds ez ist

\section{BI. $86^{\mathrm{V}}$}

auch gůt wer dar von macht ain pflaster

zů dem ruggen we vnd daz jn salarmoniatem ${ }^{112}$

zelosset ez ist auch gůt zů dem geschwer

dez miltzes ${ }^{113}$ ez ist auch guot wem die

nåßlo̊cher zeser dorrent ez ist auch gůt

vir den sandt ${ }^{114}$ vnd kumbt ez jn die

\footnotetext{
109 ,hainlichait' lies ,heimlîchkeit': „geheimnis“. Lexer (1992), S. 84

110 ,wůrm jn dem mund': Hierzu gibt Höfler keine genaue Auskunft. Es wird kein Wurm genannt, der sich explizit im Mund des Menschen ausbreitet. Deswegen ist davon auszugehen, dass es sich dabei um eine allgemeinere Bedeutung des Begriffs „wurm" handelt. „Alles, was zerfressen aussah" oder „wurmähnliche, lange Gewebsfasern“ kommen diesbezüglich in Betracht. Höfler (1970), S. 820-822

111 ,gicht': Die Gicht allein ist Höfler zufolge eine „zuckende, zitternde, krampfhafte Bewegung überhaupt". Ob der Kompilator sich absichtlich allgemein ausdrückt oder eine inm geläufige Form nicht weiter beziffert, ist schwerlich zu beweisen. Höfler (1970), S. 190

112 ,salarmoniatem“ lies ,salarmoniac': „Ammoniumchlorid“, „Salmiak“. Mildenberger (1992), Bd 56/4, S. 1640

113 ,geschwer dez miltzes': Höfler hat das Milzgeschwür nicht belegt. "geswër" ist belegt als „Schmerz, Geschwür". Es ist möglich, dass von einem allgemeinen Krankheitsgeschehen im linken Oberbauch die Rede ist. Mildenberger (1997), Bd 56/2, S. 700

114 ,sandt" lies ,sand': Gemeint sind „Gesteinsablagerungen in feinsten Körnern“ sowie „sandartiger Niederschlag aus ...Körperflüssigkeiten" und „der dadurch erzeugte Schmerz“. Höfler (1970), S. 539
} 
matrix so bringt ez daz mestrum ez offent

daz gedaumen ez zerlo̊st daz geschaiden plùt

dez etlich tropffen lait jn ain kussen vnd

daz nimbt ez fưrbet die lungen ez ist gůt

dem die autem zucket ${ }^{115}$ vnd zů den augen

vnd vir die gicht da daz scorpio gehaisse hat

wan daz o̊l gůt ist so ist ez rot vnd starkes

smackes vnd clůger sarbantz ${ }^{116}$ vnd wirt

da mit ain eÿssen ${ }^{117}$ genetz vnd jn daz für

gelait ez wirt zehandt ${ }^{118}$ prinnen ist ainem menschen

we an sinen augen der lazz des o̊ls ain

tropffen jn die augen jm wirt baß jn

ainem halben tag wem auch daz schwindet

gicht $^{119}$ an welchem glid daz sÿ vnd man tůt

\section{BI. $86^{r}$}

daz bestrichen da mit ez verlat jn zehand

wem lung vnd leber fulet ${ }^{120}$ der trinck dez

drÿ morgen so wirt jm baß vnd daz an den

bennanten o̊l vil tugent sind daz sol man bÿ

brieffen wen man sain ain tropffen vff die

hand niempt der gat durch die hand

daz man jn vnder sich sieht hangen als

\footnotetext{
115 ,autem zucket': Mittels Diphthongierung im Sinne von „Atem zucket“. Gemeint ist vermutlich eine fehlerhafte Atmung.

116 ,clůger sarbantz' lies ,sarbant": „sërpant" = „schlange, drache, teufel“. Denkbar ist die Übersetzung mit einer zugesprochenen Eigenschaft der Arznei im Sinne von ,höllisch gut'. Lexer (1992), S. 192

117 ,eÿssen“ lies ,eissen“: „eiz“ = „Eiß, Eiterbeule, Geschwür“. Mildenberger (1997), Bd 56/2, S. 534

118 ,zehandt' lies ,zehant': „sogleich, alsbald“. Lexer (1992), S. 331

119 ,schwindet gicht': Der Zusatz ,schwindet" leitet sich vermutlich von „swinden“ ab und weist somit auf einen unter der Gicht zur Abmagerung führenden Krankheitsprozess hin. Lexer (1992), S. 223

120 ,lung vnd leber fulet': Höfler belegt „die Fäulung...der Leber, der Lunge“ als „Sepsis, Dyskrasie, Kachexie“. Die separat aufgeführte "Leberfaüle“ und "Lungenfäule" geben weitere Krankheiten an. Diese sind im Kodex durch keine zusätzliche Bemerkung erwähnt und damit nicht eindeutig zu belegen. Höfler (1970), S. 123-124
} 
lang man ain pater noster mag sprechen $\quad a b^{121}$.

${ }^{121}$ Die Randbemerkung kennzeichnet das Ende des Ölbuchs durch den Kompilator. 


\section{Einführung in die Herstellungsverfahren von Arzneiölen}

Die vielfältigen Arten der Zubereitung medizinischer Öle sind ein Hauptbestandteil der edierten Kompendien dieser Arbeit. Als grundlegende Einleitung zum Verständnis der Verfahren sollen an dieser Stelle zwei Texte dienen.

Zum einen das Destillationskapitel aus dem Kräuterbuch Adam Lonitzers. Hier werden grundlegende Techniken zum Verfahren der Arzneimittelherstellung dargestellt. Zum anderen wird der Artikel ,Digestio, Sinn oder Unsinn? Zur Geschichte eines alchemistisch-pharmazeutischen Prozesses' von Willem Daems besprochen. Dieser Artikel geht auf die spezifischen Aspekte eines bestimmten Verfahrens, der Digestion, ein. Als Sonderfall der Digestion bespricht Daems die ,Digestio per solem;, ein Prozedere, das mittels Sonnenenergie seine Wirkung entfaltet. Die starke Repräsentanz dieser Methode in den Kodizes ist der Grund für die explizite Auseinandersetzung mit Daems' Artikel.

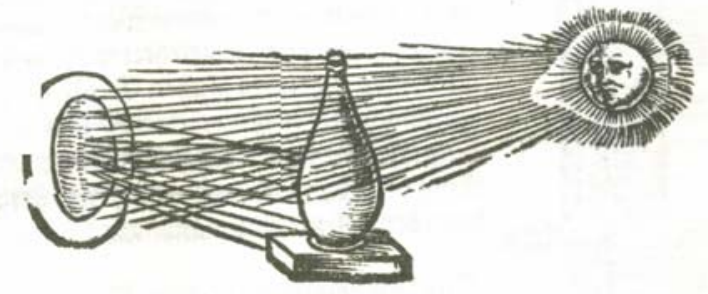

Abb. 1: Die Abbilung zeigt eine schematische Darstellung der Sonnendigestion. Aus Lonitzer, 1962, S. 11

Lonitzers Ausführungen beschäftigen sich durchgehend mit der Herstellung und Verwendung diverser Brennöfen sowie all den dazu benötigten Utensilien. Es reihen sich Kapitel „Von denen Instrumenten, welche man zum destillieren zur hand haben sol" und ein kurzer Einschub über die Wirksamkeit der Sonne zur Herstellung von Heilwassern ein. Dem Destillationsverfahren der Öle aus Gewürzen und Samen widmet Lonitzer ebenso ein eigenes Kapitel wie der Zubereitung von Wassern und deren Aufbewahrung.

Insgesamt bietet es einen geeigneten Überblick über die damals verwendeten Techniken der Destillation. Dem Thema der Arbeit entsprechend werden jene Inhalte her- 
vorgehoben, die sich mit der Zubereitung der Öle befassen. Finden sich Überschneidungen oder hilfreiche Erläuterungen zu den Inhalten der Kompendien, werden diese hier ebenfalls dargestellt.

Die Öldestillation wird bereits im einleitenden Absatz erstmals erwähnt. Gleich nach den gebrannten Wassern nennt Lonitzer das „kråfftige Oehl“ und streift dessen medizinischen Nutzten, ohne namentlich eine Anwendung zu nennen. ${ }^{122}$

Im weiteren Verlauf des Kapitels ist, wie oben erwähnt, ein kurzer Einschub über die Sonneneinwirkung auf den Prozess der Heilmittelherstellung zu finden. Zwar wird nur der Übergang der pflanzlichen Heilkraft auf Wasser mittels Sonnenenergie beschrieben, es lässt sich jedoch kein Grund für eine fehlende Analogie zur Übertragung auf Öle nachweisen.

Die Anordnungen in den Kompendien sind häufig simpel. Beispielsweise heißt es im Heilrezept für das Bibergeilöl im Farfensischen Kompendium: „secze es an die sunnen acht tage". Im Gegensatz dazu ist bei Lonitzer die Rede von einer kleinen Apparatur. Ein Spiegel soll die Sonnenstrahlen auf das Glas bündeln. Das Ganze wird durch eine Illustration verdeutlicht (siehe Abb.1).

Die Hinzunahme eines Spiegels zur Digestion ist bei Daems ausführlicher beschrieben. Er zitiert dazu Parace/sus: „Anders ist das unsichtbare Feuer. Wir meinen damit die Strahlen der Sonne. Das Feuer erhält man durch einen stählernen Spiegel oder Kristall. Es zeigt und beweist dadurch seine Wirkung und seinen Effekt.“ ${ }^{123}$

Daems Zitation verschiedener Texte aus der Zeit des Mittelalters und der Renaissance geben Aufschluss über die gewünschte Temperatur einer Digestion. Dabei schwanken die Angaben im „Buch der heiligen Dreifaltigkeit" von der Wärme einer brütenden Henne $\left(37-40^{\circ}\right)$ bis zur Sonnenwärme. Diese schätzt Daems auf höhere Werte ein. ${ }^{124}$ Erstaunlicher als die Empfehlung zum Verfahren der ,Digestio per solem' an sich ist die Tatsache, dass die Digestion in den edierten Texten überhaupt

\footnotetext{
122 vgl. Lonitzer (1962), S. 2

${ }^{123}$ Daems (1983), S. 161

${ }^{124}$ vgl. Daems (1983), S. 156
} 
nur auf diese Weise durchgeführt werden sollte. Daems stellt in seinen Ausführungen fest, dass die ältere Literatur an erster Stelle immer die Verwendung von Pferdemist zur Digestion empfehle. ${ }^{125}$ Eine solche Anweisung findet sich in den edierten Ölbüchern jedoch kein einziges Mal.

Es folgt eine gründliche Ausführung Daems' über die „Idee der Digestion“. Hieraus sollen nur die grundlegenden Ideen genannt werden. Gleich zu Beginn beschreibt er den alchemistisch-physikalischen Prozess des Verfahrens. Ein Glasgefäß solle beispielsweise mit Pflanzenbrei in Wasser oder Wein (beides auch in den Kompendien zu finden) befüllt und verschlossen werden. Die Wärmequelle reiche bis zum Flüssigkeitsspiegel. Der Prozess liefe als Verdunstung bei circa $37^{\circ}$ ab. Der obere Teil des Gefäßes diene zur Abkühlung, an dem sich eine Kondensation vollziehe. Dieses Verfahren des „Auflösen und Verdichten“ in einem abgeschlossenen Raum sei unter Alchemisten als „solve et coagula“ bekannt. ${ }^{126}$

Ein Grund für die Vorstellung, dass dieser Prozess bei menschlicher Körpertemperatur ablaufen soll, sieht Daems in der Parallele zum Blutkreislauf. Der Erklärungsansatz wird von der Idee getragen, dass im Herz die mittlere Temperatur von „heissem arteriellen“ und „kühlem venösen Blut“ bei $37^{\circ}$ liege. ${ }^{127}$

Ist in den Heilrezepten nicht die ,Digestio per solem' zur Anwendung empfohlen, tritt an deren Stelle häufig ein Destillationsverfahren, für das ein Rosenhut benötigt wird (siehe Abb.2). Zur Herstellung von Quittenöl heißt es im Farfensischen Kodex: „vnde brenn ez denn aus in i Rosen hutte“.

\footnotetext{
${ }^{125}$ vgl. Daems (1983), S. 161

${ }^{126}$ vgl. Daems (1983), S. 162-163

${ }^{127}$ vgl. Daems (1983), S. 167
} 


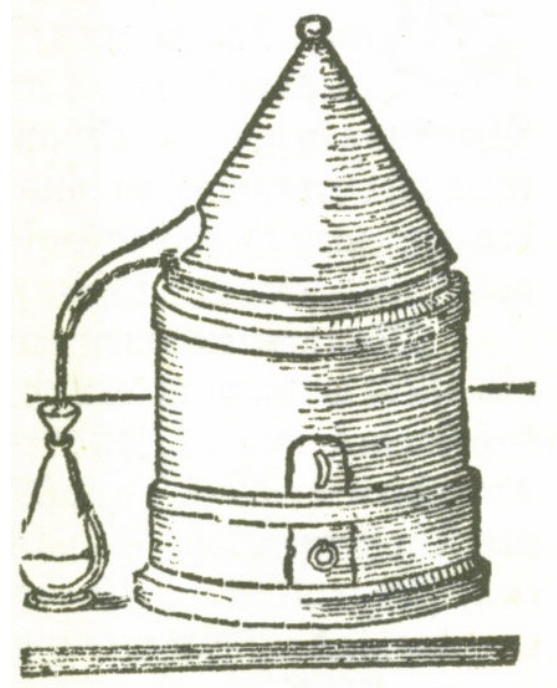

Abb. 2: Die Zeichnung skizziert den Aufbau eines Rosenhuts. Aus Lonitzer, 1962, S. 17

Lonitzer beschreibt den Rosenhut als eine gewöhnliche Art des Brennofens. Rosenhüte seien in großer Anzahl vorhanden. Ihre Herstellung sei für einen Hafner ${ }^{128}$ keine Schwierigkeit. Er benennt ihre mindere Qualität, die preiswerte Herstellung und die gute Mobilität. Verwendete Kräuter verlören jedoch angeblich leicht ihre Kraft. ${ }^{129}$

Auf den folgenden Seiten schließt sich die Destilliervorschrift für Öle aus Samen und Gewürzen an. Die hohe Wertschätzung Lonitzers für die Qualität der Öle ist hier gut erkennbar. Es seien edle Öle, „welche gantz kråfftige Wirckung in geringer Quantitet haben“. ${ }^{130}$

In diesem Abschnitt findet sich weiterhin ein Hinweis auf die Verwendung solcher Öle. Sie seien sehr üblich im Gebrauch gegen Krankheiten. ${ }^{131} \mathrm{Ob}$ diese Einschätzung auch für alle Simplizien und Komposita der Ölbücher aus den Kodizes dieser Dissertation gilt, ist dadurch selbstverständlich nicht belegt. Zumindest gibt Lonitzer in seiner Ausführung über die Öle eine orientierende Vorstellung von deren Stellenwert in der angewandten Medizin dieser Zeit.

\footnotetext{
128 ,Hafner': „Töpfer”

${ }^{129}$ vgl. Lonitzer (1962), S. 17

${ }^{130}$ vgl. Lonitzer (1962), S. 18

${ }^{131}$ vgl. Lonitzer (1962), S. 18
} 
Die genaue Beschreibung der Destillationsapparatur soll nicht näher analysiert werden. Ein Vergleich im Hinblick auf Ähnlichkeiten mit den Apparaturen in den Kompendien ist ohnehin nicht möglich, da diese in der Regel nicht näher beschrieben werden.

Interessant ist stattdessen die Erwähnung der Dauer eines solchen Destillationsverfahrens. Lonitzer beziffert es mit drei bis vier Stunden. Dem recht zügigen Verfahren fehlt leider eine Mengenangabe des gewonnenen Öls. Somit ist eine Einschätzung seiner Effizienz nicht durchführbar. Ebenso wenig kann man abschätzen, wie viel ÖI an einem Arbeitstag hätte gewonnen werden können.

Bei der Empfehlung der zu nutzenden Gefäße für die Destillation macht Lonitzer deutlich, welches Material die höchste Qualität besitzt. „Glåserne Gefåß haben vor allen den Vorzug“. ${ }^{132}$ Aufgrund der guten Akquirierbarkeit der Tongefäße seien diese an zweiter Stelle zu empfehlen. Der guten Haltbarkeit von Metallgefäßen stellt Lonitzer deren Toxizität entgegen. ${ }^{133}$ Aus diesem Grund werden diese als letzte Möglichkeit genannt.

\footnotetext{
${ }^{132}$ vgl. Lonitzer (1962), S. 19

${ }^{133}$ vgl. Lonitzer (1962), S. 19
} 


\section{Die Qualitätenlehre nach Galen}

Bevor sich der genaueren Analyse der einzelnen Arzneien gewidmet werden kann, soll an dieser Stelle eine kurze Einführung in die Humoralpathologie gegeben werden. Das Hauptaugenmerk liegt dabei auf dem griechisch-römischen Medizingelehrten Galen. Legitimiert wird diese Auswahl durch die Einordnung von Galens Werken durch Julius Berendes.

In der Monographie über ,Die Pharmazie bei den alten Kulturvölkern' bezeichnet Berendes Galens Systematik als den elementaren Baustein für das Verständnis der Medizin von den Griechen bis zum Ende des Mittelalters. ${ }^{134}$ Dieser Zeitraum umfasst exakt das ausgewählte Zeitfenster für die anschließende Analyse der Heilpflanzen.

Es wird dieser vorwegnehmende Weg gewählt, um die einzelnen Begriffe, die sich in den Exzerptionen wiederfinden, als Basiswissen voraussetzen zu können.

Galens Lehre baue von philosophischer Seite auf Plato, Aristoteles und der Stoa auf. Medizinisch seien Galens Wurzeln bei den Empirikern, Dogmatikern und Pneumatikern zu finden. Seine oberste Instanz medizinischen Wissens sei das ,Corpus Hippocraticum', das er durch eigene Beobachtungen ergänze und nach seinen Vorstellungen interpretiere. ${ }^{135}$

Hippokrates lieferte das Viererschema der Kardinalsäfte, die Galen dann aufbauend auf den Theorien der Pneumatiker „zu einem Makro- und Mikrokosmos umschlieBenden System ausbaute.“"136

Die für die Untersuchung der Arzneien im Rahmen der Dissertation grundlegende Kenntnis der Qualitätenlehre Galens stammt ursprünglich von Aristoteles. ${ }^{137}$

\footnotetext{
${ }^{134}$ vgl. Berendes (1965), Bd 2, S. 57

${ }^{135}$ vgl. Schöner (1964), S. 86

${ }^{136}$ Schöner (1964), S. 87

${ }^{137}$ vgl. Schöner (1964), S. 87
} 
Es soll nicht auf jeden Aspekt der humoralpathologischen Vorstellungen Galens eingegangen werden. Zum Verständnis der notwendigen Begriffe aus den Kompendien und der zur Analyse zu Rate gezogenen Literatur sollen diese hier besprochen werden.

Galen übernimmt die langjährige Vorstellung seiner geistigen Vorgänger, dass dem Menschen vier Elemente innewohnen: Feuer, Luft, Wasser und Erde. Ebenso lässt er keine Zweifel an dem notwendigen Gleichgewicht der vier Säfte: gelbe Galle, schwarze Galle, Schleim und Blut. Dieses Gleichgewicht sei nötig, um den Körper in einem gesunden Zustand zu bewahren, auch wenn es nach Galen nie zu dem sogenannten Zustand der Eukrasie komme, in dem alle Säfte genau gleich verteilt seien. ${ }^{138}$ Schließlich erfolgt eine Zuordnung von Qualitäten, die auf die Elemente und Säfte bezogen ist und sich wie folgt darstellt: Feuer - gelbe Galle - warm und trocken, Erde - schwarze Galle - kalt und trocken, Wasser - Schleim - kalt und feucht, Luft - Blut - warm und feucht. ${ }^{139}$

Die Einteilung der Qualitäten in verschiedene Grade bedarf an dieser Stelle keiner genaueren Erklärung. Es ist ausreichend im Gedächtnis zu behalten, dass eine hohe Zahl für eine stärkere Ausprägung der Qualität spricht. Ist eine Arznei also im ersten Grad heiß, so sei dies eine milde Ausprägung. Wird ihr eine Hitze im vierten Grad nachgesagt, so bringe diese Qualität bereits leichten Schaden für den Körper mit sich. $^{140}$

\footnotetext{
${ }^{138}$ vgl. Schöner (1964), S. 93

${ }^{139}$ vgl. Schöner (1964), S. 87

${ }^{140}$ vgl. hierzu Lonitzer (1962), S. 27 sowie Berendes (1965), Bd 2, S. 61-67
} 


\section{Kommentar zur Farfensischen Handschrift Cod. 200}

Die Grundlage der folgenden Kommentare zu den Handschriften Farfas, Harburgs und Memmingens bilden hauptsächlich die Untersuchungen Volker Zimmermanns aus der Monografie ,Ars medica' aus dem Jahr 1986.

Auf Inhalte der Edition wird in runden Klammern mit Nummern verwiesen. Die Nummern beziehen sich auf die Rezepte in dem jeweiligen kommentierten ,Ölbuch‘

Das ,Ölbuch` aus dem ,Codex Farfensis 200` wurde in den Jahren 1460-1464 im Benediktinerkloster Farfa in Latium verfasst. Die Bewohner des Klosters waren jedoch deutscher Abstammung. ${ }^{141}$ Bemerkenswert ist, dass der Kompilator genau festhält, an welchem Tag die Arbeit an dem Buch begonnen wurde. Genauso belegt er das exakte Datum seiner Fertigstellung: „Dicz buch wart an gehubin Jn MCCCCLX, XXI tage Jn dem Nouember und wart volbracht Jn MCCCCLXiiii, Xiii tage Jn dem abrille" (BI. $\left.2^{\mathrm{r}}\right)$.

Es sind zahlreiche Andeutungen im Kodex entdeckt worden, die dafür sprechen, dass der Kodex im Kloster Farfa ${ }^{142}$ selbst entstanden ist. Eine später gemachte Eintragung im Kodex weist darauf hin, dass er im Besitz eines Mönches namens Michael Schwirker (BI. 227 ${ }^{\vee}$ ) war. ${ }^{143}$

228 der 230 Blätter, die die ganze Handschrift umfasst, sind in einer schwäbischbairischen Bastarda aus der zweiten Hälfte des 15. Jahrhunderts verfasst worden. Die letzten beiden Seiten sind unbeschrieben. ${ }^{144}$

Zimmermann unterteilt in seiner Untersuchung der Handschriften den gesamten heil-

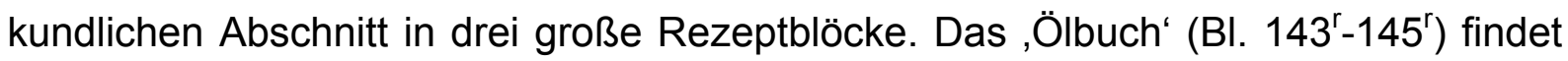
man kurz vor Ende des zweiten Blocks (BI. $\left.151^{r}\right)$. Seine Stellung innerhalb der Hand-

\footnotetext{
${ }^{141} \mathrm{vgl}$. Eis (1982), S. 10-11

142 vgl. LexMA (1989), Bd 4, Sp. 295-297

${ }^{143}$ vgl. Zimmermann (1986), S. 14

${ }^{144}$ vgl. Zimmermann (1986), S. 14
} 
schrift muss jedoch als eigenständige Textsorte angesehen werden. ${ }^{145}$ Dazu zählen weiterhin das ,Pflasterbuch“ $\left(121^{r}\right)$, das ,Salbenbuch“ (BI. 125 $\left.-135^{r}\right)$, das ,Wässer-

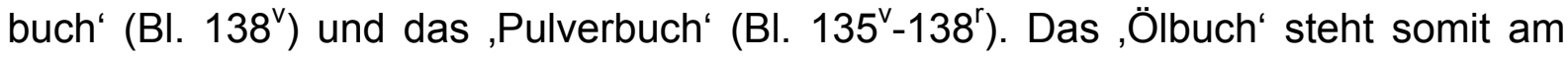
Ende dieser eigenständigen Abschnitte. Eine Ableitung über dessen Bedeutung und Relevanz ist aus den Zeilen des ,Ölbuchs' aber nicht herzustellen. Erstellt man eine Rangordnung anhand des Umfangs als Kriterium, so steht das, Ölbuch“ immerhin an dritter Stelle.

Die genauere Untersuchung der Handschrift zeigt eine durch den Kompilator vorgegebene Gliederung in 21 Kapitel. „Hie hebet sich an daz buch vnd saget vns von den edeln guten Oley di vns vnßm leibe gut sint das sint 21“. Dabei ist Grundbestandteil von 16 Rezepten eine oder mehrere Pflanzen beziehungsweise deren Droge (Frucht, Wurzel oder Kerne).

In vier Kapiteln findet man Tiere als Zutat zur Bereitung eines Öls. Das ,Ziegelöl' ist das einzige Öl, das nicht einer dieser Gruppen zuzuordnen ist. Es soll erwähnt sein, dass der Schreiber das Kapitel über die süßen und die sauren Mandelkerne als ein Kapitel zählt.

Ein zusätzliches Kapitel über das ,Oley daz wunder gut ist fur die di speise czu dem munde auswerffen vnd nicht behalden mugen vnd vndewent' zählt er ebenfalls nicht als eigenständiges Kapitel. Eine mögliche Erklärung könnte der fehlende eigenständige Name des Öls sein. Es ist als Nachtragskapitel einzuordnen.

Das ,Ölbuch“ kann als eine „weitgehend eigenständige Schöpfung“146 angesehen werden. In welchen Teilen Übereinstimmungen mit anderen Arzneibüchern zu finden sind, wird im Kapitel ,Einzelanalyse der Arzneien' (Kap. 10) näher erläutert. Es sei soviel gesagt, dass eine derartige Kongruenz für drei Ölrezepte bereits bei der Untersuchung der Handschrift durch Zimmermann nachgewiesen wurde. Für das ,Oley von der Raute', das ,Oley von den Rosen' und das ,Oley von moton daz sint cziegel', welches besser bekannt ist unter dem Namen ,Benediktenöl‘. ${ }^{147}$

\footnotetext{
${ }^{145} \mathrm{vgl}$. Zimmermann (1986), S. 15

${ }^{146}$ Zimmermann (1986), S. 69

${ }^{147}$ vgl. Zimmermann (1986), S. 69
} 
Eine strukturierte Aufteilung der Rezepte, beispielsweise nach kalten und warmen Ölen, lässt der Kompilator vermissen. Es finden sich keine von ihm deutlich gemachten Gliederungen, wie dies im ,Harburger Ölbuch“ mit den Worten „Ich hab ÿetzund gesagt von den o̊len die kalter natur sein Nun will ich sagen von den die heysser natur sein“ der Fall ist. Gegen eine gewollte Gliederung nach dieser Art spricht ebenfalls die Tatsache, dass der Verfasser die Natur und Kraft des jeweiligen Öls gar nicht erst nennt. Ihre humoralpathologische Einordnung lässt sich einzig aus den Indikationen der Öle ableiten. Ist die Galenik auf diese Weise nicht zu ermitteln gewesen, so wurde sie den entsprechenden Kapiteln der Literatur entnommen, die in der später folgenden Untersuchung Verwendung finden (Kap. 10).

Eine grobe Gliederung aus eigener Hand lässt so einen Beginn mit den Ölen warmer Natur erkennen. Es sind: ,Oley von den mandelkern', ,Oley von costoria‘, ,Oley von costo', ,Oley von scorpion', ,Oley von fochsen“ und ,Oley von mastic'. Erst das siebte Rezept bricht in Form des ,Quittenöls‘ mit dieser Einteilung. Es ist eines von vier Ölen, denen eine kalte Natur zugeschrieben wird. Die übrigen drei Öle stehen als Rezept 15, 16 und 17 in einer Reihenfolge. Es sind: ,Oley von liligen wurczel', ,Oley von feiol' und ,Oley von Rosen‘. Eine Abgrenzung der Öle zu den anderen Rezepten findet sich allerdings auch hier nicht. So folgen als letzte Kapitel, aus denen sich eine Natur des Öls herleiten lässt, das ,Oley von moton cziegel‘ und ,Oley Balsamino ader gebalsamet oley der Juden', denen wiederum eine warme Natur zugesprochen werden.

Für die abschließend folgenden Balsame und das ,Oley daz wunder gut ist' ist die Einteilung nach warmer und kalter Natur hinfällig, da es nach den medizinischen Vorstellungen der Humoralpathologie bei einem Gemisch vieler Simplizien zu einem sogenannten Kompositum zu einem Verlust der einzelnen Qualitäten kommt. „Bei der Mischung büssen die einzelnen Arzneimittel ihre eigene Facultät ein und es resultirt aus der Vereinigung eine neue Gesammtfacultät;“"148

${ }^{148}$ Berendes (1965), S. 69 
Abschließend zur Betrachtung der Qualitäten soll ein kurzer Überblick darüber gegeben werden, wie viele Öle mit der jeweiligen Qualität in der Handschrift vertreten sind. Es sind 15 warme und vier kalte Öle, die im ,Ölbuch“ Farfas genannt werden.

Besondere Beachtung soll, entsprechend dem Thema der Arbeit, selbstverständlich auch den Verfahren geschenkt werden, die zur Herstellung der Öle in den Rezepten vorgeschrieben werden. Der überwiegende Teil der Rezepte (14 der 21) beinhaltet eine Formulierung wie „vnd henge ader secze es an die sunnen“. Die Zeitangaben variieren dann von acht bis hin zu vierzig Tagen, die das Öl in der Sonne stehen soll. Mit dem Zusatz „vnd tu ez an di sunne yn dem augoste“ wird in dem Rezept zur Herstellung des ,Katzenöls' sogar vorgeschrieben zu welchem Zeitpunkt das Öl durch die Kraft der Sonne zu reifen hat. Die Vermutung liegt nahe, dass der Kompilator damit den Zustand höchster Sonneneinwirkung auf das Öl meint. Interessant ist, dass üblicherweise die Vorstellung der Alchemisten davon geprägt war, dass der Monat März den größten Erfolg für das Verrichten ihrer Arbeit verspräche. ${ }^{149}$

Das Verfahren, das hinter diesen Vorschriften steht, ist als ,Digestio per solem، ${ }^{150}$ bekannt. Einer Erläuterung dieser Prozedur wurde sich zu Beginn der Arbeit im Kapitel ,Einführung in die Herstellungsverfahren von Arzneiölen‘ (Kap. 3) ausführlich gewidmet. ${ }^{151}$

Der weniger genutzte Weg der Ölherstellung in dieser Handschrift bezieht sich auf ein nicht genauer beschriebenes Destillationsverfahren. Die zu nutzenden Geräte werden dabei nur kurz erwähnt: „vnd tu daz ding czu stilliern yn einen hute von glase". Ein Blick in die pharmaziehistorische Literatur zeigt, dass es zahlreiche Möglichkeiten des Aufbaus für solche Destillationsgeräte gab. Hierzu soll exemplarisch das Kräuterbuch des Frankfurter Stadtarztes Adam Lonitzer in dem oben bereits erwähnten Kapitel über die Ölherstellung Aufschluss geben (Kap. 3).

Die durch Destillation zu gewinnenden Öle sind: ,Oley von mastic', ,Oley von quitten',

\footnotetext{
${ }^{149}$ vgl. Daems (1983), S. 157

${ }^{150}$ vgl. Daems (1983), S.151-179

${ }^{151}$ vgl. dazu auch Keil (1999), S. 276f. und Domes und Keil (1993), S. 485
} 
,Oley von moton cziegel', ,Oley Balsamino ader gebalsamet oley der Juden', ,Der moren balsame' und der ,Balsam der feyn [ist]'. Im Fall des ,Quittenöls' sind das einzige Mal sogar beide Verfahren anzuwenden. Eine klare Abgrenzung des unterschiedlichen Nutzens beider Verfahren wird durch den Kompilator nicht vorgenommen. Warum nun ausgerechnet das ,Mastix-' und ,Quittenöl' nicht allein durch die Sonneneinwirkung zu ihrer Kraft kommen, ist nicht eindeutig zu klären. Bei den Balsamen, die flüchtige ätherische Destillate darstellen, ist die Destillationsvorschrift hingegen eindeutig nachvollziehbar. ${ }^{152}$

Für zwei Ölrezepte wird weder die Destillation noch die ,Digestio per solem' vorgegeben. Es handelt sich um das ,Oley von lorbern' und das ,Oley von krampbern'. Diese sind die einzigen aus Beeren hergestellten Öle. Aus den Lorbeeren wird ein Dekokt mit Wasser zubereitet, dessen öliger Anteil dann abgeschöpft wird. Die Wacholderbeeren werden mit Olivenöl versetzt, um aus innen ebenfalls einen Absud herzustellen. Dies ist gleichzeitig die am häufigsten zu findende Empfehlung zur Bereitung eines Öls seitens des Verfassers. Der Absud mit Wasser wird hingegen nur drei Mal empfohlen. Die Herstellung eines Dekokts mit Wein lässt sich nur für das Bibergeilöl nachweisen.

Eine besondere Stellung im Bezug auf die Zubereitungsweise nimmt der erste Teil des ,Mandelölrezepts' ein. Es findet sich keines der bereits genannten Verfahren, sondern eine Vorschrift, die eine Zerkleinerung der Kerne vorsieht, um sie anschlieBend in einem „seckel" durch eine Presse zu drücken und somit ihre öligen Bestandteile zu gewinnen.

Es stellt sich innerhalb der einzelnen Rezeptkapitel nun zuletzt die Frage nach der gewählten Struktur. Dabei lässt sich ausnahmslos beobachten, dass der Kompilator mit der Beschreibung der Droge in Form ihrer Zubereitung beginnt. Das Verhältnis der Arzneiformen bezogen auf Simplizien und Komposita liegt auf Seiten der Simplizien. Jeder Balsam - und auch das ,Benediktenöl' - bestehen dabei aus mehreren Arzneien (Rezept 18-22). Den öligen Dekokten werden lediglich in drei Fällen Ingre-

\footnotetext{
152 vgl. hierzu Daems ,Balsamkapitel‘ im LexMA (1980), Bd 1, Sp. 1390 und Mildenberger (1997), Bd $56 / 1$, S. $174-176$
} 
dienzien außer der eigentlichen Droge und dem Medium, in dem es gekocht wird, hinzugefügt (Rezept 2-4).

Den Abschluss eines jeden Kapitels bildet die Aufzählung der Heilanzeigen, die der Kompilator für das Öl vorsieht. ${ }^{153}$ Diese können wie beim ,Lilienöl' äußerst knapp ausfallen: „Dicz oley ist gut fur heise wetagen“. So kurz die Indikation auch ist, so umfassend ist die Bedeutung für ihre Anwendung. Der Verwendung gegen warme Erkrankungen sind im Rezept keine Grenzen gesetzt. Es kommt sogar vor, dass ein Öl mit den Worten „Dicz oley ist gut fur alle siechtum“ den Charakter eines Panazees zugesprochen bekommt (Rezept 18-19). Zusammenfassend ist festzustellen, dass der Kompilator die Beschreibung der Heilanzeigen recht kurz hält. Als ein möglicher Grund ist in Betracht zu ziehen, dass die Herstellungsweise für den Kompilator von vorrangiger Bedeutung als die Anwendung der Arznei war. Die Informationen über eine Verwendung der jeweiligen Arznei waren aus zahlreichen Vorgängerwerken aus dem Bereich der Heilpflanzen zu entnehmen. Die Beschreibung zur Herstellung von Arzneiölen war dagegen deutlich geringer repräsentiert.

Die umfassendste Vorschrift zur Anwendung wird für das ,Kamillenöl‘ gegeben. Es finden sich vier Indikationen. Die Fünfte endet mit einer verderbten Stelle der Handschrift. ${ }^{154}$

Den Untersuchungen Crones zufolge lässt sich der Aufbau der Kapitel mit der Droge zu Beginn und der Heilwirkung am Ende am ehesten mit den Spezialitäten-Kapiteln des ,Antidotarium Nicolai` vergleichen. ${ }^{155}$.

Das Spektrum der medizinischen Fachrichtungen, für die die Anwendungsvorschriften gelten, lässt sich auf einen überschaubaren Rahmen zusammenfassen. Das Gebiet der Gastroenterologie ist durch Heilanzeigen wie „Dicz oley ist gut vor daz we dez magen“ oder „Dicz oley ist gut die flusse dez bauches czu verstellen“ gleich an mehreren Stellen des, Ölbuchs' vertreten. Ebenfalls mehrfach erwähnt werden die Gebiete der Gynäkologie („,vnd kumbt ez jn die matrix so bringt ez daz mestrum“) und

\footnotetext{
${ }^{153}$ vgl. hierzu auch Crone, der diese Art der Aufteilung beispielhaft für die ,Freiberger Arzneimittellehre' des ,Breslauer Arzneibuches' und das ,Boec van medicinen in Dietsche' nachweist. Crone (2002), S. 33

${ }^{154}$ vgl. Fußnote 39

${ }^{155}$ zu den Gemeinsamkeiten und Unterschieden vgl. Crone (2002), S. 33-34
} 
Orthopädie, wenn man Rücken-, Seiten- und Muskelschmerzen diesem Gebiet an dieser Stelle gezielt zuordnet (,Katzenöl'). Einzelne Hinweise finden sich für die Fachrichtungen Otologie („vnd der ez in di orn tut den machet ez gehorn“) im ,Mastixöl-Kapitel“ und für die Nephrologie (,ist gut fur [...] rene“) im ,Katzenöl-Kapitel‘. Als klassisches Antidot wird das ,Skorpionöl' mit eingebracht. ,Kamillenöl' gegen Frostbeulen, ,Dillöl“ als Mittel gegen „di swacheit dez gehirnes“ und der ,Morenbalsam", der gegen Angina pectoris hilft, komplettieren die medizinischen Gebiete, die hier erwähnt werden.

Bei der Untersuchung der Quelle auf seltene und neue Rezepte hat sich gezeigt, dass es drei Rezepte gibt, die eine zumindest nicht unter diesem Namen gelistete Arznei beschreiben. Es sind die Komposita-Rezepte des "Oley Balsamino ader gebalsamet oley der Juden“, der „Balsam der feyn [ist]“ und „Der moren balsame“. Zählt man das „Oley daz wunder gut ist“ noch dazu, sind es sogar vier erstmalige Belege. Zum letztgenannten Öl sei hier auf die Untersuchungen Crones verwiesen. ${ }^{156}$ Für das "Oley der Juden“, dem zumindest ein in der Herstellung ähnliches Kompositum aus der ,Kopenhagener Wundarznei' zuzuordnen ist, gibt es eine gesonderte Untersuchung des Kapitels im Analyseteil. Da den anderen keine Korrelate zuzuordnen sind, geht die Analyse ausschließlich aus den edierten Rezepten der Kodizes hervor.

${ }^{156}$ vgl. Crone (2002), S. 37-39 


\section{Kommentar zur Harburger Handschrift Cod. III 1, $2^{0}, 43$}

Auf den Blättern $69^{r}-70^{r}$ findet sich das ,Ölbuch' der Handschrift aus Harburg. Die Handschrift weist einen Gesamtumfang von 84 Blättern auf, wovon BI. 1, 70v 71 und 72 unbeschrieben sind. Angelegt wurde sie ebenfalls in einer bayrischen Bastarda des 15 Jahrhunderts. ${ }^{157}$ Zum Entstehungszeitraum des Kodex sind darüber hinaus keine genaueren Angaben zu machen. ${ }^{158}$

Das ,Ölbuch‘ reiht sich mit seinen drei Blättern als ein kurzer Abschnitt in den heilkundlichen Teil des Kodex ein. Ihm unmittelbar vorausgehend steht ein ,Kochbuch“

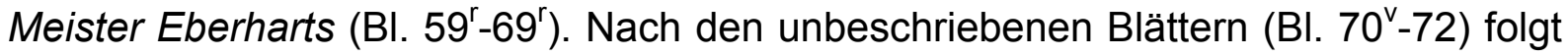
ein ,Roßarzneibuch' von Meister Albrant (BI. 73 $3^{r}-79^{r}$ ). Den Abschluss des Kompendiums bildet ein größeres ,Salbenbuch“ (BI. $\left.79^{\vee}-83^{v}\right){ }^{159}$

Mit den einleitenden Worten „Hie nach volgen Etliche o̊l warczu die gut sein vnd wie man die bereuten vnd machen soll:,", gibt der Kompilator dem Leser von vornherein eine Grundstruktur seiner Kapitel vor. Er hält sich jedoch nicht streng an seine eigene Vorgabe. So findet sich in jedem Kapitel eine Anweisung zur Herstellung des jeweiligen Öls. Die Indikationen allerdings werden meist nur spärlich oder auch gar nicht beschrieben, wie dies am Beispiel des ,Poleiöls' nachzuvollziehen ist (Rezept 7). Darüberhinaus wird erst die Herstellung und dann werden die Heilanzeigen des Öls beschrieben.

Der Schreiber des Harburger Kodex hat im Gegensatz zum Verfasser des Farfensischen Kompendiums auch eine eindeutige Makrostruktur des,Ölbuchs' festgelegt. Auf das Rezept des ,Bilsenöls‘ (Rezept 10) folgt die gliedernde Aussage: „Ich hab ÿetzund gesagt von den o̊len die kalter natur sein Nun will ich sagen von den die heysser natur sein:," Es werden demnach zuerst fünf Öle, die kalter Natur sind, beschrieben. Die restlichen neun Kapitel setzen sich aus sieben Ölrezepten zusammen, die warmer Natur sind (Rezept 6-12), und zwei abschließenden Vorschriften zur

\footnotetext{
${ }^{157} \mathrm{vgl}$. Zimmermann (1986), S. 18

${ }^{158} \mathrm{vgl}$. Zimmermann (1986), S. 18

${ }^{159} \mathrm{vgl}$. Zimmermann (1986), S. 18-20
} 
allgemeinen Herstellung von Ölen (Rezept 13-14). Das erste Nachtragskapitel beschreibt die Ölbereitung „von kraut oder vonn tzolchem von plumen oder von wurtzeln", während das zweite Nachtragskapitel denen weiterhilft, die aus den Pflanzensamen Öl zubereiten wollen.

Den Anfang des, Ölbuchs' macht das Kapitel zur Herstellung des ,Rosenöls‘ (Rezept 1). Dieses ist weiter in zwei kurze Kapitel unterteilbar. Der erste Abschnitt beschreibt das aus dem latinischen Kompendium bekannte Verfahren ,Digestio per solem'. Im Gegensatz zu der häufigen Anwendung bei Farfa, findet man es in diesem ,Ölbuch“ explizit nur zur Herstellung des ,Rosenöls'. Das überwiegend gewählte Herstellungsverfahren ist die Zubereitung eines Absuds, zu dem in den meisten Fällen Olivenöl und Wein gebraucht werden. Auffällig ist, dass die Dekokte nur zur Herstellung von Ölen warmer Natur empfohlen werden. Die kalten Öle sollen der Beschreibung des ,Rosenöls' nachempfunden zubereitet werden (Rezept 2-4). Einzig das ,Bilsenöl' wird durch eine gänzlich andere Prozedur gewonnen, die auf der Vorstellung eines Auspressprozesses durch das Gewicht von Erde fußt. Die öligen Anteile aus den Pflanzenteilen sollen herausgedrückt werden, indem zwei Gefäße ineinander gestellt werden. Das obere hat Löcher in seinem Boden, der mit den Pflanzenteilen bedeckt ist. Mit Erde abgedichtet und beschwert, soll das Öl über den Zeitraum eines Jahres ausgepresst und über die Löcher in dem darunter stehenden Gefäß aufgefangen werden (Rezept 5).

Bei der Untersuchung des ersten Rosenölkapitels zeigt sich, dass als Ingredienzien Rosenblätter und Olivenöl empfohlen werden. Alternativ wird im zweiten Abschnitt statt des Öls Maibutter genannt, durch die die Qualität des Öls gesteigert werden soll. Die Butter ist als zusätzlicher lipophiler Anteil bei den Komposita-Arzneien ,Benediktenöl' und dem ,feinen Balsam‘ aus dem Farfensischen Ölbuch bekannt. In diesem zweiten Abschnitt gibt der Kompilator vermutlich eine volkstümlich geprägte Meinung wieder („man sagt das es pesser sey dann das erste:,“). Am Rezept des ,Rosenöls‘ ist eine Beobachtung zu machen, die sich durch alle Rezepte des ,Ölbuchs' im Harburger Kompendium hindurch nachvollziehen lässt: Die Informationen zu den Heilanzeigen sind in den meisten Fällen kurz gehalten. Beim ,Rosenöl‘ fasst der Verfasser diese mit den wenigen Worten zusammen: „Das o̊l ist zumol gut fur alle hitz die dem menschen kumbt in der kranckheyt". Lediglich beim ,Muskateller- 
Salbeiöl‘ und dem ,Bibergeilöl‘ ist mehr als eine Indikation gegeben, die sich dem Leser nicht sowieso aus der Natur der Arznei heraus erschlossen hätte (Rezept 4 und 11).

Ein Überblick zeigt eine im Vergleich zum Farfensischen ,Ölbuch‘ noch geringere Breite an klaren Anwendungen. Es sind nur wenige Fachrichtungen eindeutig zuzuordnen. Die Gastroenterologie findet sich mit der Anordnung „vnd hilfft zu der dewng“ wieder. Als Mittel gegen das Quartanfieber und die Herzinsuffizienz wird der Muskateller-Salbei ebenfalls internistisch eingesetzt. Die Gicht, als im weitesten Sinne orthopädisches Krankheitsbild zu verstehen, soll sowohl durch das ,Lorbeeröl' als auch mithilfe des ,Bibergeilöls' zu beheben sein (Rezept 6 und 11). Letzteres soll ebenso gegen die Epilepsie helfen, womit zusätzlich das Gebiet der Neurologie beschritten wird.

Im Gegensatz zum ,Ölbuch' aus dem Benediktinerkloster Farfa werden im Harburger Gattungsverwandten Aussagen zur Galenik gemacht, auch wenn sich diese dabei lediglich auf den Grad der Grundqualität ,Wärme' beschränken (Rezept 6-8 und 11). So ist es dennoch ein Plus an Informationen verglichen mit den anderen beiden ,Ölbüchern'.

Ein weiterer Unterschied liegt in der Zusammenstellung der Öle. Das Harburger ,Ölbuch' beschreibt keine Herstellung von Komposita. Die Beimengung von Wein, Wasser oder Öl zu den jeweiligen Arzneidrogen stellt die einzige zusätzliche Ingredienz dar. Mit dem ,Bibergeilöl‘ findet hier zudem nur eine nicht-pflanzliche Arznei Verwendung.

Abschließend sollen hier die Rezepte einem kurzen Vergleich unterzogen werden, die sowohl im Harburger als auch im Farfensischen ,Ölbuch‘ vorkommen. Der Übersicht halber werden sie zunächst einmal genannt. Es sind die Rezepte für ,Bibergeilöl', ,Dillöl‘, ,Lorbeeröl‘, ,Rautenöl', ,Rosenöl‘ und ,Veilchenöl'. Der Vergleich des ,Benediktenöls', das sich sowohl bei Farfa als auch im Memminger ,Ölbuch‘ findet, wird bei der Analyse der Memminger Arzneischrift beschrieben. 
Vergleicht man das ,Bibergeilöl' in beiden Büchern, so sind wenige Gemeinsamkeiten festzustellen. Während Harburg nur die Bibergeildrüse selbst für das Öl vorschreibt, werden bei Farfa mit dem Schmerzwurz, Wermut, Euphorbium und dem schwarzen Nieswurz vier weitere Arzneien hinzugefügt. Mit dem Gewicht einer Unze geht die dem Öl namensgebende Arznei beinahe unter. Überschneidungen sind bei der Herstellung des Dekokts aus Öl und Wein zu erkennen, die beide Rezepte vorschreiben. Die Heilanzeigen wiederum haben nichts miteinander gemein.

Der Vergleich der Rezepte für das ,Dillöl‘ zeigt ebenfalls eine sehr geringe Überschneidung ihrer Inhalte. Der Harburger Kodex schreibt vor, dass das Öl aus den Samen gewonnen werden soll, während im Farfensischen Ölbuch vermutlich die ganze Pflanze dazu benutzt wird. Darüber hinaus wird dem Öl im Harburger Rezept Wein zugesetzt. Bei Farfa findet sich einmal mehr das ,Digestio-per-solem 'Verfahren. Die Indikationen betrachtend, verweist der Harburger Verfasser lediglich auf andere, vorher genannte, Anwendungen. „Dicz oley ist gut fur di swacheit dez gehirnes vnd des magens", erklärt der Farfensische Kompilator, und wird damit deutlich konkreter.

Die Gegenüberstellung des ,Lorbeeröls‘ stellt sich ganz anders dar. Hier liegt bis auf eine Zeitangabe in der Herstellungsvorschrift bei Farfa das gleiche Rezept vor. Harburg nennt zudem mit der „kalten Gicht“ konkret eine Krankheit, gegen die das ÖI helfen soll.

Das Rezept zum ,Rautenöl' stellt sich wiederum divergenter dar. Harburg lässt ein Absud aus Öl und Wein herstellen, ohne es, wie bei Farfa beschrieben, danach der Wärmeenergie der Sonne zuzuführen. An Heilanzeigen bietet Harburg, wie so oft, keine auf. Die Sinnhaftigkeit der bei Farfa empfohlenen Anwendung kann zumindest in Frage gestellt werden. Die Raute sei laut Harburg ein Heilkraut, das „heÿß in dem vierdn grad" ist. Inwiefern dann, wie Farfa vorschreibt, eine Anwendung für denjenigen indiziert ist, "der erhiczet ist an dem gesichte vnd an den steten dez leibes", ist aus galenischer Sicht schwer nachvollziehbar. Eine Arznei kalter Natur würde besser zu dieser Indikation passen. 
Die Untersuchungen des Rosenölrezepts beginnen bereits mit der Pflanzenart, die zur Herstellung verwendet werden soll. Während Farfa sagt, dass man „wilde rosen“ nehmen soll, erwähnt Harburg bloß die allgemeine Verwendung von Blättern. Mildenberger belegt „wilde rosen“ mit „Rosa canina“ L. ${ }^{160}$, wobei der Kompilator im Farfensischen Kodex nicht erwähnt, welchen Bestandteil der Pflanze man zu verwenden hat. Übereinstimmung lässt sich diesmal jedoch für den Herstellungsprozess nachweisen. $\mathrm{Zu}$ beiden Arzneidrogen wird Olivenöl gegeben. Die Sonnenenergie bringt das Öl schließlich zur Reifung. Farfa sieht dafür 25 Tage vor, Harburg hingegen 30 Tage.

Ebenfalls ist den beiden Rezepten gemeinsam, dass sie jeweils eine Alternative zur Gewinnung eines Rosenöls präsentieren. Bei Farfa soll das Öl drei Mal gewaschen werden, um die Qualität zu erhöhen. Es ist anzunehmen, dass es sich dabei um einen Siebvorgang handelt. Um selbiges Ziel der qualitativen Verbesserung zu erreichen, wird bei Harburg die oben bereits ausgeführte Aufwertung durch Maibutter erzielt. Deren Beimischung hat darüber hinaus noch einen weiteren Effekt. Will man das Öl im Stirnbereich auftragen, verhelfen die Butter und etwas Wachs offenbar zu einer festeren Konsistenz. Die Arznei könnte der Beschreibung nach womöglich eine salbenähnliche Funktion besessen haben. Der Anwendungsbereich des Öls wird von beiden Verfassern unspezifisch auf die warmen Gebrechen festgelegt.

Ein Vergleich der Veilchenölkapitel ist auf Grund des zu kurz gefassten Rezepts im Harburger Kompendium nicht in ausreichender Weise durchführbar.

${ }^{160}$ Mildenberger (1997), S. 1601-1603 


\section{Kommentar zur Memminger Handschrift Cod. 2, 39}

Die Abfassung des Memminger Kodex lässt sich durch eine im Text $\left(\mathrm{Bl} .8^{v}\right)$ verzeichnete Jahreszahl (1480) auf das letzte Viertel des 15. Jahrhunderts eingrenzen. Der Jahreszahl wird auf selbiger Seite auch der Entstehungsort Augsburg hinzugefügt. Die zwei großen Themen der Handschrift sind die Heilkunde (BI. $\left.1^{r}-134^{v}\right)$ und das Handwerk, dessen Beiträge über den gesamten Rahmen des Werkes verteilt zu finden sind. ${ }^{161}$

Im heilkundlichen Teil ist keine Ordnung nach dem Grundsatz ,a capite ad calcem wiederzufinden. Stattdessen finden sich stets recht kurz gehaltene Traktate, die der gesamten Handschrift eine gewisse Grundordnung verleihen. ${ }^{162}$

Es finden sich übergeordnete Themen wie ein ,Traktat über gebrannten Wein', ein ,Bluttraktat' oder auch ein ,Pesttraktat' aus der Feder Jakob Engelins von UIm. Dem gegenüberstellen lassen sich Traktate, die sich mit der Wirkung und den Kräften einzelner Arzneidrogen auseinandersetzen. Beispiele hierfür sind der Ingwer, der Muskat und der Lorbeer. ${ }^{163}$

Das Ölbuch, dessen Anfang die nicht abgesetzte Überschrift „Item ain gůt o̊l bewertz vnd daz als gůt ist als walsam" trägt, reiht sich mit seinem geringen Umfang (BI. 84 ${ }^{\mathrm{v}}$ $86^{r}$ ) dabei nahtlos in das Konzept der Handschrift ein.

Als eindeutigen Schluss bildet das Wort „ab“, das abgesetzt in der achten Zeile von BI. 86 zu erkennen ist, das Ende des, Ölbuchs'. Auf das ,Ölbuch' folgt dann ein Traktat, der von den Tugenden des "nauter wurz" berichtet (BI. 86r).

Betrachtet man die Form und den Inhalt des Memminger ,Ölbuchs', so fällt auf, dass eine Rezeptgliederung hier nicht vorhanden ist. Dies wird verständlich, wenn man den Inhalt miteinbezieht. Es handelt sich beim ,Ölbuch' dieser Handschrift um eine reine Abfassung eines Benediktenöltraktats. Mittels einer Textfuge im mittleren Teil

\footnotetext{
${ }^{161} \mathrm{vgl}$. Zimmermann (1986), S. 21

$162 \mathrm{vgl}$. Zimmermann (1986), S. 21

${ }^{163} \mathrm{vgl}$. Zimmermann (1986), S. 21
} 
des $\mathrm{Bl} .85^{\mathrm{r}}$ findet eine Überleitung von der Herstellungsprozedur zum ausführlichen Heilanzeigenteil statt. ${ }^{164}$

Eine genaue Betrachtung des Inhaltes soll an dieser Stelle nicht isoliert abgehandelt werden. Es bietet sich an, einen Vergleich mit dem Ziegelölrezept des Farfensischen ,Ölbuchs' durchzuführen. Ebenso sollen Hinweise auf Ähnlichkeiten und Divergenzen anderer bekannter Benediktenöltraktate herausgestellt werden. Darunter fällt zum einen der Passus aus einer mittelniederländischen Fassung des ,Antidotarium Nicolai', das von Braekman und Keil im ,Sudhoffs Archiv' auszugsweise wiedergegeben wird. ${ }^{165}$

Die ,Kopenhagener Wundarznei' wird als zweite Heilschrift kollationiert. ${ }^{166}$ Keil nennt beide Quellen in seinem Artikel über den ,Benediktenöl-Traktat' im Nachtragsband des Verfasserlexikons. Die deutschen Formen entsprächen „überwiegend Schrumpfformen“167. Das Originalrezept sei aus dem ,Grabadin“ des Pseudo-Mesuë entlehnt. ${ }^{168}$

Zu Beginn soll der Blick auf die Herstellungsprozedur gerichtet werden. Dabei lässt sich im Groben Einigkeit in der Vorstellung der Kompilatoren feststellen. Man nimmt den Ziegelstein und erhitzt inn im Feuer bis er "glunde rot" ist. Memmingen ist in allen Belangen aufgrund des alleinigen Kapitels sehr ausführlich. Dem Erhitzen gehen dort die Zerkleinerung auf die Größe der "wålschen nůß" und ein ausgiebiger Waschvorgang des Ziegels voraus. Im niederländischen Text wird die Größe der Stücke ganz ähnlich mit "haselnoten" beschrieben. Auch der Traktat aus der ,Kopenhagener Wundarznei' spricht gleichermaßen von Stücken, die „[...] alß groß alß nuß sintt [...]“, doch verlangt der Verfasser Ziegel, ,[...] die daß wasser nie berürett hett [...]“. Farfa bringt den Zusatz mit ein, dass die Steine, möglichst in Erde eingegraben, gealtert sein sollen. Es liegt die Vermutung nahe, dass man sich aus dem Alterungsprozess eine Verbesserung der Heilkraft der Ziegel versprach.

\footnotetext{
${ }^{164} \mathrm{vgl}$. Zimmermann (1986), S. 69

${ }^{165}$ Braekman und Keil (1971), S. 303-305

${ }^{166}$ Keil und Tenner (2000), S. 73-74

${ }^{167}$ Keil (2004), Sp. 236-237

${ }^{168}$ Keil (2004), Sp. 236-237
} 
Dem Vorgang des Erhitzens lassen alle Vorschriften das Ablöschen der heißen Ziegel in Olivenöl folgen. Im niederländischen Rezept wird dies beispielsweise mit den Worten „[...] werpse in olye van oliven [...]“ vorgeschrieben. Memmingen beschreibt die Wichtigkeit des Raucheinfangens im Hafen, der beim Brennen der Ziegel entsteht. Bei Farfa werden stattdessen sofort die Ziegel zerkleinert.

Ein entscheidender Unterschied in den Rezepten ist die nun in Farfa gemachte Vorgabe, dem Ziegelöl weitere Arzneien hinzuzufügen. Es erlangt damit die Eigenschaften einer Komposita-Arznei. Zwei Pfund des Tausendgüldenkrautes und ein Pfund alte Butter werden dem Öl beigemengt. Diese Zugaben sind unter allen vier Rezepten einzigartig.

Anschließend, und das gilt wieder für alle Vorschriften, soll das Öl in einem Rosenhut destilliert werden. Im ,Antidotarium Nicolai“ heißt es: „[...] ende set daer op u alembijt“. Das dänische Korrelat schreibt vor: „[...] vnd thun eß danne in ein erin rossen hutt [...]“. Bei Memmingen geht der Destillation eine zweitägige Lagerungsphase voraus. Alles in allem sind sich die Rezepte bezüglich der Herstellung also durchaus ähnlich.

Diese Beobachtung ist für die Anwendungsgebiete des ,Benediktenöls‘ gleichermaßen festzustellen. Einzig der Farfensische Kodex unterscheidet sich in Art und Umfang seiner Heilanzeige gegenüber den drei anderen Texten. Hier heißt es vorausschickend: „Dicz oley ist gut fur alle we“, was dem Öl eine Art Panazee-Wirkung zuspricht. Eine gleichlautende Aussage ist bei Memmingen nicht zu finden, wenngleich die Wertschätzung des Öls durch den Kompilator ebenso Erwähnung findet („daz ist gar kosber vnd ist ain hainlichait der phÿlozpharen ain lob gotes daz gar hailsam [ist]“). Es folgt im latinischen Ölbuch darauf der beispielhafte Nachtrag: „Das...ist gut fur daz [we] der gelencke vnd der nerfen vnd fur di chalde vergicht“.

Diese Indikationen sind bei Memmingen in ähnlicher Form auch nachzuweisen. Jedoch imponieren viel mehr die zahlreichen, diverse medizinische Bereiche betreffenden, Heilanzeigen. Einige davon sollen an dieser Stelle exemplarisch aufgeführt werden: 
1. Otologie - „wer dez oleum jn die vngeho̊rend oren gůst daz wider bringt daz geherd“.

2. Ophthalmologie - „ist ainem menschen we an sinen augen der lazz deß o̊ls ain tropffen jn die augen“.

3. Chirurgie - „vnd wirt da mit eÿssen genetz vnd jn daz fưr gelait ez wirt zehandt prinnen“.

4. Gynäkologie - „vnd kumbt ez jn die matrix so bringt ez daz mestrum“.

5. Innere Medizin - „wem lung vnd leber fulet der trinck dez drÿ morgen“.

Dies sind fünf von insgesamt gezählten 18 Anwendungsgebieten. Darunter finden sich beispielsweise mit dem ,Milzgeschwür‘, dem ,Foetor ex ore“ und dem „würm jn dem mund“, sehr eigenständige Indikationen. Die Fülle aufgeführter Heilwirkungen im Memminger Kodex unterstützt gleichzeitig den, vom Farfensischen Kompilator angeführten, Glauben an den Allheilmittelcharakter dieser Arznei.

Dieser wird auch von den Rezepten der ,Kopenhagener Wundarznei“ und des ,Antidotarium Nicolai' nicht widerlegt. Neben den bereits belegten Wirkungen gegen Krankheiten der Augen und Ohren sowie zahlreicher weiterer nicht näher beschriebenen Übereinstimmungen und Ergänzungen mit dem Memminger Kodex, findet sich in beiden Texten sogar eine das Gehirn des Menschen betreffende Komponente. Das Ziegelöl soll zusätzlich eine gedächtnissteigernde Wirkung besitzen.

Betrachtet man die Rezepte in ihrer Gesamtheit, steht einzig die Version des Farfensischen Kompendiums außenvor. Zunächst einmal ist es das mit Abstand kürzeste Rezept. Dies liegt in erster Linie an der knapper gefassten Formulierung der Indikationen. Jene besitzen darüberhinaus eine einzigartige Aussage: Wie bereits belegt, wird von einer Heilkraft gegen alle Formen von Krankheit gesprochen. Wörtlich genommen beinhaltet dies die warmen und die kalten Gebrechen. Der Memminger Kodex, die ,Kopenhagener Wundarznei‘ und das ,Antidotarium Nicolai‘ erwähnen explizit nur die Anwendung für kalte Gebrechen. Hinweise für die Unwirksamkeit bei warmen Krankheiten gibt es nicht, eine separate Aufführung derer ist jedoch nicht belegbar. 
Eine gewisse Eigenständigkeit muss man dem Farfensischen Rezept auch wegen seines Kompositacharakters aussprechen. Keiner der anderen Texte bietet zusätzliche Ingredienzien auf. Leider liefert der Kompilator des Farfensischen Kodex keine Hinweise für den Grund seiner abweichenden Rezeptur. 


\section{Vorbemerkungen zur Analyse der edierten Arzneien}

Im Rahmen der folgenden Analyse soll herausgestellt werden, wie sich die in den mittelalterlichen Kompendien beschriebenen Arzneien von der Antike an über das Mittelalter bis in die heutige Pharmazie und Phytotherapie entwickelt haben. Hierzu wird damit begonnen, einen Bezug zur Antike herzustellen, um möglichst genau herausarbeiten zu können, ob der Verfasser der Kompendien das Wissen seiner Vorgänger lediglich übernommen oder ob er die Anwendung einer Arznei bereits weiterentwickelt hat.

Bekannt ist, dass die mittelalterlichen Verfasser von Texten über Heilpflanzen den überwiegenden Teil ihrer Kenntnisse aus dem tradierten Wissen der antiken Schriftsteller (Dioskurides, Plinius $d$. Ä., Theophrast) bezogen und übernommen haben.

Aus ihrer herausragenden Stellung lässt sich auch die Bedeutung der antiken Heilpflanzenbeschreibungen für diese Arbeit ableiten. Sie sind der Grundpfeiler dessen, worauf die Mönche in den Klöstern ihre Kompilationen verfassten. Sei es in einer abgewandelten, durch eigene Beobachtungen erweiterten Form, oder sogar die direkte Wiedergabe lange vorhandener Kenntnisse.

An erster Stelle der Analyse sind stets die Originalstellen aus den Kodizes zu finden. Die kursive Schriftform soll dem Leser die Abgrenzung von der Sekundärliteratur erleichtern.

Stellvertretend für das antike Wissen über Heilpflanzen wird der Untersuchung die ,Arzneimittellehre' des Dioskurides aus Anazarbos aus dem 1. Jh. n. Chr. zugrundegelegt. Mit circa 600 Pflanzen gilt Dioskurides' Werk als das bedeutendste Zeugnis antiken Wissens, das bis in die Anfänge der Neuzeit eine zentrale Stellung in diesem Teil der Wissenschaft darstellte. ${ }^{169}$ Dieses Werk ist 1500 Jahre lang „die Bibel der Pharmakologen gewesen“170.

\footnotetext{
169 vgl. Marzell (1967), S. 14-15

${ }^{170}$ Bazzi (1982), S. 211
} 
Als Referenz frühmittelalterlicher Literatur wird der lyrisch abgefasste ,Hortulus' des Abtes von Reichenau Walahfrid Strabo aus dem Jahr 847 exzerpiert. Hierbei steht nicht so sehr der wissenschaftliche Fortschritt im Vordergrund, der bei Strabo eher auf dem Gebiet des Gartenbaus dienlicher wäre. Mit diesem Thema setzt er sich ausführlich auseinander.

Es soll vielmehr gezeigt werden, auf welche sprachlich bemerkenswerte Weise das Wissen über Heilpflanzen gegenüber den sachlich kurz gefassten Texten der anderen Verfasser festgehalten wurde. Genauso soll dieses Beispiel ein frühes Zeugnis sein für die Stellung der Mönche und Klöster im Rahmen der Weiterentwicklung und Verbreitung botanischen und frühpharmazeutischen Wissens.

Den Schritt vom frühen Mittelalter in die Zeit des Hochmittelalters wird mittels zweier Autoren vollzogen, deren wissenschaftliches Ansehen nahezu auf einer Stufe steht.

Die Äbtissin Hildegard von Bingen (1098-1179) macht mit ihren Werken ,Physica“ und ,Causae et curae' den Anfang. Während die ,Physica‘ eine einzelne Abhandlung der Pflanzen bereithält, wird in ,Causae et curae“ vornehmlich über die Ursache und Behandlung von Krankheiten berichtet. Die Therapie führt einige Indikationen zu den in dieser Arbeit besprochenen Heilpflanzen an. Ein ausschlaggebender Faktor für die Anführung der Heilmittellehre Hildegards ist die Eigenständigkeit der Beobachtungen, die sie von den Heilpflanzen macht und in ihren Werken niederschreibt. Sie differenziert sich auf diese Weise von einem Großteil der anderen Verfasser, indem sie nicht bloß den antiken Arzneimittelschatz tradiert. Besonders durch die Aufnahme einheimischer Heilpflanzen und deren volksmedizinischer Verwendungen leistet die Äbtissin einen großen Beitrag für die Botanik der Länder Mitteleuropas. ${ }^{171}$

Mit Albertus Magnus, dem Theologen, Philosophen und Naturforscher wird ein weiteres Werk aufgegriffen, das der Feder eines Geistlichen enstammt. Er verfasst in den sieben Büchern des ,De vegetabilibus' eine umfassende Betrachtung naturforscherischen Wissens. Von Interesse ist, dass er sein Wissen zu einem beträchtlichen Teil aus dem ,Canon medicinae‘ des arabischen Arztes Avicenna bezieht und somit einen weiteren Bestandteil mittelalterlichen Heilpflanzenwissens einbringt. Doch auch A/-

${ }^{171}$ vgl. Tschirch (1933), S. 1436-1437 
bertus Magnus werden eigene Beobachtungen und damit neue Erkenntnisse im Bereich der Heilpflanzen zugesprochen. ${ }^{172}$

Mit dem Verlassen des Mittelalters und dem Beginn der Neuzeit setzt das Bestreben nach der botanischen Aufarbeitung der Pflanzen ein. Es werden zunehmend Versuche unternommen, die Pflanzennamen zu untersuchen und der eigenen Flora zuzuordnen. Besonders die aufwendigen Holzschnitte dienen zur Abbildung der heimischen Pflanzenwelt. Es soll das Ziel sein, trotz des ungebrochenen Glaubens an das antike Wissen einen nächsten Schritt in der Reihe der Erkenntnisse der Botanik zu vollziehen. ${ }^{173}$

Diese neuen Erkenntnisse finden in den Kräuterbüchern des 16. Jh. ihr Format. Namen wie Brunfels, Bock und Fuchs zählen zu ihren bekanntesten Verfassern, wobei die beiden erstgenannten passend zu den vorher genannten Geistlichen (Hildegard und Albertus) ihre Wurzeln ebenfalls in der Theologie haben. Besonders auf dem Gebiet der Pflanzenabbildungen bieten die Kräuterbücher eine außergewöhnliche Detailtreue. Da das Hauptaugenmerk der Analyse weniger auf botanischen Aspekten liegt, sondern vielmehr die Verwendung der Heilpflanzen herausarbeiten soll, fällt die Wahl der verwendeten Monografie auf das ,Kräuterbuch' des Frankfurter Stadtarztes Adam Lonitzer aus dem Jahr 1557. In diesem Buch verarbeitet Lonitzer die Informationen einiger anderer Kräuterbücher. ${ }^{174}$ Auf diese Weise soll an dieser Stelle ein umfassender Überblick dessen erstellt werden, was Naturforscher wie Brunfels und Bock in dieser Zeit geleistet haben.

Die Analyse wird mit dem Vollzug eines großen Zeitsprungs abgeschlossen. Mittels aktueller Heilpflanzenführer (Frohne, Schoenfelder, Schilcher) wird exemplarisch für einige Arzneipflanzen herausgearbeitet, welche Inhaltsstoffe die moderne Chemie und Pharmazie aus den Gewächsen isolieren konnte. Hat ein solcher Inhaltsstoff sogar Einzug in die moderne Pharmakotherapie erhalten, womöglich mit einer Anwendung, die sich schon in der historischen Betrachtung zeigt, so wird dies an dieser Stelle herausgestellt.

\footnotetext{
${ }^{172}$ vgl. Tschirch (1933), S. 1441-1445

${ }^{173}$ vgl. Marzell (1967), S. 21

${ }^{174}$ vgl. Marzell (1967), S. 26
} 


\section{Vorbemerkungen zur Literatur im Analyseteil}

Einige Quellen der Sekundärliteratur zeichnen sich durch eine große Breite an Informationen aus, die über die jeweilige Arznei zu erfahren ist. Oberste Priorität hat der Vergleich mit den Kapiteln, die sich ebenfalls mit der Zubereitung eines Öls aus der jeweiligen Arznei beschäftigen. Ist ein solches Kapitel nicht zu finden, wird darauf folgend nach vergleichbaren Heilanzeigen gesucht und diese werden gegebenenfalls exzerpiert. Die Untersuchung der Ölzubereitung wird durch im Kommentarteil der edierten Kompendien geleistet (Kapitel 5-7). Sind in den jeweiligen Ölkapiteln keine Übereinstimmungen auszumachen, so werden zusätzlich die Abschnitte des gesamten Kapitels aus den Referenztiteln überprüft, die sich mit den anderen Zubereitungsarten der jeweiligen Arznei befassen. Bei Kongruenzen werden diese exemplarisch wiedergegeben.

Finden sich keinerlei Heilanzeigen durch den Kompilator, wird ein Auszug aus den Indikationen der Sekundärliteratur wiedergegeben, um die Arznei überhaupt medizinisch einordnen zu können.

Die Darstellung der Indikationen ist vordergründig gegenüber der Zubereitung der Arzneien. Eine Ausnahme stellt dabei nur die Herstellung von Ölen dar, wenn diese durch einen Verfasser explizit erfolgen.

Bei der Auswahl der Literatur, die exemplarisch zum Vergleich herangezogen worden ist, soll im Vorfeld der Analyse eine kurze Bemerkung gemacht werden. Es ist klar, dass sich noch etliche hilfreiche Hinweise auf die Entwicklung einer Arznei in den zahlreichen Werken der Pharmaziegeschichte befinden, die hier keine Erwähnung finden werden. Um der Untersuchung aber einen überschaubaren und damit nachvollziehbaren Rahmen zu geben, bleibt es bei der Beschränkung auf die im vorigen Kapitel vorgestellten Monografien (Kap. 8). Es ist freilich erstrebenswert, darü-

berhinaus die Werke der anderen Meister wie Plinius $d$. Ä., Theophrast, Hippokrates, Macer Floridus und Anderer hinzuzuziehen. 
Für die ausgewählte und exzerpierte Literatur gilt, dass die jeweiligen Abschnitte des Originalwerks (Bücher, Capitel, Rezepte, Verse), sofern mit angegeben, den Rezepten voranstehen.

Dabei ist es in erster Linie das Ziel der Exzerption, die pharmakologische Entwicklung der Arznei zu verdeutlichen. Die botanische Herkunft wird, soweit möglich, im Editionsteil geklärt.

Ein Großteil der Arzneien wird mehrmals in den einzelnen Werken erwähnt. Die Untersuchung beschränkt sich, ebenfalls aus Übersichtsgründen, auf die jeweiligen Hauptkapitel der Sekundärliteratur, die den Heilmitteln allein gewidmet sind.

Eine weitere vorhergehende Erläuterung sei an dieser Stelle dem Unterpunkt ,Referenzen' gewidmet. Unter diesem Punkt sind in abgekürzter Form bedeutende Werke der Arzneimittelgeschichte aufgeführt, in denen die Öle aus den untersuchten Kompendien belegt sind. Es soll ein Eindruck gewonnen werden können, der die Repräsentanz dieser Öle in den Kompendien vorhergehender (z. B. ,Circa instans') und zeitgenössischer Arbeiten (,Kopenhagener Wundarznei') repräsentiert. Die Auflistung richtet sich nach der Untersuchung Crones über die Arzneiöl-Segmente in der medizinischen Fachprosa. ${ }^{175}$ Die Abkürzungen sind folgendermaßen aufzulösen:

$-\mathrm{Cl}=$,Circa Instans' aus dem $12 \mathrm{Jh}$.

- $\mathrm{PM}=$ Der, Grabadin' von Pseudo-Mesue aus dem $13 \mathrm{Jh}$.

- Bmd = ,Boec van medicinen in dietsche' (um 1300)

- $\mathrm{KW}=$,Kopenhagener Wundarznei‘ aus dem $15 \mathrm{Jh}$.

- $\mathrm{CG}=$,Codex Guarini' (plus Kollation des Lexikon Plantarum) aus dem 15. und $16 \mathrm{Jh}$.

Der letzte Punkt der Analyse widmet sich den ,Heilanzeigen in der Übersicht'. Hier soll auf einen Blick zu ersehen sein, ob mehrere Vorschriften dieselbe Indikation liefern. Dabei geben die Zahlen alle Heilanzeigen des edierten Originals wieder. Sind Überschneidungen vorhanden, wird dies durch kleine Buchstaben inklusive der entsprechenden Textstelle hinzugefügt. Zusätzlich ist ein Kürzel des jeweiligen Autors in

${ }^{175}$ vgl. Crone (2002), S. 5-48 
runden Klammern angefügt. Geben die Ölbücher der Kodizes keine oder zu unspezifische Vorschriften, fällt dieser Teil der Analyse weg. Die Texte der Sekundärliteratur werden untereinander nur in sehr geringem Maße verglichen. Der Fokus der Untersuchung soll auf den edierten Ölbüchern liegen. 


\section{Einzelanalyse der Arzneien}

\section{$10.1 \quad$ Benediktenöl}

Als Vorbemerkung zur Nomenklatur dieses Öls sei noch einmal darauf hingewiesen, dass neben der Bezeichnung ,Benediktenöl' die Ausdrucksweisen ,Oleum le lateribus', ,Oleum philosophorum‘ und ,Ziegelöl‘ ebenso gebräuchlich waren.

Farfa: $\quad$ [...] Dicz oley ist gut fur alle we Das ist der dritte balsam vnd ist gut fur daz [we] der gelencke vnd der nerfen vnd fur di chalde vergicht"

Memmingen: , [...] ain lob gotes daz gar hailsam [ist] vnd hat grossen tugent an den siechtübigen die da kalt send wer dez oleum jn die vngehörend oren güst daz wider bringt daz geherd er töt die würm jn dem mund ez ist guit vir daz gicht vnd vir den grossen stanck des munds ez ist auch gut wer dar von macht ain pflaster zů dem ruggen we vnd daz jn salarmoniatem zelosset ez ist auch guit $z u ̊ d e m$ geschwer dez miltzes ez ist auch guot wem die nåßlöcher zeser dorrent ez ist auch güt vir den sandt vnd kumbt ez jn die matrix so bringt ez daz mestrum ez offent daz gedaumen ez zerloost daz geschaiden plüt [...] vnd daz nimbt ez fürbet die lungen ez ist guit dem die autem zucket vnd zů den augen vnd vir die gicht da daz scorpio gehaisse hat [...] vnd wirt da mit eÿssen genetz vnd jn daz furr gelait ez wirt zehandt prinnen ist ainem menschen we an sinen augen der lazz des o̊ls ain tropffen jn die augen jm wirt baß jn ainem halben tag wem auch daz schwindet gicht an welchem glid daz sÿ vnd man tit daz bestrichen da mit ez verlat jn zehand wem lung vnd leber fulet der trinck dez drÿ morgen so wirt jm baß [...]."

H. v. Bing.: $\quad$ CC: Vom Schwitzbad. Für einen Menschen, der mager und trocken ist, paßt das Schwitzbad [...] Steine [...] haben in sich Feuer und verschiedene Feuchtigkeiten [...] es ist viel gesunder mit Ziegelsteinen, weil diese gebrannt und trocken sind [...] Wer also in einem Schwitzbad baden will, soll dies mit Ziegelsteinen herrichten. Hildegard (1955), S. 343

Zwar handelt es sich in diesem Heilrezept Hildegards nicht um das Benediktenöl. Durch die Anwendung wird aber deutlich, welche Qualität dem Ziegelstein zugesprochen wird. Durch das Brennen des Ziegels aus feuchtem Ton, verliert er seine Feuchtigkeit und besitzt von da an trockene Eigenschaften. 
Lonitzer: Sechster Theil - Cap. [...] Von Ziegelsteinen wird ein Oel gebrennt/ Oleum de Lateribus genannt/ so dienlich in allen Gebrechen der Glieder und Nerven/ auch zum Miltzen/ Nieren und Ruckenwehe. Lonitzer (1962), S. 719

Referenzen: Bmd, KW.

Heilanzeigen in der Übersicht:

\section{Farfa:}

1.1. Gelenkschmerz

1.2. Muskelschmerz

1.3. Kalte Gicht

2. Memmingen:

2.1. Taubheit

2.2. Wurm im Mund

2.3. Gicht

2.4. Mundgeruch

2.5. Rückenschmerz

2.6. Milzgeschwür

2.7. Trockene Nasenlöcher

2.8. Sand/ Gries

2.9. Regel bringend

2.10. Gedärm öffnend

2.11. geronnenes Blut

2.12. säubert die Lungen

2.13. Atemstörungen

2.14. Augen

2.15. Geschwür

2.16. Lungenfäule

2.17. Leberfäule a) [...] dienlich in allen Gebrechen der Glieder [...] (Lon)

a) [...] dienlich in allen Gebrechen der Glieder [...] (Lon)

a) [...] dienlich in allen Gebrechen der Glieder [...] (Lon) a) in allen Gebrechen [...] und Ruckenwehe (Lon)

a) [...] auch zum Miltzen [...] (Lon)

a) [...] in allen Gebrechen der Nieren [...] (Lon) 


\section{$10.2 \quad$ Bibergeilöl}

Farfa: „[...] Dicz oley ist gut vor daz we dez magen vnd ist gut vor daz we der muter ader matrice vnd erwemet den erfron wetagen"

Harburg: „[...] Das o̊l ist gut Epilentiris Epilenpsia [...] Auch ist es gut fur das gicht Es sterkt vnd gibt Krafft allen gelidern:,"

Dioskurides: 2. Buch - Cap. 27: [...] Der Biber ist ein Amphibienthier [...] dessen Hoden auch gegen Schlangen wirkt. Er (der Hoden) erregt aber auch Niesen, und dient überhaupt mannigfachem Gebrauche [...] mit stinkendem Polei genommen befördert er die Menstruation, treibt den Fötus und die Nachgeburt aus. Mit Essig [...] gegen Blähungen, Krämpfe, Schlucken, tödliche Gifte und die Mistel. Mit Essig und Rosenöl [...] regt er die Schlafsüchtigen ${ }^{176}[\ldots]$ an. [...] ein geeignetes Mittel [...] bei jedem nervösen Zustande [...]. Dioskurides (1902), S. 160-161

H. v. Bing.: Phy - Cap.7-22: Der Biber ist sehr warm [...] (R1-102) [...] auch die Hoden des Bibers [...] unterdrücken das Fieber im Menschen. Hildegard (1991), S. 478

Lonitzer: Dritter Theil - Cap. 35: [...] Die Bibergeil [...] ist hitzig im dritten/ und trucken im andern Grad. [...] Bibergeil [...] ist für den fallenden Siechtagen gut [...] Fürs Gicht am Leib/ Nimm Bibergeilen [...] Benimmt das stechende Bauchwehe [...] bringt die Frauenzeit/ treibt die Nachgeburt herauß.

[...] Bibergeil Oehl [...] dienet zu allen kalten Gebrechen der Glieder/ der Nerven und Gelaiche/ für die Lähme/ Krampff [...] Stillet und legt das hefftige Frieren und Zittern in den Fiebern/ den Ruckgrad warm damit gerieben. Lonitzer (1962), S. 600-602

Referenz: Bmd.

Bemerkenswert beim Vergleich der Kompendien mit dem ,Kräuterbuch' ist, dass der Teil des Bibergeilrezepts bei Lonitzer alle Anwendungen aufzeigt, die in den Kodizes auch vorhanden sind. Dem Bibergeilöl werden im ,Kräuterbuch' andere Indikationen zugewiesen. Aus diesem Grund sind beide Abschnitte wiedergegeben worden.

\footnotetext{
176 ,Schlafsüchtigen': „Schlafsucht" belegt Höfler als „coma febrile“, eine Art „Katatonie“ oder schlicht als "Schlafkrankheit", ohne diese weiter zu definieren. Höfler (1970), S. 714
} 


\section{Heilanzeigen in der Übersicht:}

1. Magenschmerz:

2. Gebärmutter

3. Epilepsie:

4. Gicht: a) stechende Bauchweh (Lon)

a) befördert die Menstruation, treibt den Fötus und die Nachgeburt aus (Dio)

b) bringt die Frauenzeit/ treibt die Nachgeburt herauß (Lon)

a) ist für den fallenden Siechtagen gut (Lon)

b) regt er die Schlafsüchtigen (Dio)

a) Fürs Gicht am Leib (Lon)

\subsection{Bilsenöl}

Harburg: "[...] Das o̊l ist gar gut zu allerley seuchen die von hitz kommen wan es kelt ser"

Dioskurides: 4. Buch - Cap. 69: [...] Es gibt davon drei Arten [...] Zum arzneilichenGebrauche geeignet [...] ist der dritte [...] hat eine weisse Blüthe ${ }^{177}[\ldots]$ eignet sich am besten zu schmerzstillenden Kollyrien ${ }^{178}$, sowie gegen heftigen und heißen Fluss, gegen Ohrenschmerzen und Gebärmutterleiden, [...] gegen Augen-, Fuss-, und sonstige Entzündungen. [...] wirksam [...] bei Husten, Katarrh [...] und sonstigem Blutverlust [...] ein gutes Mittel bei Podagra, angeschwollenen Hoden und nach der Niederkunft entzündeten Brüsten [...] Die frischen Blätter [...] sind [...] am meisten schmerzlindernd. Drei oder vier mit Wein getrunken heilen bösartige Fieber [...]. Dioskurides (1902), S. 402-403

Dioskurides liefert außerdem eine Beschreibung zur Herstellung des Bilsenöls. Dabei werden nur die Samen des $H$. albus (L.) zerstoßen und mit heißem Wasser vermischt. Zur Fertigstellung fehlen dann noch das Durchsieben und Nachpressen. Im Gegensatz hierzu wird das Öl des Harburger Kompendiums wesentlich aufwendiger hergestellt. So beträgt die Lagerungszeit der Samen, Blätter und „ko̊pfchen“ allein ein Jahr. Eine Abgrenzung der Bilsenart wird nicht vorgenommen. Dioskurides hält das weiße Bilsenkraut für das heilkundlich Geeignetste unter den Bilsenkräutern. Beren-

\footnotetext{
177 gemeint ist Hyoscyamus albus (L.)

178 Ott-Voigtländer belegt in ihrem ,Wörterverzeichnis“ das mittelhochdeutsche Wort „ougensalbe“ als Synonym für „Kollyrium“. Ott-Voigtländer (1979), S. 94
} 
des berichtet in seinem Kommentar allerdings, dass sowohl $H$. niger als auch $H$. albus dieselben Wirkstoffe (Alkaloide: Scopolamin, Hyoscyamin) enthalten. Ob also tatsächlich ein Unterschied zwischen den Wirkungsweisen der Bilsenkrautarten besteht, ist fraglich. ${ }^{179}$

H. v. Bing.: Phy - Cap. 1-110: Das Bilsenkraut ist kalt und weich und ohne Kräfte. (R1-320) [...] wo Finnen im Menschen sind [...] zerreibe es an jenem Ort mit dem Saft (R1-321) [...] wo [...] zu große Hitze entsteht, dort werde jene Stelle mit diesem Öl gesalbt, und es kühlt inn [...]. (R1-322) Damit ein Betrunkener wieder zu sich kommt [...]. Hildegard (1991), S. 128

Alb. Mag $^{180}$.: Cap. $10-\S 362-363:$ [...] Niger autem venenosus est, et similiter rubeus, sed non tantum. Albus etiam veneno non caret, sed tamen aliquando ministratur. Est autem frigidus et siccus secundum omnes species suas. In operatione autem est stupefactivus, et sua stypticitate abscidit fluxum sanguinis; et sedat dolores percussivos, temperatus autem cum impinguantibus impinguat, eo quod coagulat sanguinem. Resolvit duritiem testiculorum, et confert erysipelae. Folia dormire faciunt comesta, et permutant rationem. Eius etiam succus linitus super apostemata mamillarum confert; [confert] dolori matricis, et abscidit fluxum sanguis ex ea. Est autem venenum, quo et ratio permiscetur et memoria destruitur, et in maniam convertitur homo [...] Albertus (1992), S. $526-527$

Lonitzer: $\quad$ Anderer Theil - Cap. 58: [...] Bilsamkraut und Saame/ ist kalter Natur und Eigenschafft in dem dritten vollkommenen Grad/ einer schädlichen gifftigen Qualität/ [...] mag aber äusserlich zu vielen Dingen genützt werden [...]. Lonitzer (1962), S. 214-215

An dieser Stelle kann das ,Kräuterbuch“ keine weiteren Erkenntnisse bringen. Der Harburger Kompilator hält sich mit Heilanzeigen beim Bilsenkraut zurück. Deshalb sind die übrigen Auszüge ausreichend, um einen Überblick über die Verwendung der Arznei zu erhalten.

\footnotetext{
179 vgl. Dioskurides (1902), S. 62

${ }^{180}$ Die am Beginn der Exzerption stehenden Kapitel enstammen, dem Titel der Monografie entsprechend, alle aus ,De vegetabilibus Buch 6, Traktat 2' des Albertus Magnus.
} 
Frohne: $\quad$ Angewandter Pflanzenteil: Hyoscyamusblätter, Bilsenkrautsamen Inhaltsstoffe ${ }^{181}$ : Hyoscyamin, Scopolamin

Wirkung: Die Alkaloide wirken parasympatholytisch. Sie gehören zur Reihe der Atropinderivate (Inhaltsstoff von Atropa belladonna (L.)).

Anwendung: Eine Verordnung der Droge (Samen, Blätter) gilt als obsolet. Grund dafür sind die zu starken Schwankungen des Alkaloidgehalts. Scopolamin findet als zentralwirkendes Parasympatholytikum mit antiemetischer Wirkkomponente bei der Behandlung der Reisekrankheit Verwendung. Seine Wirkung ist im ZNS stärker als die der anderen Atropinderivate. Frohne (2002), S. 307-309

Schilcher: Indikationen: Spasmen im Bereich des Gastroinstestinaltrakts.

Darreichungsform: Eingestelltes Hyoscyamuspulver [...]. Schilcher und Kammerer (2003), S. 46,47

Während Schilcher mit der Verwendung des Hyoscyamuspulvers eine zulässige Indikationsform für das Bilsenkraut belegt, hält Frohne seine Nutzung aufgrund der möglichen anticholinergen Nebenwirkungen (Tachykardie, Obstipation) für veraltet.

\subsection{Dillöl}

Farfa: $\quad$ [...] Dicz oley ist gut fur di swacheit dez gehirnes vnd des magens"

Obwohl das Dillöl im Harburger Kompendium in einem eigenen Kapitel beschrieben wird, sind keine Heilanzeigen angegeben. Ausführlich widmet sich Stannard in der Festschrift für Willem Daems den Möglichkeiten der medizinischen Dillanwendung. ${ }^{182}$

Dioskurides: 3. Buch - Cap. 60: Das Speiseanethon [...] befördert als Trank die Milchabsonderung, lindert Leibschneiden ${ }^{183}$ und Blähungen [...] stillt leichtes Erbrechen, treibt den Harn und beruhigt den Schlucken [...] Von Nutzen [...] für hysterische Frauen. Der gebrannte Same [...] vertreibt Geschwülste am After. Dioskurides (1902), S. 302

Dioskurides gewinnt das Dillöl nur aus der Dillblüte, die im Öl liegend mazeriert werden soll. ${ }^{184}$

\footnotetext{
${ }^{181}$ Die Inhaltsstoffe sind in einer oftmals gekürzten Fassung wiedergegeben und sollen nur einen Ausblick auf das geben, was die Wissenschaft mittlerweile über diese Verbindungen in Heilpflanzen weiß. In erster Linie sind die allgemeinen Begriffe der anorganischen und organischen chemischen Verbindungen angegeben. In Klammern stehen dann Beispiele für diese Stoffklasse. Bsp.: Phenolcarbonsäure (Vanillinsäure).

182 Stannard (1982), S. 411-424

183 ,Leibschneiden': Gemeint sind Verwundungsschmerzen im Körper. Höfler (1970), S. 590

${ }^{184}$ vgl. Dioskurides (1902), S. 70
} 
Dioskurides: 1. Buch - Cap. 61: Es hat die Kraft, die Gebärmuttergegend zu erweichen und zu eröffnen, ist wirksam gegen das Wechselfieber, erwärmt, hebt die Erschlaffung, und ist heilsam gegen Gelenkschmerzen. Dioskurides (1902), S. 70

H. v. Bing.: Phy - Cap. 1-67: Der Dill ist von trockener und warmer [...] Natur. (R1201) [...] gekocht gegessen unterdrückt er die Gicht [...]. Hildegard (1991), S. 95

CC: Vom Lungenschmerz. [...] Nimm auch Dill [...] und fülle das mit reinem, gutem Wein gekocht, in einen Topf. Hildegard (1955), S. 262-263

CC: Vom Milzschmerz. [...] soll dieser Mensch Kerbel nehmen und etwas weniger Dill, mit Weizenbrot und Essig [...]. Hildegard (1955), S. $282-283$

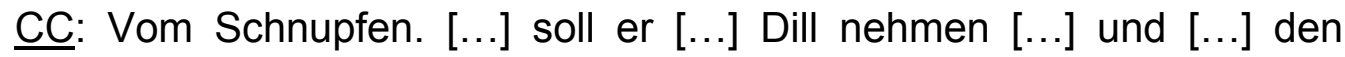
Rauch [...] in sich aufziehen [...]. Hildegard (1955), S. 283

An dieser Stelle wird sich den beiden veterinärmedizinischen Indikationen (Schweine, Schafe) des Dills aus ,Causae et Curae' nicht weiter gewidmet, da der humanmedizinische Aspekt der Arbeit vordergründig ist.

Alb. Mag.: Cap. - § 282: [...] Est autem calidum et siccum, et est maturativum frigidorum humidorum, et est sedativum dolorum, et carminativum ventositatum, et similiter oleum ejus; et quod est siccum, vehementius resolvit; et provocat somnum, et similiter eius oleum; et assiduatio comestionis eius debilitat visum; et si sorbeatur semen aneti in sorbitionibus lac facientibus, facit abundare lac, et alias multas habet operationes. Albertus (1992), S. 481

Lonitzer: $\quad$ Anderer Theil - Cap. 312: [...] Sein Natur ist warm im Ende des dritten Grads/ und trocken im Anfang deß andern Grads. [...] Dillöl/ ist gut wider den Schmertzen der Ohren [...] Dill [...] mit Oel [...] vermischt/ ist fast gut der Mutter und hilfft der andern Geburt herauß [...] Dill gessen/ stärcket das Hirn und den Magen [...]. Lonitzer (1962), S. 483

Frohne: $\quad$ Angewandter Pflanzenteil: Dillfrüchte Inhaltsstoffe: Carvon, Cumarine, Kaffeesäurederivate Wirkung: Steigerung der Magensaftsekretion, spasmolytisch an der glatten Muskulatur des Gastrointestinaltrakts, karminativ ${ }^{185}$. Anwendung: Meteorismus. Frohne (2002), S. 68-69

Schilcher: Indikationen: Dyspeptische Beschwerden. Schilcher (2003), S. 68 Referenzen: CG, PM.

185 ,Karminativa': „Mittel gegen Blähungen“. Pschyrembel (2010) 


\section{Heilanzeigen in der Übersicht:}

1. Schwäche der Gehirnes

a) stärcket das Hirn und den Magen (Lon)

2. Schwäche des Magens

a) Blähungen [...] stillt leichtes Erbrechen (Dio)

b) stärcket das Hirn und den Magen (Lon)

c) Steigerung der Magensaftsekretion (Fro)

\section{$10.5 \quad$ Fuchsöl}

Farfa: $\quad$ [...] Dicz oley ist gut fur alle gruntlose we di mit chelde lauffen vnd vor we der vergicht"

H. v. Bing.: Phy - Cap. 7-21: Der Fuchs ist sehr warm [...] wegen der Verschiedenheit [...] (R7-097) taugt sein Fleisch nicht zum Essen für den Menschen. [...] (R7-099) ein Mensch, der Skrofeln ${ }^{186}$ an seinem Körper hat, der nehme Fuchsschmalz [...] und damit salbe er oft die Skrofeln. Hildegard (1991), S. 477

Lonitzer: Dritter Theil - Cap. 46: [...] Fuchsöl [...] dienet den Podagrischen und den lahmen Gliedern/ dem Rückenwehe/ und den Nieren/ warm darmit geschmieret. [...]. Lonitzer (1962), S. 615-616

Referenzen: PM.

\section{Heilanzeigen in der Übersicht:}

1. Gicht

a) Fuchsöl [...] dienet den Podagrischen und den lahmen Gliedern/ (Lon)

Schneider belegt die Verwendung von Fuchsöl aus Vorschriften von Galen und Mesue. Ein Blick auf die medizinischen Anwendungsgebiete, die Schneider belegt, bringt keine neuen Indikationen für das Öl. ${ }^{187}$ Eine weitaus genauere Untersuchung der Fuchsanwendung bietet Polhill in ihrer Bearbeitung des ,Tierbuch“ von Hans Minner. $^{188}$

\footnotetext{
186 ,Skrofeln“ lies ,Skropheln': „1. vergrösserte, angeschwollene Halsdrüsen. 2. Drüsen-Kropf“. Höfler (1970), S. 654-655

${ }^{187}$ vgl. Schneider (1968), Bd 1, S. 69

${ }^{188}$ vgl. Polhill (2006), S. 177-178
} 


\subsection{Holunderöl}

Harburg: „Oleum sambucum Sambucus ${ }^{189}$ heyßt holder der ist heyß an dem dritten grad das o̊l macht man von holder plut [...] vnd ist gut als die andern die heyß sein

Auch ist ein ander o̊l von holder das ist kalter natur das macht man von den pern die man über mer bringt der vindt man hie nicht:,"

Der Harburger Kompilator nennt keine Anwendungsgebiete für den Holunder, weshalb hier einige Indikationen exemplarisch dargestellt werden.

Auch bei Dioskurides sind keine Heilanzeigen für den Holunder zu finden. Das Kapitel hat einen überwiegend botanisch-deskriptiven Charakter. ${ }^{190}$ Ein Indiz für den Grund der mangelnden Anwendungshinweise bei Dioskurides und Albertus Magnus enthält das unten angeführte Kapitel Hildegards über den Gebrauch des Holunders.

H. v. Bing: Phy - Cap. 3-44: Der Holunder ist mehr warm als kalt und taugt wenig zum Gebrauch des Menschen, wie auch seine Frucht, es sei denn, daß sie nur dem Menschen dienlich ist. Jedoch wer Gelbsucht hat, gehe in ein Dampfbad und lege Blätter dieses Baumes auf erhitzte Steine und gieße Wasser darüber. Und dann lege er auch seine Sprossen in reinen Wein, damit dieser den Geschmack annimmt, und so trinke er in diesem Bade mäßig. [...]. Hildegard (1991), S. 276

Lonitzer: Erster Theil - Cap. 66: [...] Holder und Attich/ seynd warm und trocken [...] Die Wurtzeln [...] treiben die Wassersucht gewaltig auß. Holderblätter [...] stillen des Podagrams schmertzen [...] Die Blätter oder Frucht [...] benemmen die Geschwulst der Füssen [...] Von Holderblüet macht man Essig und Oel/ haben obgemeldte Tugend [...]. Lonitzer (1962), S. $119-120$

Frohne: $\quad$ Angewandter Pflanzenteil: Holunderblüten Inhaltsstoffe: Flavonoglykoside (Rutin), Phenolcarbonsäure (Chlorogensäure) ätherisches Öl, Kaliumsalze, cyanogenes Sambunigrin in Spuren.

Wirkung: Diaphoretisch ${ }^{191}$

Anwendung: Als Diaphoretikum, z.B. bei Erkältungskrankheiten. Frohne (2002), S. 494-495

Referenzen: Cl, PM.

189 ,Sambucus': „Sambucus nigra“ (L.), Fischer (1967), S. 283

${ }^{190}$ vgl. Dioskurides (1902), S. 465

191 ,Diaphoretika': „Sudorifera; schweißtreibende Mittel“. Pschyrembel (2010) 


\section{7 Öl der Juden}

Farfa: $\quad$ "[...] Dicz oley ist gut fur alle siechtum Wenne die Juden halden es gar vor ein chastlich ding vnde ist gut fur alle chalde siechtum"

Kop. Wund.: „Also mache ein balsamus, der heissett balsam artificialiß: Recipe [...] aloeß [...] oppopentum, bedelium [...] myrem [...] masticiß [...] sarcocolle $[\ldots]$ laudanum $[\ldots]$ carpobalsam $[\ldots]$ olibanum $[\ldots]$ sangwis traconis $[. .$. castorium $[\ldots]$ spicanardi $[\ldots]$ macis $[\ldots] .$.

Dieser Auszug aus der ,Kopenhagener Wundarznei‘ stellt nur die Namen der Bestandteile des Balsams dar, die mit dem „Oley der Juden“ übereinstimmen. Es ist die einzige Quelle, die bei der Untersuchung der Herkunft des ,Judenöls‘ derartige Überschneidungen in der Rezeptur aufweist. Dreizehn der circa zwanzig Zutaten des Farfensischen Kodex finden sich in dem „balsam artificialiß“ der Wundarznei. ${ }^{192}$ Als eigenständiger Zusatz sind nur drei Zutaten zu nennen: „grana paradisi“, „serapinum“ und „corticis tertie arborum“. Das Balsamholz (,xilobalsam“) wird durch die Verwendung der Balsamfrucht nicht dazu gezählt.

Die Beobachtung dieser Ähnlichkeiten ist kein Beweis für eine identische Herkunft beider Rezepte. Eine gemeinsame Grundrezeptur in der Zusammenstellung der beiden Balsame ist jedoch nicht zu übersehen. Es liegt demnach die Vermutung nahe, dass sich die Kompilatoren solcher Kodizes auch bei den Balsamen an einem Referenztext orientierten. Dieser wurde vermutlich noch nach eigenen Vorstellungen punktuell ergänzt, gekürzt oder anderweitig modifiziert.

\subsection{Kamillenöl}

Farfa: $\quad$ [...] Dicz oley ist gut fur alle tieffe we der beine vnd der nerfen vnd fur geswolst die von chelde sint vnd fur alle chalde we vnd vertreibet daz we in den gelencken"

Dioskurides: 3. Buch - Cap. 144 (154): [...] Die Wurzeln, Blüthen und das Kraut haben erwärmende und verdünnende Kraft; im Trank und Sitzbade befördern sie die Menstruation, treiben den Embryo aus sowie den Stein und den Urin [...] ferner gegen Blähungen und Darmverschlingung [...] vertreiben die Gelbsucht und heilen Leberleiden [...] gegen Blasenentzün-

\footnotetext{
${ }^{192}$ vgl. Keil und Tenner (2000), S. 75
} 
dung [...] auch bei Geissauge ${ }^{193}$, gekaut heilen sie Soor [...] mit Oel [...] um das periodische Fieber zu vertreiben. [...]. Dioskurides (1902), S. $352-353$

Die heilige Hildegard von Bingen spricht vom Mutterkraut. Schulz (Übersetzer der $\mathrm{CC}$ ) bestimmt es als Chrysanthemum parthenium - Falsche Kamille. Fraglich ist, ob Hildegard diese Pflanze mit der echten Kamille verwechselt oder ihr aufgrund ihres ähnlichen Aussehens die gleiche Wirkung zuspricht. Bei Farfa heißt es, dass die Kamille gegen die Geschwülste wirkt, „die von chelde sint“. Auch Hildegard spricht von der warmen Natur des Mutterkrauts.

H. v. Bing.: Phy - Cap. 1-116: Das Mutterkraut ist warm und hat einen angenehmen Saft, und (R1-348) den schmerzenden Eingeweiden ist dieser wie eine [...] Salbe. [...] (R1-349) Und wenn die Frauen den Monatsfluss haben [...] sollen sie diese Suppe [...] essen, und dies bereitet eine [...] leichte Reinigung des Schleims und des inneren Unrats [...]. Hildegard (1991), S. 135 Cap. 1-116

CC: [...] Ein Mensch, der an Kolik leidet, soll Mutterkraut nehmen [...] Hildegard (1955), S. 293

$\underline{\text { CC: }}$ [...] Leidet jemand am Blutfluß, so nimm zwei Eidotter [...] an Mutterkrautsaft [...]. Hildegard (1955), S. 297

Alb. Mag.: Cap. 4 - $§ 294:$ [...] Est autem calida et sicca, et secundum Galenum propinqua est virtuti rosae in subtiliatione. Est enim aperitiva subtiliativa mollificativa et resolutiva cum pauca attractione[...] Sedat autem apostemata calida mollificando et resolvendo, et lenificat dura non multum stricta, et bibitur propter apostemata viscerum spissa. Et confortat membra nervosa omnia [...] Et est confortativa cerebri [...] Aufert icteritiam. Si autem praegnans sedeat in aqua ipsius, educit embryonem et secundinam. Et confert iliacae passioni, et alias plurimas nobiles habet operationes. Albertus (1992), S. 486-487

Lonitzer: $\quad$ Anderer Theil - Cap. 68: [...] Seynd hitzig und trocken im ersten Grad. Ihr Tugend ist weich zu machen/ und zu sänfftigen [...] gelegt auf harte Geschwer/ weichet und sänfftigt den Schmertzen [...] Mit Chamillenöl schmier die lahmen Glieder [...]. Lonitzer (1962), S. 223-224

Frohne: $\quad$ Angewandter Teil: Kamillenblüten

Inhaltsstoffe: Ätherisches Öl mit Chamaluzen, Spathulenol u.A., Flavonoide (Apigenin), Hydroxycumarine (Herniarin, Umbelliferon), Phenolcarbonsäuren (Kaffee-, Vanillinsäure), Cholin, Proazulene (Matricin, Matricarin).

Wirkung: Antiphlogistisch, spasmolytisch, antibakteriell.

193 ,Geissauge“ lies ,Geisauge‘: „Augenwinkelgeschwür“. Höfler (1970), S. 20 
Anwendung: Entzündungen (Gastrointestinaltrakt, Mund, Haut, Schleimhaut, Luftwege), Abszesse. Frohne (2002), S.354-357

Schilcher beschreibt den Wirkmechanismus der Flavonoiddroge aus der Kamillenblüte bezüglich ihrer entzündungshemmenden Wirkung. Sie wirken als Cyclooxygenasehemmer unter anderem auf die Bildung von Prostaglandinen, die wiederum Entzündungsmediatoren sind. ${ }^{194}$ Das entspricht demselben Wirkmechanismus, wie er für die Nicht-steroidalen Antirheumatika (u.a. Ibuprofen, Diclofenac, Aspirin) nachgewiesen ist.

Referenzen: PM, KW.

\section{Heilanzeigen in der Übersicht:}

1. Beinschmerzen

2. Muskel/ Sehnenschmerzen

3. Geschwülste (Abszesse) a) Mit Chamillenöl schmier die lahmen Glieder (Lon)

a) Et confortat membra nervosa omnia (Alb)

b) Mit Chamillenöl schmier die lahmen Glieder (Lon)

a) Sedat autem apostemata calida mollificando et resolvendo (Alb)

b) Gelegt auf harte Geschwer (Lon)

c) Abszesse (Fro)

4. Gelenkschmerzen a) Mit Chamillenöl schmier die lahmen Glieder (Lon)

b) Die Hemmung der Prostaglandinsynthese bewirkt zusätzlich eine Schmerzlinderung. (Schil)

\subsection{Katzenöl}

Farfa: $\quad$ [...] Vnd daz oley ist gut fur alle we dez rucken vnd rene“

Lonitzer: Dritter Theil - Cap. 28: [...] Katzenfleisch ist hitzig und trocken/ heilet den Schmerzen der gülden Adern ${ }^{195} /$ erwärmet die Nieren/ und dienet auch zu dem Schmertzen des Jucken [...]. Lonitzer (1962), S. 597

Lonitzers Heilanzeige für die Nieren bestärkt die Vermutung, dass es sich bei dem Wort „rene" aus dem Farfensischen Kompendium ebenfalls um die Niere handelt.

\footnotetext{
${ }^{194}$ vgl. Schilcher und Kammerer (2003), S. 123-126

195 ,gülden Adern': „Hämorrhoiden“. Höfler (1970), S. 4
} 
Wiederum sind die Ausführungen Polhills aus ,Minners Tierbuch' sehr hilfreich. Hervorgehoben wird dort die Wirkung gegen Podagra und Fazialisparese. ${ }^{196}$ Die ungenaue biologische Nomenklatur der Katzenrasse, sowohl bei Minner als auch bei Farfa, wird bei dieser Untersuchung hingenommen.

\section{Heilanzeigen in der Übersicht:}

1. Rückenschmerz

$\begin{array}{ll}\text { 2. Nierenschmerz } & \text { a) erwärmet die Nieren (Lon) }\end{array}$

\subsection{Kostusöl}

Farfa: $\quad$ [...] Dicz oley ist gut fur alle chalde wetagen vnd sich do mite salbet do der wetagen ist"

Dioskurides: 1. Buch - Cap. 15: Den Vorzug hat der arabische Kostus, der weiss und leicht ist [...] Er hat erwärmende, harntreibende, die Menstruation befördernde Kraft und ist bei Gebärmutterleiden heilsam [...] hilft [...] den von der Otter Gebissenen [...] mit Wein [...] auch gegen Krämpfe und Blähungen [...] mit Wasser [...] treibt er den Bandwurm ab. Mit Oel als Salbe dient er gegen Fieberschauer vor den Anfällen, und gegen Lähmungen; [...]. Dioskurides (1902), S. 41

Referenzen: PM.

Lonitzer übernimmt das Kapitel über den Kostus von Dioskurides. ${ }^{197}$

Anzumerken ist die in vielen Quellen erwähnte Problematik, die die eindeutige Zuordnung des Kostus schon seit je her erschwert. So behauptet Berendes in seiner Ausführung über Galen: „Myrrhe und Costus muss man ächt gesehen haben, um sie von Fälschungen unterscheiden zu können." 198 Seinem Kommentar zum Kostuskapitel des Dioskurides ist zu entnehmen, dass die Arznei im Mittelalter nicht mehr im

\footnotetext{
${ }^{196}$ vgl. Polhill (2006), S. 147-149

${ }^{197}$ vgl. Lonitzer (1962), S. 541-542

${ }^{198}$ Berendes (1965), S. 73
} 
Handel zu finden gewesen sei. ${ }^{199}$ Eine weitere ausführliche Schilderung der Problematik liefert Schneider in seinem ,Lexikon zur Arzneimittelgeschichte‘. ${ }^{200}$

\subsection{Lilienöl}

Farfa: $\quad$ \#[...] Dicz oley ist gut fur heise wetagen“

Dioskurides: 1. Buch - Cap. 62: Die Bereitung des susischen Salböls. ${ }^{201}$ Das susische Oel, welches Einige auch Lilienöl nennen [...] Einige bereiten es einfach aus Behen- oder einem anderen Oel und Lilien [...] Es hat erwärmende, erweichende, gegen Verstopfung und Entzündung der Gebärmutterumgebung gerichtete Kraft und überhaupt ist es von allen am nützlichsten bei Frauenkrankheiten] [...] führt [...] die Galle durch den Bauch ab, treibt auch den Urin [...]. Dioskurides (1902), S. 71

3. Buch - Cap. 107 (117): [...] Die [...] Wurzel heilt mit Rosensalb Feuerbrandwunden, erweicht die Gebärmutter, befördert die Menstruation und bringt Wunden zum Vernarben. Mit Honig [...] heilt sie durchschnittene Sehnen und Verrenkungen [...] Mit Essig [...] besänftigt sie Hodenentzündungen. Dioskurides (1902), S. 332-333

Dem einfachen Rezept der Lilienölherstellung steht, analog zum Rosenölrezept, ein deutlich komplexeres Rezept voran. Dioskurides bezeichnet das aufwändiger herzustellende Öl als das bevorzugte. Da das Lilienölkapitel des Farfensischen Kompendiums im Gegensatz zu den Ausführungen des griechischen Gelehrten sehr kurz gehalten ist, wird an dieser Stelle nur das Kurzrezept von Dioskurides wiedergegeben. 202

Walah. Str.: [...]

Lilia nostra premit, necnon si perfidus anguis

Ingenitis collecta dolis serit ore venena

Pestifero, caecum per vulnus ad intima mortem

Corda feram mittens, pistillio lilia praestat

Commacerare gravi sucosque haurire Falerno.

$\mathrm{Si}$ quod contusum est summo liventis in ore

Ponatur puncti, tum iam dinoscere vires

Magnificas huiusque datur medicaminis ultro.

\footnotetext{
199 vgl. Dioskurides (1902), S. 42

${ }^{200}$ vgl. hierzu Schneider (1968), S. 380-382

201 Disokurides (1902), S. 72

202 Dioskurides (1902), S. 72
} 
Haec etiam laxis prodest contusio membris.

Strabo (1978), S. 88

Alb. Mag.: $\quad$ Cap. $11-\S 371:$ [...] Est autem calidum et siccum, et radix eius est abstersiva desiccativa, et oleum eius est vehementius subtile et lenificativum, eo quod flos eius est subtilior sua radice [...] Radix etiam confert exustioni [...] Fit etiam ex radice eius decoctio ad dolorem dentium, et quando decoquitur radix eius cum oleo rosarum, non est ei aliquod par medicamentum ad dolores matricis. Aperit radix eius orificia haemorrhoidarum: et oleum eius confert contra morsum venorosum [...] et extrahit foetum de matrice. Albertus (1992), S. 530-531

H. v. Bing.: $\quad$ Phy: Cap. 1-23: Die Lilie ist mehr kalt als warm. (R1-064) Nimm daher den Kopf einer Lilienwurzel [...] Und wer dann die weiße Lepra [...] hat, den salbe oft damit [...] (R1-612) Aber die rote Lepra kann ähnlich geheilt werden. [...]. Hildegard (1991), S. 59

Es wird noch ein weiteres Rezept für die Lilie angegeben, das jedoch auf der Verwendung von Stängeln und Blättern basiert. Im Kompendium wird allerdings von der „liligern wurczel“ berichtet, weshalb dieses Rezept hier außen vor gelassen wird.

Lonitzer: $\quad$ Anderer Theil - Cap. 377: [...] Lilienblumen sind gemischter Natur/ die Wurtzel und Blätter zertheilen/ trocknen und säubern/ doch am meisten die Wurtzel. Das Oel von den weißen Lilie ist gar gut/ [...] erwärmet [...] die kalte Mutter/ und erweicht die Feuchtigkeit/ so darinnen verhartet ist [...] Die Wurtzel von den heimischen weissen Lilien/ [...] mit Reinberger Schmeer/ oder Baumöl vermischt/ und das auf die Geschwer gelegt/ erweicht dieselbige fast wol [...] Lilienwurtzel [...] mit Rosenöl gemischt/ ist gut fürn Brand am Leib [...]. Lonitzer (1962), S. 531

Referenzen: Bmd, PM, KW

Die Wurzeln und Blätter der Lilie scheinen eine unterschiedliche Kraft zu besitzen. Farfa berichtet uns nur von der Wurzel und außerdem nur von einer Anwendung „für heise wetagen“. Demnach scheint die Wurzel, nach der Auffassung des Kompilators, kalter Natur zu sein. Lonitzer gibt sowohl Anwendungen für kalte als auch warme Krankheiten an, wobei die kalte Natur der Pflanze deutlich häufiger Erwähnung findet. Einzig das weiße Lilienöl hat eine erwärmende Wirkung. Es ist leider nicht genauer aufgeführt, aus welchem Teil der Pflanze das Öl gewonnen wird. Allerdings liegt die Vermutung nahe, dass es sich, vergleichbar mit anderen Ölen, um die Blätter handelt. ${ }^{203}$

${ }^{203}$ vgl. Lonitzer (1962), S. 530-532 


\subsection{Lorbeeröl}

Farfa: $\quad$ „[...] Dicz o̊ley ist gut fur alle we die von chalden sachen chomen sinz Salbet man daz we do mit vnd lege henffin werg darauf ader vngewaschen wolle"

Harburg: „[...] das ist gut fur die kalten gicht und fur alle seuchen die von kalten dyngen komen wann es ist heyß in dem dritte grad"

Dioskurides: 1. Buch - Cap. 106: Lorbeer [...] Erwärmend und erweichend [...] bei Gebärmutter- und Blasenleiden [...] Die Früchte [...] wirken [...] gut bei Phthisis ${ }^{204}$ und Orthopnöe und Rheumatismus der Brust ${ }^{205}$. Mit Wein [...] gegen Skorpionenstich [...] beseitigen [...] die weisen Hautflecken. Der [...] Saft hilft bei Ohrenschmerzen und Schwerhörigkeit. Dioskurides (1902), S. 64

1. Buch - Cap. 49: Lorbeeröl [...] wird aus den Lorbeeren hergestellt, wenn sie überreif sind, indem sie mit Wasser gekocht werden [...] Es hat erwärmende, erweichende, anregende [...] Kraft [...] gutes Mittel bei allen Neuralgien, Ohrenleiden und katarrhalischen Zuständen ${ }^{206}[\ldots]$. Dioskurides (1902), S. 64

H. v. Bing.: Phy: Der Lorbeerbaum ist warm und etwas vom Trockenen, und er bezeichnet die Beständigkeit. Nimm (R3-080) [...] die Blätter des Lorbeers und zerstoße sie und drücke ihren Saft aus [...] und es wird deinen Magen von allem Unrat reinigen [...] (R3-082/083) Aber koche auch [...] die Blätter des Baumes in Wasser und wenn du Kopfweh hast, oder (Schmerzen) in der Brust [...] Seite [...] Rücken [...] Lenden, salbe dich dort damit [...] (R3-081) die Frucht [...] ist sehr warm und ziemlich trocken [...] wenn sie jemand roh genießt, unterdrückt sie alle Fieber. [...] (R3-085) Aber presse auch das Öl aus diesen Beeren, und wo in deinem Körper die Gicht dich plagt, salbe dich dort damit [...] (R3-087) Und wenn du Kopfweh hast, zerstoße die Beeren [...] (R3-089) Und wenn du Magenschmerzen hast, koche diese Beeren in Wein, und trinke diesen Wein warm [...] und er treibt sogar das Fieber aus inm aus. (R3-090) Aber wenn diese Beeren roh sind, presse das Öl aus innen heraus und wenn du damit deine Augen innen betupfst, nimmt es ihnen die Trübung. (R3-091) Wenn du auf dem Herz schmerzen hast, [...] oder wenn du auf der Seite oder im Rücken leidest, salbe dich dort damit [...] (R3-092) Wenn du sogar einen stinkenden Magen hast [...]

\footnotetext{
204 „Phthisis': „Schrumpfung, Schwund; alte Bezeichnung für die durch Tuberkulose herbeigeführte allgemeine Auszehrung." Pschyrembel (2010)

205 ,Rheumatismus der Brust': Eine Bedeutung, die auf entzündliche Prozesse der Gelenke im Brustbereich, zum Beispiel der Rippen oder des Sternums, anspielt, ist möglich. Der Rheumatismus wird bei Höfler aber auch mit der Erkältung gleichgesetzt. Eine dieser Alternativen kommt in Frage. Vgl. Höfler (1970), S. 506

${ }^{206}$,katarrhalische Zustände‘: „Schleimhautentzündung“. Höfler (1970), S. 260
} 
dann bereite mit diesem Öl und mäßig Mehl Törtchen und iß sie [...] Hildegard (1991), S. 251 Cap. 3-15

$\underline{\text { CC: }}$ Von der Unenthaltsamkeit [...] so stoße er Lorbeeren und doppelt soviel Diptam zu Pulver, und trinke dies [...] in [...] angewärmten Wein. Hildegard (1955), S. 286

CC: Vom Zorn. Wer aber dermaßen vom Zorn bewegt wird, daß er schmerzlich darunter leidet, nehme Lorbeeren [...]. Hildegard (1955), S. 294

Lonitzer: $\quad$ Erster Theil - Cap. 19: [...] Auß der Frucht deß Lorbeerbaums/ wird ein Oel gemacht/ [...] Loröl ist warm und hat die Krafft zu eröffnen. Dieses Oel ist gut für Wehthum der Brust/ und für alle Wehthum der Glieder/ so von Kälte kommen [...] Und ist nütz zu allen von kalter Feuchtigkeit entstandenen Gebrechen. Lonitzer (1962), S. 71

Frohne: $\quad$ Angewandter Pflanzenteil: Lorbeerblätter, Lorbeerfrüchte.

Inhaltsstoffe: Ätherisches Öl mit Monoterpenen (1,8-Cineol), Sesquiterpenlactone (Costunolid), Glyzeride (Laurin-, Ölsäure).

Wirkung: Äußerlich hyperämisierend.

Anwendung: Stomachikum ${ }^{207}$, Hautreizmittel zur Förderung der lokalen Durchblutung (Oleum Lauri expressum). Frohne (2002), 331-332

Referenzen: $\mathrm{Cl}, \mathrm{CG}, \mathrm{Bmd}, \mathrm{PM}$.

\subsection{Muskatellersalbeiöl}

Harburg: $\quad$ "[...] vnd ist gut den die an der quartan ${ }^{208}$ arbeuten vnd alle des hertzen tragheit und das understandn zweyfel an den sinnen [...]"

Walah. Str.: [...] stomachique moras ventremque salubri

Provocat auxilio radicis munere coctae.

Strabo (1978), S. 90

H. v. Bing.: Phy - Cap. 1- 161: Der Muskateller-Salbei ist warm, und (R1-455) er ist gut gegen Gift [...]. Hildegard (1991), S. 166-167

Schoenf: Drogen: Blühende Sprossspitzen.

Inhaltsstoffe: Ätherisches Öl mit Linalylacetat, Linalool, Sclareol.

Wirkung: Antispasmodisch, verdauungsfördernd, antibakteriell.

\footnotetext{
207 ,Stomachika': Oberbegriff für „Magenmittel“. Darunter fallen zum Beispiel Antazida oder Karminativa. Roche (2003)

208 "quartan': „Quartanfieber“ oder „Quartanie“ bezeichnet ein „sich alle vier Tage einstellendes Wechselfieber". Höfler (1970), S. 486. Galen ordnet seine Herkunft der schwarzen Galle und damit dem sie produzierenden Organ der Milz zu. Schöner (1964), S. 89
} 
Anwendung: Volksmedizin: Menstruationsstörungen, Mundspülungen,Verdauungsstörungen. Schoenfelder (2001), S. 288

\section{Heilanzeigen in der Übersicht:}

1. Viertagefieber (,Quartanie“)

2. Herzinsuffizienz (,des hertzen tragheit“)

3. Verwirrtheit („Zweifel an den Sinnen“)

\subsection{Mandelöl}

Farfa: $\quad$ "Sawer ader susse Mandelkern [...] Dicz oley ist gut vor daz we yn dem rucken vnd we der seiten vnd dem dye Nerwer we tun"

„Oley von den sawern Mandelkern [...] Dicz oley ist der we vnd in der seiten vnd vor rucke we der nerfen"

Dioskurides: 1. Buch - Cap.176: Die [...] Wurzel des bitteren Mandelbaumes vertreibt die Sommerflecken im Gesicht [...] Im Zäpfchen treiben sie die Menstruation, mit Essig oder Rosensalbe [...] helfen sie bei Kopfschmerzen, [...] mit Honig gegen [...] Geschwüre und [...] Hundsbiss. Genossen sind sie schmerzstillend [...] treiben den Harn und helfen [...] gegen Blutsturz, bei Nieren- und Lungenentzündung [...] Die süsse [...] Mandel ist aber, was die Wirkung betrifft, viel schwächer als die bittere [...]. Dioskurides (1902), S. 142

H. v. Bing.: Phy: Der Mandelbaum ist sehr warm und hat etwas Feuchtigkeit in sich [...] seine ganze Kraft in der Frucht steckt. (R3-058) Aber wer [...] Kopfweh hat, esse oft die inneren Kerne dieser Frucht [...] (R3-059) Aber wer lungenkrank ist und einen Schaden an der Leber hat, esse diese Kerne oft [...]. Hildegard (1991), S. 246 Cap. 3-10

Lonitzer: Erster Theil - Cap. 32: [...] Die Mandeln sind warmer Natur/ doch die bittere mehr [...] Das Oel aber/ so von den bittern Mandeln/ ist ein wenig und mässig warm. Seine Natur ist zertheilen und aufzulösen. Das Oel aber so von den bittern Mandeln wird außgetruckt/ öffnet mehr/ treibet den Harn und die Frauenzeit/ und zerbricht den Stein der Nieren und Blasen. Das süsse Mandelöl lindert die Rauhe Keele/ ist gut der Lungen/ den harten und truckenen Gliedern [...] ist gut der versehrten Blasen und Mutter [...] Bitter Mandelöl eröffnet die Verstopffung/ und zertheilt die Windigkeit und Dämpffe/ ist sonderlich gut zu den Taubsichtigen/ deßgleichen dem sausen [...] der Ohren/ macht die harten Gennadern lind [...]. Lonitzer (1962), S. 82-83

Frohne: $\quad$ Angewandter Teil: Mandeln (P. dulcis Mill.), Mandelöl (Kaltpressung der Samen, raffiniert) 
Inhaltsstoffe: Glyzerine der Öl-, Linolsäure

Anwendung: Dispersionsmittel für ölige Injektionen (P. dulcis), Amygdalin (Vit. $B_{17}$ ) aus dem Bittermandelöl (P. dulcis Mill. var. amara Webb.) ist Hauptkomponente eines umstrittenen Krebsmittels namens Laetrile. Frohne (2002), S. 453-454

Referenzen: CG (Bittermandel), PM (süß und bitter)

\section{Heilanzeigen in der Übersicht:}

1. Schmerzen in Rücken, a) Genossen sind sie schmerzstillend (Dio) Seite, Muskeln
b) wer Kopfweh hat (Hil)
c) den harten und truckenen Gliedern (Lon)

\subsection{Mastixöl}

Farfa: $\quad$ [...] Dicz oley ist gut fur alle siechtum dez magen vnd der ez in di orn tut den machet ez gehorn"

Dioskurides widmet dem Mastixbaum zwei Kapitel $(50,51)$ im ersten der fünf Arzneibücher. Da im Kapitel über das ,Mastixharzöl' die Indikationen zu finden sind, die auch in ähnlicher Weise im Farfensischen Kompendium geliefert werden, beschränkt sich die Exzerption auf diesen Abschnitt. ${ }^{209}$

Dioskurides: 1. Buch - Cap. 51: [...] Es ist wirksam gegen alle Gebärmutterleiden, mässig erwärmend, adstringirend, erweichend, wirksam gegen die den Magen überziehenden Verhärtungen, Bauchschmerzen und Dysenterieanfälle $^{210}[\ldots]$. Dioskorides (1902), S. 64-65

Schoenf.: $\quad$ Angewandter Teil: Mastix (Harz des Baumes). Inhaltsstoffe: Triterpene (Masticadienonsäure, Oleanolsäure, Tirucallol), Ätherisches Öl mit Monoterpenen (Pinen, Myrcen).

Anwendung: Keine medizinische Anwendung. Schoenfelder (2001), S. 312

Referenzen: CG, Bmd, PM, KW.

\footnotetext{
${ }^{209}$ vgl. Dioskurides (1902), S. 64-65

210 ,Dysenterie‘: „Ruhr“. Pschyrembel (2010)
} 


\section{Heilanzeigen in der Übersicht:}

1. Magenkrankheit

2. Taubheit a) wirksam gegen die den Magen überziehenden Verhärtungen, Bauchschmerzen und Dysenterieanfälle (Dio)

\subsection{Nardenöl}

Berendes erklärt in seinem Kommentar eingängig die Nomenklatur der Narde.

Kurzversion: 1. Indische Narde = Valeriana/ Patrinia Jatamansi Jones

2. Syrische Narde = Patrinia scabiosaefolia Fisch.

3. Keltische Narde $=$ Valeriana celtica L. ${ }^{211}$

Wie in der Edition bereits ausgeführt, ist im Harburger Kodex aller Wahrscheinlichkeit nach von Nardostachys jatamansi L. die Rede.

Harburg: $\quad$ „[...] Es hilfft fur alle seuchen die von kalter natur komen vnd hilfft zu der dewng"

Dioskurides: 1. Buch - Cap. 6: [...] Sie haben erwärmende, austrocknende, urintreibende Kraft, weshalb sie [...] den Stuhlgang und [...] die Ausflüsse aus der Gebärmutter stellen [...] helfen [...] gegen Übelkeit, Magenschmerzen, Blähungen, Leberleiden, Gelbsucht und Nierenleiden. In Wasser abgekocht [...] heilen sie die Gebärmutterentzündungen. Ferner wirken sie gegen die in den Augen abgesonderte, die Augenlider fäulende Flüssigkeit $^{212}$ [...]. Dioskurides (1902), S. 29

Lonitzer: $\quad$ Anderer Theil - Cap. 117: [...] Es wird ein edel köstlich Oel hiervon gemacht/ [...] welches Natur ist zu erwärmen/ zu zertheilen/ subtil zu machen. Ist gut zu allen kalten windichten Gebrechen des Hirns/ Magens/ Leber/ Miltzes/ Nieren/ Blasen/ und Beermutter [...]. Lonitzer (1962), S. 284-285

Frohne: $\quad$ Angewandter Teil: Nardenwurzel.

Inhaltsstoffe: Ätherisches Öl mit Valeranon, Jatamansin, Lomatin, Nardol, Sesquiterpene (Jatamol).

Wirkung: Diuretisch, karminativ, spasmolytisch, sedierend. Frohne (2002), S. 377

Referenzen: Cl, PM, KW.

${ }^{211}$ vgl. Dioskurides (1902), S. 29-32

${ }^{212}$ Höfler belegt das ,Fliessende Auge“ als „eitriger Bindehaut-Katarrh mit starker Sekretion“ sowie das ,Fluss-Auge“ als „Triefauge“ oder „Oculus lacrymans“. Höfler (1970), S. 20 


\section{Heilanzeigen in der Übersicht:}

1. Verdauungsförderung
a) weshalb sie [...] den Stuhlgang stellen (Dio)
b) helfen [...] gegen Übelkeit, Magenschmerzen, Blä- hungen (Dio)
c) Ist gut zu allen kalten windichten Gebrechen des Ma- gens (Lon)
d) karminativ, spasmolytisch (Fro)

\subsection{Poleiöl}

Das Harburger Kompendium gibt keine Indikationen für das Poleiöl an. Es heißt allerdings: „[...] Nÿm poley so er pluet [...]“. Dazu rät auch Lonitzer in seinem Kapitel über den Polei. ${ }^{213}$

Dioskurides: 3. Buch - Cap. 33 (36): Polei [...] ist eine bekannte Pflanze, welche [...] der Verdauung hilft. Getrunken befördert es die Menstruation, treibt die Nachgeburt und die Leibesfrucht aus [...] für sich allein hilft es bei Podagra [...]. Dioskurides (1902), S.284

Walah. Str.: [...]

Puleium quoque decoctum curabit, amice,

Et potu et fotu stomachum (mihi crede) morantem.

$[\ldots]$

Fas ususque sinit: ramum coniungito pulei

Auriculae, ne forte caput turbaverit aestus

Solis in aerio si te perflarit aperto.

[...]

Strabo (1978), S. 92

Alb. Mag.: $\quad$ Cap. $15-\S 422:$ [...] Et est calida et sicca, et pastus bonus ovium et attractiva. Per naturam suam est autem dissolutiva. Albertus (1992), S. 555

Lonitzer: $\quad$ Anderer Theil - Cap. 103: [...] Ist hitzig und trocken im dritten Grad [...]. Lonitzer (1962), S. 268-269

Lonitzer führt viele Heilanzeigen auf, die sich zu großen Teilen in der anderen Literatur (z. B. Dioskurides) wiederfinden. Ein Unterschied zum Kompendium, das, wie angemerkt, keine Heilanzeigen vorgibt, ist die Einordnung in das Qualitäten- und Grad-

${ }^{213}$ vgl. Lonitzer (1962), S. 268-269 
system der Humoralpathologie. „Das macht man vonn poley das ist heyß in dem vierden grad“, heißt es im Harburger Kapitel.

Schoenf.: $\quad$ Angewandter Pflanzenteil: Poleiminzenkraut.

Inhaltsstoffe: Ätherisches Öl mit Pulegon, Menthon, Piperiton, Flavonoide.

Anwendung: Keine medizinische Anwendung aufgrund zum Teil tödli cher Nebenwirkungen. Schoenfelder (2001), S. 254

Referenzen: Bmd, PM.

\subsection{Quittenöl}

Farfa: $\quad$ "[...] Dicz oley ist gut die flusse dez bauches czu verstellen di si den bauch mit salbet"

Dioskurides: 1. Buch - Cap. 160: Die Quittenäpfel sind dem Magen wohlbekömmlich, harntreibend, gebraten [...] milder, denen dienlich, die an Magen, Dysenterie, Blutspeien und Cholera leiden [...] der Aufguss davon ist denen [...] zu empfehlen, die Magen- und Bauchfluss haben [...] Dioskurides (1902), S. 135-136

Im 55. Kapitel des ersten Buches widmet sich Dioskurides der Zubereitung des Quittenöls. Allerdings stimmen weder seine Angaben zu den Ingredienzien mit denen des Harburger Kompediums überein, noch geben beide für das Öl ähnliche Indikationen an. $^{214}$

H. v. Bing.: Phy - Cap. 3-4: Der Quittenbaum ist mehr kalt [...] (R3-021) Denn wer gichtkrank ist, esse oft diese Frucht [...] (R3-022) Und wer viel Speichel auswirft, esse oft diese Frucht [...] (R3-023) Aber wo es an einem Menschen Geschwüre oder Übelriechendes hat, koche [...] diese Frucht [...]. Hildegard (1991), S. 239

Lonitzer: $\quad$ Erster Theil - Cap. 12: [...] Die Quitten seyn einer kalten und zusammenziehender Natur/ kalt im ersten/ und trocken im andern Grad [...] In Kranckheiten des Gedärms soll man keine Quitten geniesen/ dann sie stopffen. Auch seyn sie nit gut zu nützen in Kranckheiten deß Fiebers/ so man Stulgäng begehrt [...]. Lonitzer (1962), S. 61

\footnotetext{
${ }^{214}$ vgl. Dioskurides (1902), S. 67-68
} 
Die Indikationen Lonitzers bringen keine neuen Erkenntnisse, weshalb stattdessen Kontraindikationen aufgeführt werden, deren Vorkommen in den Rezepten der Kompendien eher Seltenheitswert besitzen.

Schoenf.: Drogen: Samen, Kerne.

Inhaltsstoffe: Schleimstoffe, Amygdalin, fettes Öl.

Anwendung: Antitussiv, mildes Laxans, Verbrennungen, Wundliegen, Hämorrhoiden, Entzündungen im Mund-, Rachenraum. Schoenfelder (2001), S.60

Referenzen: PM.

\section{Heilanzeigen in der Übersicht:}

1. Durchfall

a) denen dienlich, die an Magen, Dysenterie, Blutspeien und Cholera leiden [...] der Aufguss davon ist denen [...] zu empfehlen, die Magen- und Bauchfluss haben (Dio)

b) Und wer viel Speichel auswirft (Hil)

c) In Kranckheiten des Gedärms soll man keine Quitten geniesen/ dann sie stopffen. (Lon)

Lonitzer scheint hier den Vorteil der stopfenden Wirkung für die Durchfallkrankheit zu vergessen. Eine schlichte Ungenauigkeit im Ausdruck ist die andere Möglichkeit.

\subsection{Rautenöl}

Farfa: $\quad$ [...] Dicz oley ist gut der erhiczet ist an dem gesichte vnd an den steten dez leibes. ${ }^{215 ،}$

Harburg: „[...] es ist gut vnd heÿß in dem vierdn grad:,"

Dioskurides: 3. Buch - Cap. 45: [...] Beide sind brennend, erwärmend [...] harntreibend, die Menstruation befördernd [...] stellen [...] den Durchfall. Sie sind ein Gegenmittel gegen Gifte [...] Mit Oel gekocht [...] wirft es den Bandwurm hinaus [...] Roh [...] bewirkt es Schärfe des Gesichts ${ }^{216}[\ldots]$. Dioskurides (1902), S. 294

Dioskurides erwähnt in seinem Kapitel über die Raute drei Arten. Berendes weist der Berg- oder Gartenraute Ruta graveolens L. zu. Die wilde Raute ist inmzufolge Pega-

${ }^{215}$ Die Vorschrift gilt wohl am ehesten für die Verwendung beim atopischen Ekzem.

${ }^{216}$ Höfler (1970), S. 555-556 
num Harmala L.. Die kultivierte Raute ist eine Abart der Ruta graveolens L. Die oben angeführten Indikationen für die Raute gelten für die beiden erstgenannten Arten.

Walah. Str.: Dicitur occultis adprime obstare venenis (89) Toxicaque invasis incommoda pellere fibris. (90) Strabo (1978), S. 78

H. v. Bing.: Phy - Cap. 1-64: [...] sie hat gemischte Wärme in sich, aber doch mehr Wärme. Sie ist stark an Kräften in der Feuchtigkeit, (R1-177) und sie ist gut gegen die trockenen Bitterkeiten [...] (R1-178) Und wenn sie gegessen ist, unterdrückt sie die unrechte Hitze des Blutes [...] so wird es dem Menschen, der melancholisch ist, besser gehen [...] (R1-611) wenn jemand eine andere Speise gegessen hat, wovon es ihn schmerzt, esse er nachher Raute [...] (R-179) Auch ein Mensch, der triefende Augen ${ }^{217}$ hat, nehme Raute [...]. Hildegard (1991), S. 91-92

CC: [...] Wer schwarze oder verdunkelte Augen hat [...] nehme Rautensaft. Hildegard (1955), S. 257

CC: [...] Leidet ein Mensch [...] an Nieren- oder Lendenschmerz [...] Dann soll solch ein Mensch Raute [...] nehmen [...]. Hildegard (1955), S. 269

CC: Vom Leibschmerz [...] dann soll er [...] Raute [...] kochen [...]. Hildegard (1955), S. 269

Alb. Mag.: $\quad$ Cap. 16 - $\S$ 428: [...] Est autem calida et sicca et est incisiva resolutiva carminitiva mundificativa venarum ulcerativa et styptica, et delet morpheam cum nitro posito super eam. [...] Resolvit apostemata, et maxime gumma eius. Bibita confert paralysi et emplastrata. Ipsa etiam acuit visum [...] digerit etiam et facit appetitum cibi, et confortat stomachum, et confert spleni. Exsiccat sperma, et abscidit ipsum, et deiicit desiderium concubitus. Confert rigori febrium comestio eius, et inunctio olei eius. Resistit venenis. Er bibat, qui timet, ne in potu sumat venenum et pungi a venenosis, pondus unius unciae de semine eius cum foliis suis cum vino [...] Multum autem de ipsa sumere et maxime de silvestri est perniciosum. Plurima autem alia facit, diversis praeparationibus medicorum praeparata. Albertus (1992), S. 559-560

Lonitzer: $\quad$ Anderer Theil - Cap. 123: [...] Die heimisch Raut ist von Natur heiß und trucken im dritten Grad. Die Blätter und Saamen werden in der Artzney gebraucht [...] Darum soll man Rauten/ und das Oel darvon zu den Clystierungen ${ }^{218}$ brauchen/ wider das Grimmen und Cholicam [...] Rauten gesotten in Oel/ das warm in die Ohren gethan/ vertreibt derselbigen Würm [...]. Lonitzer (1962), S. 290-292

\footnotetext{
217 ,triefende Augen': „chronischer Bindehaut-Katarrh, Ophthalmica catarrhalis“. Höfler (1970), S. 23

${ }^{218}$, ,Clystierungen‘: Abgeleitet vom ,Klistier‘ = „Einlauf“.
} 
Frohne: $\quad$ Angewandter Teil: Rautenkraut (oberirdischer Pflanzenteil).

Inhaltsstoffe: Ätherisches Öl mit Ketonen, Flavonoide (Rutin), Hydroxycumarine (Umbelliferon), Furanocumarine (Psoralen), Pyranocumarine. Alkaloide vom Fluorchinolontyp (Dictamnin) und weitere Alkaloide.

Wirkung: Spasmolytisch, sedativ, antimikrobiell, entzündungserregend, emmenagog ${ }^{219}$, photosensibiliserend.

Anwendung: Wissenschaftlich nicht belegte volksmedizinische Anwendung. Von einer Selbstmedikation muss...dringend abgeraten werden. Frohne (2002), 485-487

Der enthaltene Wirkstoff Psoralen ist Bestandteil der sogenannten PUVA (Psoralen + UV-A-Strahlen), die zu dermatologischen Therapiezwecken genutzt wird. Hauptanwendungsgebiete sind dabei unter anderem die Behandlung der Psoriasis und Vitiligo. $^{220}$

Referenzen: Bmd, PM.

\section{Heilanzeigen in der Übersicht:}

1. Erhitzung des Gesichtes/ a) bewirkt es Schärfe des Gesichts (Dio) Leibes

b) Confert rigori febrium comestio eius, et inunctio olei eius. (Alb)

c) unterdrückt sie die unrechte Hitze des Blutes (Hil)

\subsection{Rosenöl}

Farfa: $\quad$ [...] Dicz oley ist gut fur erhiczunge vnd geswolne vnd heise siechtum“

Harburg: „[...] Das ol ist zumol gut fur alle hitz die dem menschen kumbt in der kranckheyt"

Dioskurides: 1. Buch - Cap. 53: Die Bereitung des Rosenöls [...] Einige pressen die Rosen für sich allein und behandeln sie dann an der Sonne mit dem Oel [...] indem sie es acht Tage hindurch umrühren und vierzig Tage bis zum dritten Auszuge an der Sonne stehen lassen [...] Es hat aber adstringierende Kraft [...] es mildert die Hitze des Magens, ist ein Nährmittel für hohle Geschwüre [...] mit Erfolg zu gebrauchen gegen Reize der Eingeweide und der Gebärmutter. Dioskurides (1902), S. $66-67$

219 ,Emenagoga': „Die Menstruation regulierende Pharmaka“. Zetkin und Schaldach (1999) S. 530

${ }^{220}$ Zu den Indikationen für die Therapie mit PUVA vgl. Moll (2005), S. 51-53 
Dioskurides Kapitel 53 beschreibt noch eine weitere, deutlich aufwändigere, Form der Rosenölherstellung. Die Herstellungsvorschrift der Kompendien kommt dem oben angeführten Rezept deutlich näher. ${ }^{221}$

Walah. Str.: [...]

Haec quia non Tyrio Germania tinguitur ostro, Lata nec ardenti se Gallia murice iactat, Lutea purpurei reparat crementa quotannis Ubertim floris, tantum qui protinus omnes Herbarum vicisse comas virtute et odore. Dicitur, ut merito florum flos esse feratur. Inficit hic oleum proprio de nomine dictum, Quod quam saepe fiat mortalibus utile curis, Nec meminisse potest hominum nec dicere quisquam. $[\ldots]$ Strabo (1978), S. 99

Strabo preist die Rose als die „Blume der Blumen“222. Heilanzeigen finden sich jedoch keine in seiner Strophe über die Rose.

H. v. Bing.: Phy: Die Rose ist kalt [...] (R1-059) [...] nimm ein Rosenblatt, lege es auf die Augen. Es zieht [...] das Trieffen, heraus und macht sie klar. (R1060) [...] wer etwas Geschwüre [...] hat, lege Rosenblätter darauf [...] (R1-061) Und wer jähzornig ist, der nehme Rose [...] (R1-062) Die Rose werde genommen [...] wo der Mensch vom Krampf oder von der Lähmung geplagt wird [...]. Hildegard (1991), S. 58-59

CC: [...] Leidet jemand am weißen Fleck des Auges ${ }^{223}$ [...] nehme er Bockshornklee, tauche inn in Rosenöl und lege ihn so auf die Augen [...]. Hildegard (1955), S. 258

$\underline{\text { CC: }}$ [...] Wenn ein Mensch [...] feurige Augen hat [...] nehme er [...] Rosensaft [...]. Hildegard (1955), S. 256

Die Erwähnung des Rosenöls fällt bei Albertus auffällig kurz aus. Das ist insofern bemerkenswert, als dass er keinen eigenen Abschnitt verfasst, obwohl Strabo noch, wie zuvor erwähnt, von der herausragenden Stellung der Pflanze spricht.

Lonitzer: $\quad$ Erster Theil - Cap. 63: [...] Alle [...] Rosen seynd kühlender stopffender Art [...] Man macht darauß [...] Oel [...] Rosenöl auf einen Brand gestrichen/ hilfft wol [...] Diß Oel ist gut über die hitzige Leber gestrichen. Auf

\footnotetext{
${ }^{221}$ vgl. Dioskurides (1902), S. 66-67

${ }^{222}$ Strabo (1978), S. 99

${ }^{223}$,weißen Fleck des Auges': „Glaukom“ Höfler (1970), S. 158
} 
den Schlaff gestrichen/ benimmt es das Hauptwehe [...] In der Speiß genützt/ benimmt es die Hitz deß Magens und Leber [...]. Lonitzer (1962), S. 113-115

Frohne: $\quad$ Angewandter Teil: Hagebuttenschalen, Hagebutten, Hagebuttenkerne, Rosenblütenblätter (von R. gallica L. und $R$. centifolia L.).

Inhaltsstoffe: Vitamin C, Sorbitol, Pektine, Carotinoide. Rosenöl: Citronellol, Geraniol, Nerol, 2-Phenylethanol.

Wirkung: Laxierend, diuretisch.

Anwendung: Teemischungen zum Abführen, Blasen- und Nierentees. Frohne (2002), S. 477-479

Schilcher: Wirkungen: antiphlogistisch

Indikationen: leichte Entzündungen im Bereich der Mund- und Rachenschleimhaut. Schilcher (2003), S. 201

Referenzen: $\mathrm{Cl}, \mathrm{Bmd}, \mathrm{PM}, \mathrm{KW}$.

Dem Rosenöl werden bakterizide und antiphlogistische Wirkung zugesprochen. Ein Grund für den geringen Einsatz der Substanz sind die Herstellungskosten des Öls. Für 1g Öl werden circa 3-4 kg Blütenblätter gebraucht. ${ }^{224}$

Auf die Zeit bezogen, aus der die untersuchten Kompendien stammen, belegt Dressendörfer den Preis für eine Unze (29,8 Gramm) Rosenöl gemäß einer Taxe aus dem Jahr 1453 mit 8 d (Denarius, Pfennig). ${ }^{225}$ Gemessen an den Lebensmittelpreisen im München des 15. Jahrhunderts entspricht dies einem Gegenwert von vierzig Hühnereiern. ${ }^{226}$

\section{Heilanzeigen in der Übersicht:}

1. Erhitzungen

2. Geschwulst a) Alle Heilanzeigen gegen heiße Leiden zählen dazu. Darum ist es nicht nötig, diese genauer zu beurteilen.

a) Ist ein Nährmittel für hohle Geschwüre (Dio).

b) Wer etwas Geschwüre [...] hat, lege Rosenblätter darauf (Hil).

\footnotetext{
${ }^{224}$ vgl. Schoenfelder (2001), S. 208

${ }^{225}$ Dressendörfer (1978), S. 146

${ }^{226}$ Dressendörfer (1978), S. 120
} 


\subsection{Seerosenöl}

Harburg: „[...] das hilfft fur aller hand seuchen die von hitz kommen"

Dioskurides: 3. Buch - Cap 138 (148): [...] Trocken dann mit Wein getrunken hilft sie bei Magenschmerz, Dysenterie und verkleinert die Milz [...] die Fuchskrankheit ${ }^{227}$ heilt sie mit Pech aufgelegt [...]. Dioskurides (1902), S. $349-350$

Hil. v. Bing.: Phy - Cap. 1 - 215: Die weiße Seerose ist kalt [...] und (R1-569) sie ist wie ein unnützes Kraut [...]. Hildegard (1991), S. 204

Lonitzer: $\quad$ Anderer Theil - Cap. 224: [...] Ist kalter und feuchter Natur im andern Grad [...] Seeblumen machen schlaffen/ legen alle unnatürliche Hitz deß Haupts/ der Leber/ Magens und Hertzens [...] Nimm Seeblumen/ Violöl/ unzeitig Baumöl/ jedes gleichviel/ und eine wenig Granatäpffelwein [...] bestreich die hitzige Cholerische Apostemen [...] damit/ es vertreibts [...]. Lonitzer (1962), S. 393-394

Referenzen: Bmd, PM, KW.

Interessanterweise sprechen alle Autoren der Seerose eine nicht unerhebliche Heilwirkung zu. Nur Hildegard von Bingen fällt mit ihrer Beurteilung der Arznei gänzlich aus dem Rahmen. Ihrer Erfahrung nach würde sie weder nützen noch schaden. ${ }^{228}$ Wie die Äbtissin zu dieser Meinung kommt, führt sie leider nicht weiter aus.

Bei der Recherche nach der Seerose in den herangezogenen aktuellen Heilpflanzenführern, ist keine Nutzung der Pflanze erwähnt. Eine Tatsache, die den Vermutungen Hildegards eine gewisse Nachhaltigkeit verleiht.

\subsection{Skorpionöl}

In seiner Beschreibung der einzelnen Wirkungsprinzipien der Arzneimittel äußert sich Galen auch zu den Antidoten. Er nennt sie ,Alexetheria' oder ,Alexipharmaca'. Seiner Beschreibung nach besteht ihre Wirksamkeit sowohl gegen das Gift von Tieren als auch gegen sonstige, nicht näher erläuterte, Gifte. Galen benennt das Prinzip ihrer Wirkung mit den Worten „ex contrario“. Man setzt sie folglich gegenteilig ihrer eige-

${ }^{227}$,Fuchskrankheit': Möglich, dass die ,Fuchssucht' damit gemeint ist. Eine Form des Haarausfalls verursacht durch die Krätzmilbe (Sarcoptes scabies var. vulpis). Vgl. Höfler (1970), 704

${ }^{228}$ vgl. Hildegard (1991), S. 204 
nen Natur ein. Für das Skorpionöl, dem Hildegard eine warme Natur zuordnet, bedeutet dies eine vorzugsweise Anwendung gegen kalte Gifte.

Farfa: $\quad$ "[...] Dicz oley ist gut fur alle giftige bise sam spinnen vnd scorpione“

Dioskurides: 2. Buch - Cap. 13: Landskorpion. Der rohe, fein zerriebene Landskorpion aufgelegt ist ein Heilmittel gegen seinen eigenen Stich [...]. Dioskurides (1902), S. 156

H. v. Bing.: Phy - Cap. 8 - 13: Der Skorpion hat glühende Wärme und Hitze in sich [...] (R8-017) Und (im Skorpion) sind keine Heilmittel [...]. Hildegard (1991), S. 511

Lonitzer: $\quad$ Dritter Theil - Cap. 66: [...] Gläser mit bitter Mandelöle/ darinnen Scorpion gestorben und noch ligen/ solches Oehl ist ein gewisse Artzney für alles Gifft/ auch für die Pestilenz und gifftige Trüsen. Für Lenden- und Blasenstein und schweres Harnen/ ist solches Oehle eine gewisse Artzney [...]. Lonitzer (1962), S. 627

Referenzen: PM.

Heilanzeigen in der Übersicht:

1. Antidot

a) ein Heilmittel gegen seinen eigenen Stich (Dio)

b) solches Oehl ist ein gewisse Artzney für alles Gifft (Lon)

\subsection{Speiköl}

Zur Nomenklatur des Speiks sind einige Vorbemerkungen zu machen. Es wird ein römischer Speik („Valeriana celtica“ L.) vom deutschen Speik („Lavandula spica“ L.) unterschieden. Lonitzer gibt ebenfalls die italienische Version des Namens wieder, was im Bezug auf den ,Codex Farfensis' durchaus hilfreich ist. Aus diesen Angaben wird ersichtlich, dass „Lavandula spica“ im Italienischen den Namen „spigo“ trägt. 229 Demnach ist bei Farfa der deutsche Speik gemeint, den Lonitzer in seinem Kapitel nochmals gegen die kleinere Art des ,Lavendels‘ abgrenzt. ${ }^{230}$ Die Bezeichnungen „römisch“ und „deutsch“ dürfen in diesem Fall nicht zu wörtlich genommen werden.

\footnotetext{
${ }^{229}$ Lonitzer (1962), S. 285

230 Lonitzer (1962), S. 285
} 
So merkt Lonitzer bei der Herkunft des römischen Speik an: „Wächst in India auf den Bergen / und um den Fluß Ganges“"231. Allein die Tatsache, dass es ein italienisches Korrelat für den deutschen Speik gibt, ist ein deutlicher Hinweis auf sein Vorkommen in dieser Region.

Farfa: $\quad$ [...] Dicz oley ist gut fur siechtum das chalt ist"

H. v. Bing.: Phy - Cap. 1-25: Der wilde Lavendel ist warm und trocken, und seine Wärme ist gesund. (R1-070/071) Und wer Lavendel in Wein kocht oder [...] mit Honig und Wasser kocht und so lau oft trinkt, der mildert den Schmerz in der Leber und in der Lunge und die Dämpfigkeit in seiner Brust, und er bereitet (sich) reines Wissen und einen reinen Verstand. Hildegard (1991), S. 61

Lonitzer: $\quad$ Anderer Theil - Cap. 118: [...] Die Blumen in Wein gesotten [...] treibt den Harn fürdert die [...] Nachgeburt/ stillet das Magenwehe [...] Hat auch viel andere Tugend/ für alle Gebresten deß Hirns/ so von Kälte kommen [...]. Lonitzer (1962), S. 285-286

\subsection{Veilchenöl}

Farfa: $\quad$ "[...] Dicz oley ist gut czu salben die tobelichen fieber vnd fur alle vergicht di heis ist"

Dioskurides: 4. Buch - Cap. 120 (122): Veilchen [...] hat eine kühlende Kraft. Seine Blätter [...] helfen bei Erhitzung des Magens, bei Augenentzündung und Mastdarmvorfall. Es heisst, dass der purpurne Theil der Blüthe [...] bei Schlundmuskelentzündung und Epilepsie der Kinder helfe. Dioskurides (1902), S. 432-433

Berendes lässt keinen Zweifel aufkommen, dass es sich, genau wie im Farfensischen Kompendium, bei der Beschreibung der Arznei um Viola odorata L. handelt. ${ }^{232}$

H. v. Bing.: Phy - Cap. 1-103: (A1) Das Veilchen ist zwischen warm und kalt [...] Es ist gut gegen die Verdunkelung der Augen. Nimm daher gutes Öl und bring es [...] zum Sieden, und [...] wirf Veilchen hinein [...] (R1-288) Und wenn jemand durch Melancholie und Verdruß im Sinn beschwert wird und so die Lunge schädigt, der koche Veilchen in reinem Wein [...] (R1-289) Und ein Mensch, der feurige Augen hat [...] der nehme Veilchensaft [...] (R1-290) Auch ein Mensch, der Schwere im Kopf hat oder in den Nieren, oder irgendwo von Lähmungen geplagt wird, der presse Veilchensaft durch ein Tuch [...] (R1-291) [...] wenn er irgendwelche

\footnotetext{
${ }^{231}$ Lonitzer (1962), S. 284

232 vgl. Dioskurides (1902), S. 433
} 
Geschwüre in seinem Körper hat [...] (R1-292) Und wer an dreitägigem Fieber leidet [...]. Hildegard (1991), S. 120

An dieser Stelle wurde die Zubereitung mit Öl zusätzlich angeführt, um einen Vergleich mit dem Kompendium zu ziehen. Zudem ist es bisher das einzige Rezept, in dem Hildegard eine Arznei in Öl zubereiten lässt. Ansonsten werden vornehmlich Pulver und Salben in den Rezepten beschrieben. Interessant ist die folgende Einordnung Lonitzers, der das Veilchen in der Häufigkeit seiner Verwendung gleich hinter der Rose nennt.

Lonitzer: $\quad$ Anderer Theil - Cap. 226: [...] Violen seyn kalt im ersten Grad/ und feucht im andern [...] Ist auch sonderlich gut/ Pflasterweiß aufs Podagra gelegt [...] Violöl ist zu vielen Sachen gut/ sonderlich in die Ohren gelassen/ hilfft es für allerley derselbigen Gebrechen. Benimmt auch das Hauptweh [...] Mit dem Oel den Bauch bestrichen/ vertreibt es den Spulwurm [...] Diese Blum/ ist nach der Rosen/ die allergebräuchlichste unter allen Blumen/ in der Artzney und Apotecken. Lonitzer (1962), S. 395-396

Frohne: $\quad$ Angewandter Teil: Veilchenwurzel (der Viola odorata L.) Inhaltsstoffe: Saponine, Salicylsäuremethylester.

Wirkung und Anwendung: Sekretolytikum (nicht wissenschaftlich belegt) mit Verwendung bei Bronchitis. Frohne (2002), S. 568-569

Referenzen: Cl, CG, Bmd, PM, KW.

\section{Heilanzeigen in der Übersicht:}
1. Tobeliches Fieber
a) Epilepsie (Dio)
b) dreitägigem Fieber (Hil)
2. Gicht
a) aufs Podagra gelegt (Lon)

\subsection{Wacholderbeeröl}

Farfa: $\quad$ [...] Dicz oley ist gut fur daz we in der seiten vnd fur daz vergicht der sich mit salbt."

Dioskurides: 1. Buch - Cap. 103: [...] Ihre Frucht [...] ist mäßig erwärmend und zusammenziehend, dem Magen wohlbekömmlich. Getrunken wirkt sie bei Brustleiden, Husten, Blähungen, Leibschneiden ${ }^{233}$ und gegen den Biss

\footnotetext{
${ }^{233}$ siehe Fußnote 183
} 
wilder Thiere. Sie ist [...] urintreibend daher dient sie [...] bei Krämpfen, inneren Zerreissungen und bei Mutterkrämpfen. Dioskurides (1902), S. 97

H. v. Bing.: Phy - Cap. 3-43: Der Wacholder ist mehr warm als kalt [...] (R3-180) Nimm daher von der Frucht [...] und es [...] mindert den Schmerz in der Brust oder in der Lunge und Leber [...]. Hildegard (1991), S. 275

CC: Vom Lungenschmerz [...] Nimm Wacholderbeeren [...] koche dies in reinem, gutem Wein [...]. Hildegard (1955), S. 263

Lonitzer: $\quad$ Erster Theil - Cap. 25: [...] Der Baum ist warm und trucken im dritten Grad/ die Frucht aber im ersten Grad [...] Wecholderbeer befördern den Harn [...] sind gut für den Husten/ Blähen und Grimmen/ stärcken das Geäder/ setzen und lindern alle Geschwulst [...] Wecholderholtz Oel [...] ist gut für das Gegicht im Leib [...] Wecholderbeer-Oel [...] hat alle Krafft und Tugenden/ so in diesem Capitel von der Frucht gemeldet worden/ ist doch viel kräfftiger und lieblicher zugebrauchen [...]. Lonitzer (1962), S. $75-76$

Frohne: $\quad$ Angewandter Teil: Wacholderbeeren, Wacholderholz

Inhaltsstoffe: Beeren: Ätherisches Öl mit Terpenen (Pinen, Terpinen). Wacholderöl: Catechingerbstoffe, Flavonoide, Biflavone, Inulin.

Wacholderholzöl: Sesquiterpene, Catechingerbstoffe, Lignane.

Wirkung: Diuretisch (Beeren), Vermehrte Perfundierung des Nierenparenchyms (Wacholderöl).

Anwendung: Dyspepsie, Diuretikum, Karminativum, Rheuma-Bad (Wacholderholzöl). Frohne (2002), S. 322-324

Referenzen: PM, KW.

Heilanzeigen in der Übersicht:

1. Seitenschmerz

2. Gicht

a) Leibschneiden kann man als Oberbegriff eines abdominellen Schmerzes begreifen (Dio)

b) nimmt den Schmerz in der Leber (Hil) - Seitenschmerz ist unspezifisch, darum ist auch Leberschmerz möglich

a) Wecholderholtz Oel [...] ist gut für das Gegicht im Leib (Lon)

Ausführlichst beschäftigt sich Kurschat-Fellinger mit dem Wacholder und seinem Vorkommen in diversen Arzneimittelvorschriften. Zur Einholung weiterer Indikationen und Herstellungsverfahren sei an dieser Stelle auf die Dissertation ,Kranewitt‘ ver- 
wiesen. ${ }^{234}$ Gerade das Kapitel über das Wacholderbeeröl ist insbesondere zu empfehlen, da es thematisch den stärksten Bezug zu dem Kompendium aufweist. ${ }^{235}$ Darüber hinaus ist in der Festschrift für Willem Daems ein Kapitel über einen ,Jeneverbestraktaat' abgedruckt. ${ }^{236}$

\footnotetext{
${ }^{234}$ Kurschat-Fellinger (1983)

${ }^{235}$ Kurschat-Fellinger (1983), S. 119-121, 200-204

${ }^{236}$ Boot (1982), S. 533-542
} 


\section{Ermittlung von Arzneimittelpreisen}

Wer die Öle, die in den Kompendien durch Herstellungsvorschriften erwähnt werden, nicht selber produzieren wollte, konnte diese käuflich auf Messen erwerben. Es bietet sich an, den Blick auf den Preis solcher Öle zu richten, um gemessen an einem durchschnittlichen Gehalt eines Kaufmanns oder Handwerkers die Verfügbarkeit einer derartigen Arznei zu jener Zeit abschätzen zu können. Zwecks einer solchen Betrachtung wird an dieser Stelle die Dissertation Werner Dressendörfers herangezogen. In ihr werden Arzneitaxen aus der Mitte des 15. Jahrhunderts untersucht. Dieser Zeitraum stimmt idealerweise grob mit den Verfassungsdaten der untersuchten Kompendien überein. Es ist anzunehmen, dass die Taxen regionsspezifischen Schwankungen unterlagen. Für den süddeutschen Raum besitzen sie allerdings eine ausreichende Gültigkeit; da mit Memmingen und Harburg bereits zwei Kompendien in dieser Region verfasst wurden, dienen die Preise als gute Orientierungshilfe.

Dressendörfer ediert insgesamt vier Listen mit Arzneitaxen, die im achten Kapitel seiner Dissertation zu finden sind. Die umfangreichste Liste stammt aus dem ,Grazer Codex 311'. Benannt ist sie als Taxe ,JH 1453' nach Johann Hartlieb, dessen Anteil an der Fertigstellung dieser Taxe nicht endgültig geklärt ist. ${ }^{237}$ Klar ist nur, dass das sogenannte ,Kräuterbuch“ Hartliebs auf Konrad von Megenberg zurückgeht. ${ }^{238} \mathrm{lhr}$ kommt im Rahmen dieser Untersuchung besondere Bedeutung zu. Es ist dort einmalig von Preisen die Rede, die für bereits hergestellte Öle gelten. Es sind 27, wovon 19 mit den Ölen aus den Ölbüchern übereinstimmen. Lediglich sechs Öle sind in der Taxe ,JH 1453، nicht belegt (Muskateller-Salbeiöl, Katzenöl, Lavendelöl, Poleiöl, Holunderöl und das Benediktenöl). Diese Kongruenz könnte ein Indiz dafür sein, dass die erwähnten Öle zu jener Zeit einen regen Gebrauch erfuhren oder zumindest einen hohen Bekanntheitsgrad besaßen. Alle Öle werden mit Preisen aufgelistet und sollen hier exemplarisch erwähnt werden. Sie stehen in der Reihenfolge, in der sie in der Edition Dressendörfers zu finden sind. Ihr Preis (in d = „Denarius, Pfennig“ ange-

\footnotetext{
${ }^{237}$ vgl. Dressendörfer (1978), S. 64-67

${ }^{238}$ vgl. Dressendörfer (1978), S. 172
} 
geben) bezieht sich immer auf das Gewicht einer Unze (entspricht nach dem Nürnberger Apothekergewicht 29,8 Gramm $^{239}$ ):

Olivenöl

Skorpionöl

Süßmandelöl

Bittermandelöl

Rosenöl

Veilchenöl

Lilienöl

Dillöl

Kamillenöl

Nardenöl

Mastixöl

Rautenöl

Bibergeilöl

Costusöl

Seerosenöl

Fuchsöl

Lorbeeröl

Wacholderöl

Bilsenöl
$6 d$

$16 d$

$6 d$

$8 d$

$8 d$

$8 d$

$8 d$

$6 d$

$6 \mathrm{~d}$

$8 d$

$8 d$

$6 d$

$8 d$

$6 d$

$6 d$

$8 d$

$6 d$

$56 \mathrm{~d}$

$6 d^{240}$

Auch wenn die Zubereitung der Öle nicht exakt dieselbe ist, wie man sie in den Kompendien findet, sind die Preise trotzdem ein gutes Richtmaß, um wenigstens eine grobe Vorstellung davon zu erlangen, was es einen Bürger des 15. Jahrhunderts kostete, wenn er die Anwendung der Arznei für sich vorgesehen hatte.

Zusammenfassend lässt sich bei der Betrachtung der Preise feststellen, dass alle Öle, bis auf das ,Skorpionöl' (16 Pfennige) und das ,Wacholderöl' (56 Pfennige), für sechs oder acht Pfennige pro Unze zu erwerben waren. ${ }^{241}$ Zum Vergleich: Der

\footnotetext{
${ }^{239} \mathrm{vgl}$. Schneider (1962), S. 91

${ }^{240}$ Dressendörfer (1978), S. 146-147

${ }^{241} \mathrm{vgl}$. Dressendörfer (1978), S. 146-147
} 
durchschnittliche Tageslohn eines Zimmermanns im München von 1489 beträgt am Tag 18 Pfennige. Die verwendeten Daten liefert idealerweise ebenfalls Dressendörfer in seiner Arbeit. Der Betrag bezieht sich auf einen Sommerlohn inklusive Verpflegung. ${ }^{242}$ Orientiert man sich erneut an dem Durchschnittspreis von acht Pfennigen für eine Unze der untersuchten Öle, wird deutlich, dass der Erwerb der Arzneiöle kaum für jedermann erschwinglich gewesen sein kann. Um diesem Aspekt einen weiteren reellen Bezug zu verschaffen, sei an dieser Stelle noch ein Gegenwert in Form von Lebensmitteln genannt. 1460 waren in München für acht Pfennige immerhin vier bis fünf Pfund Rindfleisch zu erstehen. ${ }^{243}$

Fallen im Glossar Namen, nach deren Zubereitungsvorschrift die Öle hergestellt werden sollen, so sind diese Mesue und Nicolai (entsprechend ihren Antidotarien). ${ }^{244}$ Von besonderem Interesse sind bei dieser Untersuchung natürlich die ausgefallenen Balsame am Ende des ,Farfensischen Ölbuchs', deren Herkunft sich schwer nachweisen lässt ${ }^{245}$. Ihre komplexe Zusammensetzung, die zur genaueren Bestimmbarkeit eines Preises idealerweise auch Gewichtsangaben enthält, lässt bereits im Vorhinein erahnen, dass es sich um einen hohen finanziellen Aufwand gehandelt haben muss, wenn man die Ingredienzien ausschließlich käuflich erwerben wollte.

Als Beispiel sei an dieser Stelle das ,Judenöl' genannt. Es besteht aus circa 24 Ingredienzien, wovon die Taxe ,JH 1453، vierzehn mit Preisen belegt. Da bei einigen wenigen Arzneien nicht der Unzenpreis genannt wird, musste eine Umrechnung nach den Angaben des Nürnberger Apothekergesetzes erfolgen. Dieses wurde freilich erst 1555 erlassen. Von einer engen Orientierung an bisher gültigen Gewichtsangaben ist jedoch auszugehen.

Die vierzehn Zutaten sind grob gerechnet für 169 Pfennige zu bekommen. Bezieht man nun die restlichen zehn Bestandteile des Balsams mit einem Durchschnittspreis (169/14) der bekannten Preise mit ein, ergibt sich ein Gesamtpreis von circa 290 Pfennigen. Setzt man diesen überschlagenen Preis ins Verhältnis zu den anderen

\footnotetext{
${ }^{242}$ vgl. Dressendörfer (1978), S. 121

${ }^{243}$ Dressendörfer (1978), S. 120

${ }^{244}$ vgl. Dressendörfer (1978), S. 169-315

${ }^{245}$ Kap. (19) - (22)
} 
genannten Ölen, die mit einem Durchschnittspreis von sieben Pfennigen zu kaufen sind, so wird verständlich, warum der Kompilator Anmerkungen wie „So halt es schone sam einen schacz" in die Rezepte einbringt.

Allerdings wird dem Kompositum dafür auch eine deutlich breitere Wirkung zugesprochen („Dicz oley ist gut fur alle siechtum“). Ihren panazeeischen Charakter spricht man dem Öl vermutlich am ehesten zu, weil man die Vorstellung besaß, ein Öl würde die Kraft aller Einzelarzneien, die für seine Herstellung verwendet werden, in sich vereinen. An Wechselwirkungen, die die Wirksamkeit zu Ungunsten des Heilmittels verändern könnten, wurde bei solchen Rezepten möglicherweise weniger gedacht. 


\section{Zusammenfassung}

Bei der Edition der Handschriften aus dem 15. Jahrhundert sind viele bekannte Muster vorheriger Schriften wiederzuerkennen. Das ,Harburger Ölbuch` unterteilt die aufgeführten Arzneiöle nach kalter und warmer Natur. Im ,Memminger Kodex، widmet der Kompilator dem bereits ausführlich durch geistige Vorgänger beschriebenen ,Benediktenöl' das ganze Kapitel. Einzig der ,Codex Farfensis‘ lässt Ansätze einer unabhängigen Textwiedergabe erkennen. Es gibt keine erkennbare oder wiederkehrende Form bei der Auflistung der Arzneien. Ebenso wird nicht die sonst oft gewählte Struktur ,a capite ad calcem‘ gewählt.

Inhaltlich bietet ebenfalls das, Ölbuch‘ aus dem latinischen Benediktinerkloster die meiste Eigenständigkeit. Trotzdem weisen die Untersuchungen durch Eis und Zimmermann darauf hin, dass der Schreiber des Kodex hauptsächlich Abschriften von bekannten Traktaten anfertigte. Besonders das Komposita-Kapitel im ,Ölbuch“ bietet jedoch Arzneiformen auf, die so in den Werken wichtiger Vorgänger auf diesem Gebiet nicht zu finden sind („Oley Balsamino ader gebalsamet oley der Juden“, „Balsamo der morn“, „Balsamo der fein vnd gut ist“).

Betrachtet man den Vergleich der Arzneien seit der griechischen Antike über das Mittelalter bis in die Neuzeit und die moderne Pharmazie, wird schnell deutlich, dass sich die wenigsten Indikationen in unsere Zeit übertragen lassen. Es gibt durchaus einige Überschneidungen in der Verwendung mancher Arzneien aus Sicht der Phytotherapie oder der Volksmedizin. Die Auswertung der exzerpierten Literatur zeigt beispielsweise, dass die Wirkung der Kamille gegen Abszesse bereits Albertus Magnus bekannt war und etwa 750 Jahre später unter der gleichen Indikation im Heilpflanzenatlas Frohnes zu finden ist.

Auch das Gegenteil ist indes der Fall: In aktuellen Pflanzenführern heißt es, dass die Arzneidrogen aufgrund verschiedenster, zum Teil schwerer, Nebenwirkungen völlig aus der Therapie verschwunden seien. Diese Warnungen stellen ein negatives Zeugnis über die empirische Verwendung der Arzneien durch Gelehrte wie Dioskurides aus. Ein Beispiel stellt die Abkehr von der Verwendung des Poleis dar. Dioskuri- 
des empfiehlt inn zur Verdauung und bei Menstruationsbeschwerden. Schoenfelder verbietet die Verwendung von Polei in der Medizin, aufgrund zum Teil tödlicher Nebenwirkungen.

Sucht man nach Übereinstimmungen bei den Wirkstoffen der modernen Pharmazie und denen, die mit heutigen technischen Möglichkeiten in den damals wie heute genutzten Pflanzen nachgewiesen sind, ist die Summe der Kongruenz äußerst gering. Zwei Gegenbeispiele bilden das Scopolamin aus dem Bilsenkraut und das Psoralen aus der Raute. Scopolamin wird als zentral wirksames Parasympatholytikum in der Therapie der Reisekrankheit verwendet. Das Psoralen verstärkt den heilenden Effekt der UV-A-Strahlen bei der Therapie (PUVA) der Psoriasis und Vitiligo.

Begibt man sich auf die Suche nach Gründen für die Divergenzen, wird schnell klar, dass es in erster Linie die unterschiedlichen Vorstellungen von Krankheit und Therapie sind, die einen solchen Vergleich scheitern lassen. Die humoralpathologischen Ansätze Hippokrates' (ca. 460-370 v.Chr.) und Galens prägten die Medizin schließlich bis zum Beginn der Neuzeit. Erst mit der voranschreitenden Bedeutsamkeit der Chemie für die Weiterentwicklung der Medizin verändert sich der Forschungsansatz für das Gewinnen neuer Arzneimittel. Die iatrochemische Lehre Paracelsus' (14931541) beruht auf dem Denkspruch: „Aufgabe der Chemie ist es, Heilmittel für Krankheiten darzustellen, denn der Lebensprozess ist hauptsächlich ein chemischer." ${ }^{246}$ Eben dieser Paracelsus vollzieht eine klare gedankliche Trennung zur Medizin seiner Vorgänger. Durch die Verbrennung des ,Kanons', einer Schrift, dessen Verfasser Avicenna oder Mesuë - noch nicht abschließend geklärt ist, wendet er sich demonstrativ von der Lehre seiner geistigen Vorgänger ab. ${ }^{247}$ Was Paracelsus in dieser Zeit begründet, lässt sich heute in den hochtechnologisierten Laboratorien der Pharmaziekonzerne weiter verfolgen.

Abschließend ist festzuhalten, dass mit den fortschreitenden Möglichkeiten, die die moderne Chemie bietet, der hauptsächlich auf Empirie und volkstümlicher Überlieferungen basierte Gebrauch von Heilpflanzen einen immer geringer werdenden Stellenwert im Bereich der angewandten Medizin einnimmt. Untermauern lässt sich diese

${ }^{246}$ Tschirch (1933), S. 1673

${ }^{247}$ vgl. Tschirch (1933), S. 1673 
Feststellung vor allem durch die geringe Anzahl an Indikationen, die für die Heilpflanzen aus den Kompendien in heutigen Heilpflanzenführern nachzuweisen sind. 


\section{Literaturverzeichnis}

Albertus (1992)

Albertus Magnus: De vegetabilibus Buch VI, Traktat 2. Herausgegeben von Schmitz R und Krafft F (Quellen und Studien zur Geschichte der Pharmazie) in der Übersetzung von Biewer K; Wissenschaftliche Verlagsgesellschaft mbH, Stuttgart 1992

Battisti und Alessio (1952)

Battisti C, Alessio G: Dizionario etimologico italiano, Bd 3; G. Barbèra, Firenze 1952

Bazzi (1982)

Bazzi F: Ein unveröffentlichtes Herbar aus dem 15. Jahrhundert - Präsentation und Kommentar; in: Medizin im mittelalterlichen Abendland; hrsg. von Baader G, Keil G; Wissenschaftliche Buchgesellschaft, Darmstadt 1982

Becela-Deller (1998)

Becela-Deller C: Ruta graveolens L. - Eine Heilpflanze in kunst- und kulturhistorischer Bedeutung; Herausgegeben von Keil G; unter Mitwirkung von Domes J, Holler M, Kahle E, Proff P, Weißer C; (WmhF Bd 65); Königshausen \& Neumann, Med. Diss. Würzburg 1998

Berendes (1965)

Berendes J: Die Pharmazie bei den alten Kulturvölkern: Historisch-kritische Studien. Bd 1-2. Georg Olms Verlagsbuchhandlung Hildesheim 1965. Reprografischer Nachdruck der Ausgabe Halle 1891

Boot (1982)

Boot C: Jeneverbestraktaat tot recept, in Festschrift zum 70. Geburtstag von Willem F. Daems; herausgegeben von Keil G; unter Mitwirkung von Holler M, Kahle E, Proff P; (WmhF Bd 24); Horst Wellm Verlag, Pattensen/ Han. 1982, S. 533-542; 
Braekman und Keil (1971)

Braekman W, Keil G: Fünf mittelniederländische Übersetzungen des 'Antidotarium Nicolai' - Untersuchungen zum pharmazeutischen Fachschrifttum der mittelalterlichen Niederlande. Sudhoffs Archiv - Zeitschrift für Wissenschaftsgeschichte Band 55, Franz Steiner Verlag GmbH 1971, Seite 258-319;

Bulle und Rigutini (1912)

Bulle O, Rigutini G: Neues italienisch-deutsches und deutsch-italienisches Wörterbuch = Nuovo dizionario italiano-tedesco e tedesco-italiano, 5. Stereotypausgabe;Bd 1; Bernhard Tauchnitz, Leipzig 1912

Bunsmann-Hopf (2003)

Bunsmann-Hopf S: Zur Sprache in Kochbüchern des späten Mittelalters und der frühen Neuzeit - ein fachkundliches Wörterbuch; herausgegeben von Keil G; unter Mitwirkung von Domes J, Groß D, Kahle E, Proff P, Weißer C; (WmhF Bd 80); Königshausen \& Neumann, Med. Diss. Würzburg 2003

Crone (2002)

Crone C: Die "Würzburger Wundarznei" - Ein chirurgisches ArzneimittelHandbuch des Spätmittelalters, Textausgabe, Teil VII: Edition des siebten Segments (Arzneiöle), Med. Diss. Würzburg 2002

Daems (1983)

Daems WF: Digestio: Sinn oder Unsinn? Zur Geschichte eines alchemistischpharmazeutischen Prozesses, in: Festschrift für Alfons Lutz und Jakob Büchi, hrsg. von Hans-Rudolf Fehlmann und François Ledermann; Zürich 1983 (= Veröffentlichungen der Schweizerischen Gesellschaft für Geschichte der Pharmazie, 2), S.151-179;

Daems (1993)

Daems WF: NOMINA SIMPLICIUM MEDICINARUM EX SYNONYMARIIS MEDII AEVI COLLECTA - Semantische Untersuchungen zum Fachwortschatz hoch- und spätmittelalterlicher Drogenkunde. (Studies in ancient Medicine. Hrsg. von J. Scarborough), E.J. Brill; Leiden 1993 
Dioskurides (1902)

Dioskurides P: Des Pedanios Dioskurides aus Anazarbos Arzneimittellehre in fünf Büchern. Übersetzt von Berendes J, Ferdinand Enke Verlag, Stuttgart 1902

Domes und Keil (1993)

Domes J und Keil G: Der „Momordica-“ oder „Balsamöl-Traktat“. Ein Beispiel für die Indikationsübertragung vom Erdöl auf den Jerusalemsapfel, in: „ein teutsch puech machen". Untersuchungen zur landessprachlichen Vermittlung medizinischen Wissen. Ortolf-Studien, 1. hrsg. von Gundolf Keil, redig. von Johannes G Mayer und Christian Naser; Wiesbaden 1993 (=Wissensliteratur im Mittelalter, 11), S. 480-498;

Dressendörfer (1978)

Dressendörfer W: Spätmittelalterliche Arzneitaxen des Münchner Stadtarztes Sigmund Gotzkircher aus dem Grazer Codex 311 - Ein Beitrag zur Frühgeschichte des süddeutschen Apothekenwesens; herausgegeben von Keil G; unter Mitwirkung von Holler M, Kahle E, Proff P; (WmhF Bd 15); Horst Wellm Verlag, Med. Diss. Pattensen/ Han. 1978

Eis (1982)

Eis G: Medizinische Fachprosa des späten Mittelalters und der frühen Neuzeit. Rodopi, Amsterdam 1982.

Fischer (1967)

Fischer H: Mittelalterliche Pflanzenkunde, Georg Olms Verlag, Hildesheim 1967. Reprografischer Nachdruck der Ausgabe München 1929

Frohne (2002)

Frohne D: Heilpflanzenlexikon: ein Leitfaden auf wissenschaftlicher Grundlage, 7. Auflage; Wissenschaftliche Verlags Gesellschaft, Stuttgart 2002 
Georges (1998)

Georges KE: Ausführliches lateinisch-deutsches Handwörterbuch: aus den Quellen zusammengetragen und mit besonderer Bezugnahme auf Synonymik und Antiquitäten unter Berücksichtigung der besten Hilfsmittel Bd 1-2, 8. Auflage; Wissenschaftliche Buchgesellschaft, Darmstadt 1998

Grimm (1984)

Grimm J, Grimm W: Deutsches Wörterbuch von Jacob Grimm und Wilhelm Grimm Bd 1-33. Deutscher Taschenbuch Verlag, München 1984

Haas (1956)

Haas H: Spiegel der Arznei - Ursprung, Geschichte und Idee der Heilmittelkunde. Springer Verlag, Berlin 1956

Hildegard (1955)

Von Bingen $\mathrm{H}$ : Ursachen und Behandlung der Krankheiten (causae et curae) aus der Sammlung "Panopticum Medicum Bd 4“ in der Übersetzung von Schulz H, Karl F. Haug Verlag, Ulm/Donau 1955

Hildegard (1991)

Von Bingen H: Heilkraft der Natur „Physica“ - Das Buch vom inneren Wesen der verschiedenen Naturen der Geschöpfe. Hrsg. von der Basler Hildegard Gesellschaft in der Übersetzung von Marie-Luise Portmann; Pattloch Verlag, Basel 1991

Höfler (1970)

Höfler M: Deutsches Krankheitsnamen-Buch, Georg Olms Verlag, Hildesheim 1970. Reprografischer Nachdruck der Ausgabe München 1899 
Hübner (1934)

Hübner A: Grundsätze für die Herausgabe und die Anweisungen zur Druckeinrichtung der Deutschen Texte des Mittelalters. In: J. Rothe, Das Lob der Keuschheit. Hrsg. von H. Neumann (Deutsche Texte des Mittelalters. Hrsg. von der Preußischen Akademie der Wissenschaften, Bd 38) Mayer \& Müller, Leipzig 1934, S 5-9;

Keil (1999)

Keil G: „Aqua ardens“: Vom Kurztraktat zum Beruf des Branntweinbrenners. In: Schriftlichkeit und Lebenspraxis im Mittelalter. Erfassen, Bewahren, Verändern (= Akten des internationalen Kolloquiums, 8.-10. Juni 1995), hrsg. von Hagen Keller, Christel Meier[-Staubach] und Thomas Scharf; München 1999 (=Münstersche Mittelalterschriften, 76), S. 267-278;

Keil und Tenner (2000)

Keil G, Tenner C: Die „Kopenhagener Wundarznei" - ein chirurgisches Arzneimittel-Handbuch von 1468 aus dem nördlichen Elsaß. Erschienen: [ca. 2000] Anbieter: Göttingen: Niedersächsische Staats- und Universitätsbibliothek Umfang: Online-Ressource

Keil (2004)

Keil G: Benediktenöl-Traktat. In: Die deutsche Literatur des Mittelalters, Verfasserlexikon. Bd 11, Sp. 236-237, Walter de Gruyter, Berlin 2004

Kurschat-Fellinger (1983)

Kurschat-Fellinger S: Kranewitt - Untersuchungen zu den altdeutschen Übersetzungen des nordischen Wacholderbeertraktats (= Mittelalterliche Wunderdrogentraktate, III); herausgegeben von Keil G; unter Mitwirkung von Holler M, Kahle E, Proff P, Weißer C; (WmhF Bd 20); Horst Wellm Verlag, Med. Diss. Pattensen/Han. 1983 
Lexer (1992)

Lexer M: Mittelhochdeutsches Taschenwörterbuch, 38. unveränderte Auflage; S. Hirzel Wissenschaftliche Verlagsgesellschaft, Stuttgart 1992

LexMA (1980)

Daems WF: Balsamkapitel. In: Lexikon des Mittelalters. Bd 1, Sp. 1389. Artemis Verlag, München 1980

LexMA (1989)

Zielinski H: Farfa. In: Lexikon des Mittelalters. Bd 4, Sp. 295-297. Artemis Verlag, München 1989

Lonitzer (1962)

Lonitzer A: Kreuterbuch : Kunstliche Conterfeytunge der Bäume, Stauden, Hecken, Kräuter, Getreyd, Gewürtze etc. Mit eigentlicher Beschreibung derselben Nahmen in sechserley Sprachen ... Item von den führnehmsten Gethieren der Erden ... Dessgleichen von Metallen, Ertze, Edelgesteinen, Gummi und gestandenen Säfften. Konrad Kölbl Verlag, München 1962. Reprint der Ausgabe Ulm 1679

Marzell (1943)

Marzell H: Wörterbuch der deutschen Pflanzennamen. Bd 1-5; S. Hirzel Verlag, Leipzig 1943

Marzell (1967)

Marzell H: Die Geschichte und Volkskunde der deutschen Heilpflanzen. Wissenschaftliche Buchgesellschaft, Darmstadt 1967

Mildenberger (1997)

Mildenberger J: Anton Trutmanns >Arzneibuch< - Teil II: Wörterbuch Bd 1-5; herausgegeben von Keil G; unter Mitwirkung von Domes J, Holler M, Kahle E, Proff P, Weißer C; (WmhF Bd 56); Königshausen \& Neumann, Med. Diss. Würzburg 1997 
MlatWb (1999)

Lehmann P, Stroux J: Mittellateinisches Wörterbuch bis zum ausgehenden 13. Jahrhundert. In Gemeinschaft mit den Akademien der Wissenschaften zu Berlin, Göttingen, Heidelberg, Leipzig, Mainz, Wien und der Schweizerischen Akademie der Geistes- und Sozialwissenschaften; herausgegeben von der Bayerischen Akademie der Wissenschaften; Bd 2: C; C. H. Beck, München 1999

Moll (2005)

Moll I: Dermatologie. (Duale Reihe), 6. Auflage; Thieme Verlag, Stuttgart 2005

Ott-Voigtländer (1979)

Ott-Voigtländer U: Das St. Georgener Rezeptar - Ein allemannisches Arzneibuch des 14. Jahrhunderts aus dem Karlsruher Kodex St. Georgen 73. Teil I: Text und Wörterverzeichnis; herausgegeben von Keil G; unter Mitwirkung von Holler M, Kahle E, Proff P; (WmhF Bd 17); Horst Wellm Verlag, Med. Diss. Pattensen/ Han. 1979

Polhill (2006)

Polhill ME: Hans Minners >Tierbuch< (ca. 1478): Edition - Kommentar - Wörterbuch; herausgegeben von Keil G; unter Mitwirkung von Domes J, Kahle E, Proff P, Weißer C; (WmhF Bd 88); Königshausen \& Neumann, Med. Diss. Würzburg 2006

Pons (1998)

Klausmann-Molter B: Pons Wörterbuch für Schule und Studium: italienischdeutsch, deutsch-italienisch. Klett, Stuttgart 1998

Pritzel und Jessen (1967)

Pritzel G, Jessen C: Die deutschen Volksnamen der Pflanzen. Neuer Beitrag zum deutschen Sprachschatze. Aus allen Mundarten und Zeiten zusammengestellt. Verlag P. Schipperges N.V., Amsterdam 1967. Reprint der Ausgabe Hannover 1882 
Pschyrembel (2010)

Pschyrembel: Klinsches Wörterbuch. 262. Auflage; Walter de Gruyter, Berlin 2010, s.v. ,Diaphoretika', ,Phthisis', ,Dysenterie', ,Karminativa'.

Roche (2003)

Roche: Roche-Lexikon Medizin, herausgegeben von der Hoffmann-La Roche AG und Urban \& Schwarzenberg, 5. Auflage; Urban \& Schwarzenberg, München 2003, s.v. ,Stomachika‘

Schilcher und Kammerer (2003)

Schilcher H, Kammerer S: Leitfaden Phytotherapie, 2. Auflage; Urban \& Fischer, München 2003

Schmitz (1998)

Schmitz R: Geschichte der Pharmazie. Govi-Verlag, Eschborn 1998

Schneider (1962)

Schneider W: Lexikon alchemistisch-pharmazeutischer Symbole, Verlag Chemie, Weinheim 1962

Schneider (1968)

Schneider W: Lexikon der Arzneimittelgeschichte: Sachwörterbuch zur Geschichte der pharmazeutischen Botanik, Chemie, Mineralogie, Pharmakologie, Zoologie. Bd 1-6. Govi Verlag, Frankfurt am Main 1968-1975

Schoenfelder (2001)

Schoenfelder P: Der neue Kosmos-Heilpflanzenführer: über 600 Heil- und Giftpflanzen Europas, Kosmos, Stuttgart 2001

Schöner (1964)

Schöner E: Das Viererschema in der antiken Humoralpathologie. In: Sudhoffs Archiv für Geschichte der Medizin und Naturwissenschaften. Hrsg. von Heischkel, Schimank, Steudel, Zaunick; Beiheft 4. Franz Steiner Verlag GmbH, Wiesbaden 1964 
Stannard (1982)

Stannard J: The multiple uses of Dill in Medieval Medicine, in: Festschrift zum 70. Geburtstag von Willem F. Daems; herausgegeben von Keil G; unter Mitwirkung von Holler M, Kahle E, Proff P; Bd 24. Horst Wellm Verlag, Pattensen/ Han. 1982, S. 411-424; (=WmhF)

Strabo (1978)

Strabo W: Der Hortulus des Walahfrid Strabo - Aus dem Kräutergarten des Klosters Reichenau in der Übersetzung von Stoffler H D, Jan Thorbecke Verlag Sigmaringen 1978

Tschirch (1933)

Tschirch A: Allgemeine Pharmakognosie: Dritte Abteilung (Handbuch der Pharmakognosie), Bd 1; Bernard Tauchnitz Verlag, Leipzig 1933

Zetkin und Schaldach (1999)

Zetkin M, Schaldach H: Lexikon der Medizin, 16. Auflage; Ullstein Medical, Wiesbaden 1999

Zimmermann (1985)

Zimmermann V: Jüdische Ärzte und ihre Beiträge zur Heilkunde des Spätmittelalters. Koroth 8, 245-254

Zimmermann (1986)

Zimmermann V: Rezeption und Rolle der Heilkunde in landessprachigen handschriftlichen Kompendien des Spätmittelalters. Ars Medica - Texte und Untersuchungen zur Quelle der alten Medizin. IV. Abteilung. Landessprachliche und mittelalterliche Medizin, Bd 2. Franz Steiner Verlag Wiesbaden, Stuttgart 1986 


\section{Danksagung}

Vor allem danke ich Herrn Prof. Dr. Dr. Volker Zimmermann für die Überlassung des Themas. Er bot mir damit die Möglichkeit, auf meinem Wunschgebiet, der Geschichte der Medizin, zu promovieren.

Über den gesamten Zeitraum war Prof. Zimmermann stets für alle Fragen offen. Mit Kritik und Lob wies er mir den richtigen wissenschaftlichen Weg. Seine Geduld wusste ich dabei immer zu schätzen.

Ich möchte mich überdies herzlich bei allen Korrekturlesern bedanken, die sich aufmerksam der Arbeit gewidmet haben, um sie zu verbessern. Namentlich sind dies: Melanie Imenkamp, Matthias Hensel und Ludmila Utte.

Mein weiterer Dank gebührt meiner Mutter ebenso wie der Sekretärin unseres Instituts, Frau Guenther-Fecke. Beide halfen mir bei zahlreichen Fragen bezüglich Layout und Formatierung. 


\section{Lebenslauf}

Am 26. August 1984 wurde ich, Thomas Aßfelder, als zweiter von drei Söhnen des Optikers Rainer Aßfelder und der Sekretärin Agnes Aßfelder, geb. Stremer, in Essen geboren.

Von 1991-1995 besuchte ich die Ludwig-Kessing-Grundschule in Essen-Überruhr. Anschließend besuchte ich das Carl-Humann-Gymnasium in Essen-Steele, an dem ich 2004 die allgemeine Hochschulreife erlangte.

Vom August 2004 bis Mai 2005 leistete ich meinen Zivildienst beim MalteserHilfsdienst im Bereich Mahlzeitendienst ab.

Zum Sommersemester 2006 nahm ich das Medizinstudium an der Georg-AugustUniversität in Göttingen auf. Im April 2008 bestand ich das Physikum mit der Note 2,0. Aktuell bin ich Student im 10. Fachsemester. Ab Februar 2011 beginne ich das Praktische Jahr im Städtischen Klinikum Lüneburg. 